\title{
ECO2N: A TOUGH2 Fluid Property Module for Mixtures of Water, $\mathrm{NaCl}$, and $\mathrm{CO}_{2}$
}

\author{
Karsten Pruess \\ Earth Sciences Division, Lawrence Berkeley National Laboratory \\ University of California, Berkeley, CA 94720
}

June 2005 


\begin{abstract}
ECO2N is a fluid property module for the TOUGH2 simulator (Version 2.0) that was designed for applications to geologic sequestration of $\mathrm{CO}_{2}$ in saline aquifers. It includes a comprehensive description of the thermodynamics and thermophysical properties of $\mathrm{H}_{2} \mathrm{O}-\mathrm{NaCl}$ $\mathrm{CO}_{2}$ mixtures, that reproduces fluid properties largely within experimental error for the temperature, pressure and salinity conditions of interest $\left(10{ }^{\circ} \mathrm{C} \leq \mathrm{T} \leq 110{ }^{\circ} \mathrm{C} ; \mathrm{P} \leq 476\right.$ bar; salinity up to full halite saturation). Flow processes can be modeled isothermally or non-isothermally, and phase conditions represented may include a single (aqueous or $\mathrm{CO}_{2}$-rich) phase, as well as two-phase mixtures. Fluid phases may appear or disappear in the course of a simulation, and solid salt may precipitate or dissolve. This report gives technical specifications of ECO2N and includes instructions for preparing input data. Code applications are illustrated by means of several sample problems, including problems that had been previously investigated in a code intercomparison study.
\end{abstract}




\section{TABLE OF CONTENTS}

LIST OF FIGURES

vii

LIST OF TABLES

xi

1. INTRODUCTION

1

2. FLUID PHASES AND THERMODYNAMIC VARIABLES IN THE

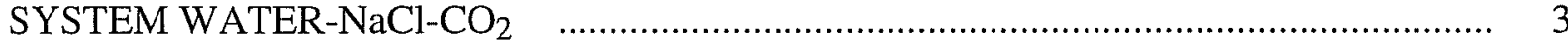

2.1 Phase Composition ...................................................................................... 7

2.2 Phase Change .......................................................................................... 10

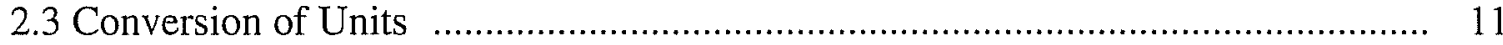

3. THERMOPHYSICAL PROPERTIES OF WATER-NaCl-CO $\mathrm{CO}_{2}$ Mixtures $\quad . . . \ldots \ldots \ldots \ldots \ldots \ldots \ldots \ldots \ldots . . . . . . . .13$

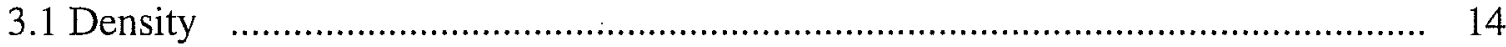

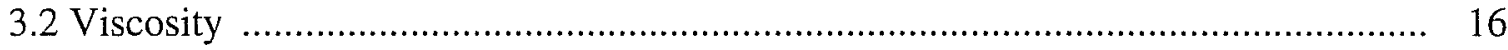

3.3 Specific Enthalpy .................................................................................. 16

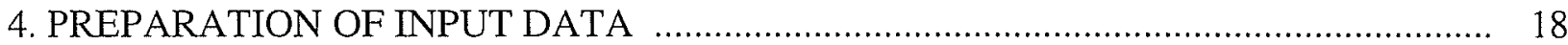

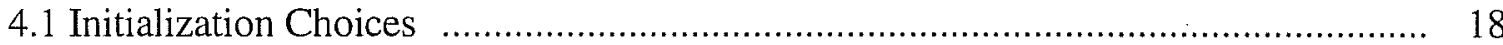

4.2 Permeability Change from Precipitation and Dissolution of Salt .......................... 20

4.3 Choice of Program Options ........................................................................... 22

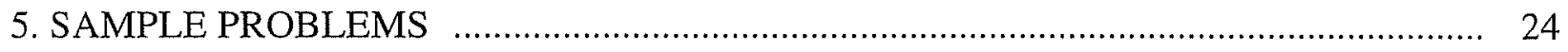

5.1 Problem No. 1 (*tab*) - Demonstration of Initialization Options ........................ 24

5.2 Problem No. 2 (*rec3*) - Radial Flow from a CO 2 Injection Well ........................ 28

5.3 Problem No. 3 (*r1dv*) $-\mathrm{CO}_{2}$ Discharge Along a Fault Zone ............................. 37

5.4 Problem No. 4 (*tp7*) - $\mathrm{CO}_{2}$ Injection into a 2-D Layered Brine Formation ....... 46

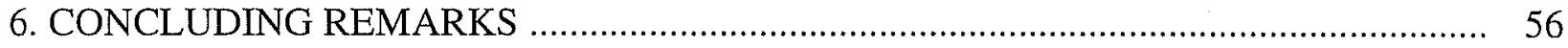

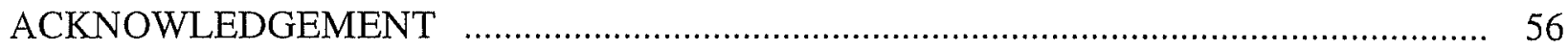

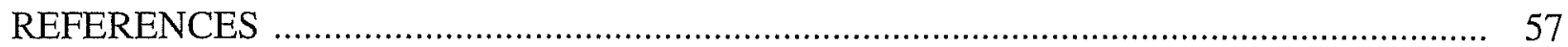

APPENDIX A. Code Intercomparison Problem 3: Radial Flow from a $\mathrm{CO}_{2}$ Injection Well ........ 59

APPENDIX B. Code Intercomparison Problem 4: $\mathrm{CO}_{2}$ Discharge Along a Fault Zone ............. 61

APPENDIX C. Code Intercomparison Problem 7: $\mathrm{CO}_{2}$ Injection into a

2-D Layered Brine Formation 


\section{LIST OF FIGURES}

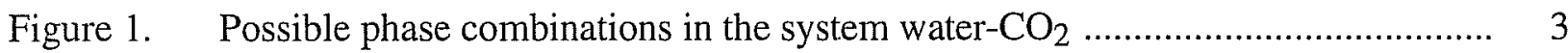

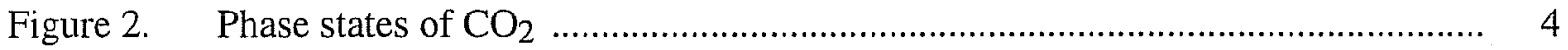

Figure 3. Dissolved $\mathrm{CO}_{2}$ mass fractions at $\mathrm{T}=30^{\circ} \mathrm{C}$ for pure water $(0 \mathrm{~m})$ and 4-molar $\mathrm{NaCl}$ brine

Figure 4. $\mathrm{H}_{2} \mathrm{O}$ mass fractions in gas at $\mathrm{T}=30{ }^{\circ} \mathrm{C}$ for pure water $(0 \mathrm{~m})$ and 4-molar $\mathrm{NaCl}$ brine

Figure 5. Concentration of water in gas and $\mathrm{CO}_{2}$ in the liquid (aqueous) phase for salinities ranging from zero to fully saturated

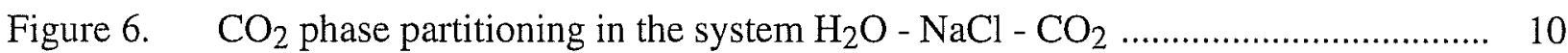

Figure 7. Schematic of the temperature-pressure tabulation of $\mathrm{CO}_{2}$ properties .................... 14

Figure 8. Model for converging-diverging pore channels ............................................... 20

Figure 9. Porosity-permeability relationship for tubes-in-series model ............................... 21

Figure 10. TOUGH2/ECO2N input file for sample problem 1 - demonstration of initialization options

Figure 11. Primary variables internally used in ECO2N for the INCON data

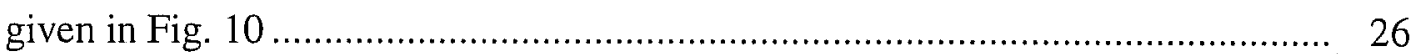

Figure 12. Output data for sample problem 1 ............................................................... 27

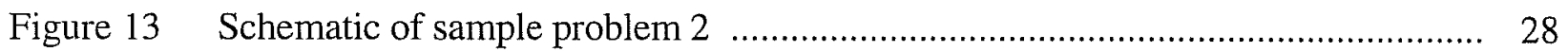

Figure 14 TOUGH2 input file for grid generation for radial injection problem .................. 29

Figure 15 Modified MESH file for radial injection problem …........................................ 29

Figure 16 TOUGH2 input file for radial injection problem ............................................. 30

Figure 17 Part of printed output for radial flow problem ..................................................... 31

Figure 18 Simulated pressures as a function of the similarity variable ................................ 33

Figure 19 Simulated gas saturations ............................................................................. 34

Figure $20 \quad$ Simulated solid saturations …………........................................................ 34

Figure 21 Simulated $\mathrm{CO}_{2}$ mass fraction in aqueous phase ….......................................... 35 
Figure 22 Simulated $\mathrm{NaCl}$ mass fraction in aqueous phase

Figure 23 Simulated water mass fraction in $\mathrm{CO}_{2}$-rich phase 36

Figure 24 TOUGH2 input file for fault zone problem ……............................................. 38

Figure 25 Part of printed output for fault leakage problem ................................................ 40

Figure 26 Simulated $\mathrm{CO}_{2}$ fluxes at bottom and top of fault zone ....................................... 42

Figure 27 Simulated water flux at top of fault zone ……….............................................. 43

Figure 28 Gas saturation profiles at times of $10^{7}$ and $10^{9}$ seconds ................................... 43

Figure 29 Pressure profiles at times of $10^{7}$ and $10^{9}$ seconds ............................................. 44

Figure 30 Dissolved $\mathrm{CO}_{2}$ mass fraction in aqueous phase (top) and dissolved water mass fraction in gas (bottom) after $10^{7} \mathrm{~s}$................................................. 45

Figure 31 Code fragment of subroutine GXYZ, modified for sand-shale medium ................ 46

Figure 32 TOUGH2 input file for $\mathrm{CO} 2$ injection into a 2-D layered brine formation ............ 48

Figure 33 Part of printed output for problem of $\mathrm{CO} 2$ injection into a layered brine formation ............................................................................. 49

Figure 34 Time evolution of pressures in two grid blocks and time stepping ...................... 51

Figure 35 Gas flow rates at the well block ................................................................ 51

Figure $36 \quad$ Gas saturations at the well block and its neighbors ......................................... 52

Figure 37 Phase saturations at the well block ............................................................. 52

Figure 38 Absolute values of aqueous phase flow rates between the well block and neighboring grid blocks .......................................................................... 53

Figure 39 Solid saturations in the well block and its neighbors ...................................... 53

Figure 40 Contour map of fluid pressures after 2 years of $\mathrm{CO}_{2}$ injection .......................... 54

Figure 41 Contour map of gas saturations after 2 years of $\mathrm{CO}_{2}$ injection .......................... 54

Figure 42 Contour map of dissolved $\mathrm{CO}_{2}$ mass fractions after 2 years of $\mathrm{CO}_{2}$ injection .................................................................. 55

Figure B.1 Schematic of the fault zone model (a) and applied boundary conditions (b) .......... 61

Figure C.1 Schematic representation of geometry for $\mathrm{CO}_{2}$ injection in Utsira Formation ....... 64 


\section{LIST OF TABLES}

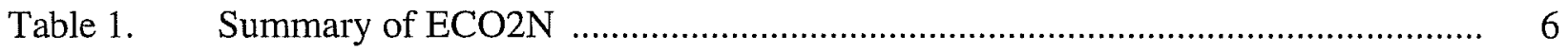

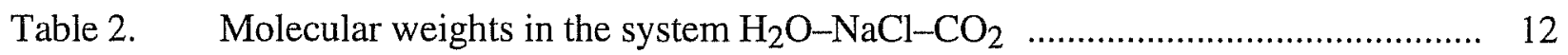

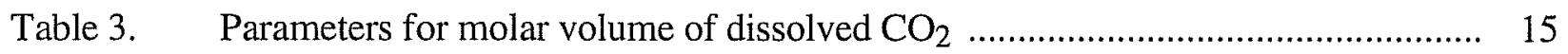

Table 4. PVT properties at a temperature of $45^{\circ} \mathrm{C}$ at selected pressures, as used in the TOUGH2/ECO2N simulation ............................................................ 39

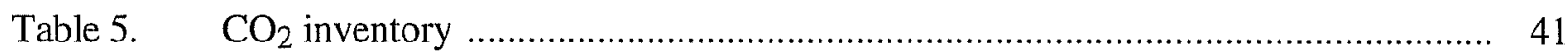

Table 6. MESHMAKER input data for grid generation ................................................ 47

Table 7. $\quad \mathrm{CO}_{2}$ inventory for injection into a saline 2-D layered system ............................. 55

Table A.1 Hydrogeologic parameters ……..................................................................... 60

Table A.2 Initial conditions and injection specifications ……….......................................... 60

Table C.1 Initial conditions and injection specifications ……........................................... 64

Table C.2 Hydrogeologic parameters …...................................................................... 66 


\section{Introduction}

Injection of $\mathrm{CO}_{2}$ into saline formations has been proposed as a means whereby emissions of heat-trapping greenhouse gases into the atmosphere may be reduced. Such injection would induce coupled processes of multiphase fluid flow, heat transfer, chemical reactions, and mechanical deformation. Several groups have developed simulation models for subsets of these processes. The present report describes a fluid property module "ECO2N" for the general-purpose reservoir simulator TOUGH2 (Pruess et al., 1999; Pruess, 2004), that can be used to model non-isothermal multiphase flow in the system $\mathrm{H}_{2} \mathrm{O}-\mathrm{NaCl}-\mathrm{CO}_{2}$. TOUGH2/ECO2N represents fluids as consisting of two phases: a water-rich aqueous phase, herein often referred to as "liquid," and a $\mathrm{CO}_{2}$-rich phase referred to as "gas." In addition, solid salt may also be present. The only chemical reactions modeled by ECO2N include equilibrium phase partitioning of water and carbon dioxide between the liquid and gaseous phases, and precipitation and dissolution of solid salt. The partitioning of $\mathrm{H}_{2} \mathrm{O}$ and $\mathrm{CO}_{2}$ between liquid and gas phases is modeled as a function of temperature, pressure, and salinity, using the recently developed correlations of Spycher and Pruess (2005). Dissolution and precipitation of salt is treated by means of local equilibrium solubility. Associated changes in fluid porosity and permeability may also be modeled. All phases - gas, liquid, solid - may appear or disappear in any grid block during the course of a simulation. Thermodynamic conditions covered include a temperature range from ambient to $100{ }^{\circ} \mathrm{C}$ (approximately), pressures up to $600 \mathrm{bar}$, and salinity from zero to fully saturated. These parameter ranges should be adequate for most conditions encountered during disposal of $\mathrm{CO}_{2}$ into deep saline aquifers.

ECO2N is written in Fortran 77 and is "plug-compatible" with TOUGH2, Version 2.0. The code is intrinsically single-precision, but requires 64-bit arithmetic, which on 32-bit processors (PCs and workstations) may be realized by using compiler options for generating 64-bit arithmetic. For example, on an IBM RS/6000 computer, this may be accomplished with the compiler option "-qautodbl=dblpad". ECO2N may be linked with standard TOUGH2 modules like any of the fluid property modules included in the TOUGH2 V 2.0 package. As an example, we list the linking instruction that would be used on an IBM RS/6000 workstation.

f77 -o zco2n t2cg22.o meshm.o eco2n.o t2f.o t2solv.o ma28.o

Execution of an input file * $\mathrm{rcc}^{*}$ would be made with the command

zco $2 n<r c c 3>r c c 3$. out 
The present report is a user's guide for the TOUGH2/ECO2N simulator. Information provided in the TOUGH2 users' guide (Pruess et al., 1999) is not duplicated here. We begin with a discussion of phase conditions and thermodynamic variables in the system $\mathrm{H}_{2} \mathrm{O}-\mathrm{NaCl}-\mathrm{CO}_{2}$, for conditions of interest in geologic sequestration of $\mathrm{CO}_{2}$. This is followed by a discussion of our thermophysical property model, and guidance for preparing input data. Several sample problems are provided which document code performance and serve as a tutorial for applications. 


\section{Fluid Phases and Thermodynamic Variables in the System Water-NaCl-CO}

In the two-component system water- $\mathrm{CO}_{2}$, at temperatures above the freezing point of water and not considering hydrate phases, three different fluid phases may be present: an aqueous phase that is mostly water but may contain some dissolved $\mathrm{CO}_{2}$, a liquid $\mathrm{CO}_{2}$-rich phase that may contain some water, and a gaseous $\mathrm{CO}_{2}$-rich phase that also may contain some water. Altogether there may be seven different phase combinations (Fig. 1). If $\mathrm{NaCl}$ ("salt") is added as a third fluid component, the number of possible phase combinations doubles, as in each of the seven phase combinations depicted in Fig. 1 there may or may not be an additional phase consisting of solid salt. Liquid and gaseous $\mathrm{CO}_{2}$ may coexist along the saturated vapor pressure curve of $\mathrm{CO}_{2}$, which ends at the critical point $\left(\mathrm{T}_{\text {crit }}, \mathrm{P}_{\text {crit }}\right)=\left(31.04{ }^{\circ} \mathrm{C}, 73.82\right.$ bar; Vargaftik, 1975), see Fig. 2. At supercritical temperatures or pressures there is just a single $\mathrm{CO}_{2}$-rich phase.

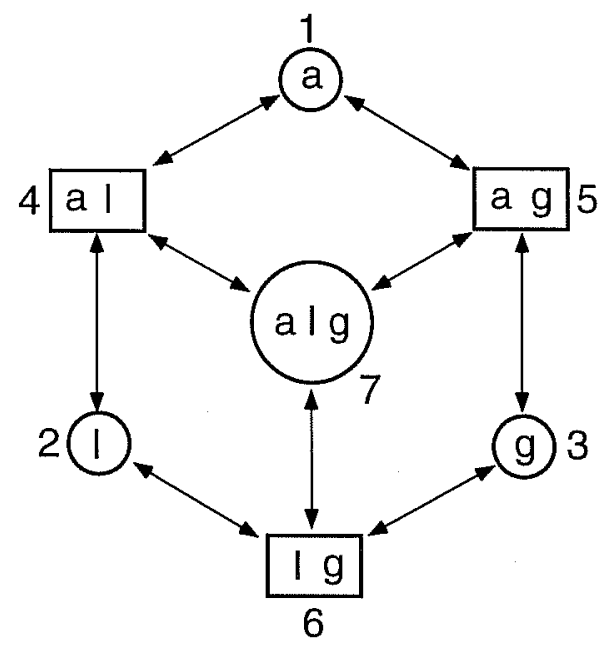

Figure 1. Possible phase combinations in the system water- $\mathrm{CO}_{2}$. The phase designations are a - aqueous, 1 - liquid $\mathrm{CO}_{2}, \mathrm{~g}$ - gaseous $\mathrm{CO}_{2}$. Separate liquid and gas phases exist only at subcritical conditions.

The present version of ECO2N can only represent a limited subset of the phase conditions depicted in Fig. 1. Thermophysical properties are accurately calculated for gaseous as well as for liquid $\mathrm{CO}_{2}$, but no distinction between gaseous and liquid $\mathrm{CO}_{2}$ phases is made in the treatment of flow, and no phase change between liquid and gaseous $\mathrm{CO}_{2}$ is treated. Accordingly, of the seven phase combinations shown in Fig. 1, ECO2N can represent the ones numbered 1 (single-phase aqueous with or without dissolved $\mathrm{CO}_{2}$ and salt), 2 and 3 (a single $\mathrm{CO}_{2}$-rich phase that may be either liquid or gaseous $\mathrm{CO}_{2}$, and may include dissolved water), and 4 and 5 (two-phase conditions consisting of an aqueous and a single $\mathrm{CO}_{2}$-rich phase, with no distinction being made as to whether the $\mathrm{CO}_{2}$-rich phase is liquid or gas). $\mathrm{ECO} 2 \mathrm{~N}$ cannot represent conditions 6 (two-phase mixture of 


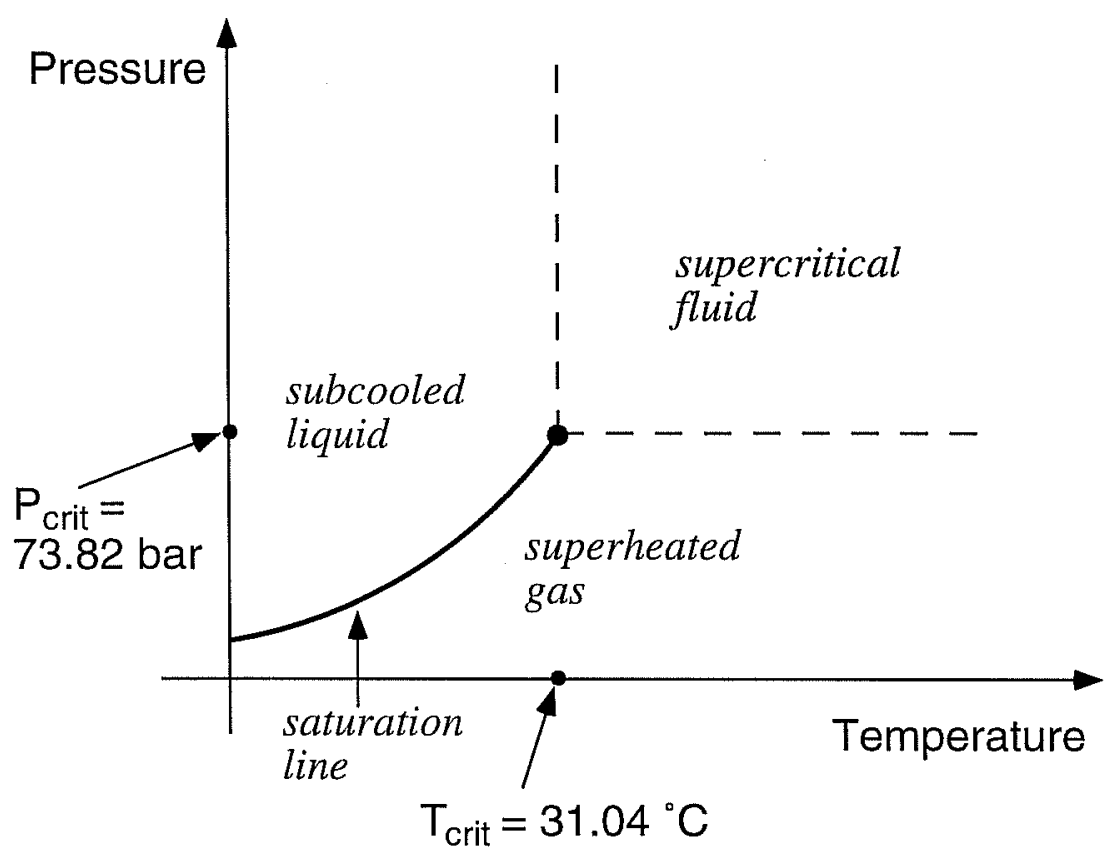

Figure 2. Phase states of $\mathrm{CO}_{2}$.

liquid and gaseous $\mathrm{CO}_{2}$ ) and 7 (three-phase). All sub- and super-critical $\mathrm{CO}_{2}$ is considered as a single non-wetting phase, that will henceforth be referred to as "gas." ECO2N may be applied to sub- as well as super-critical temperature and pressure conditions, but applications that involve subcritical conditions are limited to systems in which there is no change of phase between liquid and gaseous $\mathrm{CO}_{2}$, and in which no mixtures of liquid and gaseous $\mathrm{CO}_{2}$ occur.

Numerical modeling of the flow of brine and $\mathrm{CO}_{2}$ requires a coupling of the phase behavior of water-salt- $\mathrm{CO}_{2}$ mixtures with multiphase flow simulation techniques. Among the various issues raised by such coupling is the choice of notation. There are long-established notational conventions in both fields, which may lead to conflicts and misunderstandings when they are combined. In an effort to avoid confusion, we will briefly discuss notational issues pertaining to partitioning of $\mathrm{CO}_{2}$ between an aqueous and a gaseous phase.

Phase partitioning is usually described in terms of mole fractions of the two components, which are denoted by $\mathrm{x}$ and $\mathrm{y}$, respectively, where $\mathrm{x}_{1}=\mathrm{x}_{\mathrm{H} 2 \mathrm{O}}$ and $\mathrm{x}_{2}=\mathrm{x}_{\mathrm{CO}}$ specify mole fractions in the aqueous phase, while $\mathrm{y}_{1}=\mathrm{y}_{\mathrm{H} 2 \mathrm{O}}$ and $\mathrm{y}_{2}=\mathrm{y}_{\mathrm{CO} 2}$ give mole fractions in the gas phase (Prausnitz et al., 1986; Spycher et al., 2003). We follow this notation, except that we add the subscript "eq" to emphasize that these mole fractions pertain to equilibrium partitioning of water and $\mathrm{CO}_{2}$ between co-existing aqueous and gas phases. Accordingly, we denote the various mole 
fractions pertaining to equilibrium phase partitioning as $\mathrm{x}_{1 \text {,eq }}, \mathrm{x}_{2, \mathrm{eq}}, \mathrm{y}_{1 \text {,eq }}$, and $\mathrm{y}_{2 \text {,eq }}$, while the corresponding mass fractions are denoted using upper-case $\mathrm{X}$ and $\mathrm{Y}$. Mass fractions corresponding to single-phase conditions, where water and $\mathrm{CO}_{2}$ concentrations are not constrained by phase equilibrium relations, are denoted by $\mathrm{X}_{1}$ (for water) and $\mathrm{X}_{2}$ (for $\mathrm{CO}_{2}$ ) in the aqueous phase, and by $\mathrm{Y}_{1}$ and $\mathrm{Y}_{2}$ in the gas phase.

In the numerical simulation of brine- $\mathrm{CO}_{2}$ flows, we will be concerned with the fundamental thermodynamic variables that characterize the brine- $\mathrm{CO}_{2}$ system, and their change with time in different subdomains (grid blocks) of the flow system. Four "primary variables" are required to define the state of water- $\mathrm{NaCl}-\mathrm{CO}_{2}$ mixtures, which according to conventional TOUGH2 useage are denoted by $\mathrm{X} 1, \mathrm{X} 2, \mathrm{X} 3$, and $\mathrm{X} 4$. A summary of the fluid components and phases modeled by ECO2N, and the choice of primary thermodynamic variables, appears in Table 1. Different variables are used for different phase conditions, but two of the four primary variables are the same, regardless of the number and nature of phases present. This includes the first primary variable X1, denoting pressure, and the fourth primary variable $\mathrm{X} 4$ which is temperature. The second primary variable pertains to salt and is denoted $X_{s m}$ rather than $X 2$ to avoid confusion with $X_{2}$, the $\mathrm{CO}_{2}$ mass fraction in the liquid phase. Depending upon whether or not a precipitated salt phase is present, the variable $X_{\mathrm{sm}}$ has different meaning. When no solid salt is present, $X_{\mathrm{sm}}$ denotes $X_{\mathrm{s}}$, the salt mass fraction referred to the two-component system water-salt. When solid salt is present, $X_{S}$ is no longer an independent variable, as it is determined by the equilibrium solubility of $\mathrm{NaCl}$, which is a function of temperature. In the presence of solid salt, for reasons that are explained below, we use as second primary variable the quantity "solid saturation plus ten," $X_{\mathrm{sm}}=\mathrm{S}_{\mathrm{s}}+10$. Here, $\mathrm{S}_{\mathrm{s}}$ is defined in analogy to fluid saturations and denotes the fraction of void space occupied by solid salt.

The physical range of both $X_{S}$ and $S_{S}$ is $(0,1)$; the reason for defining $X_{s m}$ by adding a number 10 to $S_{s}$ is to enable the presence or absence of solid salt to be recognized simply from the numerical value of the second primary variable. As had been mentioned above, the salt concentration variable $\mathrm{X}_{\mathrm{S}}$ is defined with respect to the two-component system $\mathrm{H}_{2} \mathrm{O}-\mathrm{NaCl}$. This choice makes the salt concentration variable independent of $\mathrm{CO}_{2}$ concentration, which simplifies the calculation of the partitioning of the $\mathrm{H}_{2} \mathrm{O}$ and $\mathrm{CO}_{2}$ components between the aqueous and gas phases (see below). In the three-component system $\mathrm{H}_{2} \mathrm{O}-\mathrm{NaCl}-\mathrm{CO}_{2}$, the total salt mass fraction in the aqueous phase will for given $\mathrm{X}_{\mathrm{S}}$ of course depend on $\mathrm{CO}_{2}$ concentration. Salt mass fraction in the two-component system $\mathrm{H}_{2} \mathrm{O}-\mathrm{NaCl}$ can be expressed in terms of salt molality (moles $\mathrm{m}$ of salt per $\mathrm{kg}$ of water) as follows. 
Table 1. Summary of ECO2N

\begin{tabular}{|c|c|}
\hline Components & $\begin{array}{l}\text { \# 1: water } \\
\# \text { 2: } \mathrm{NaCl} \\
\# 3: \mathrm{CO}_{2}\end{array}$ \\
\hline $\begin{array}{l}\text { Parameter choices } \\
(\mathrm{NK}, \mathrm{NEQ}, \mathrm{NPH}, \mathrm{NB})=\end{array}$ & $\begin{array}{l}(3,4,3,6) \text { water, } \mathrm{NaCl}, \mathrm{CO}_{2} \text {, nonisothermal (default) } \\
(3,3,3,6) \text { water, } \mathrm{NaCl}, \mathrm{CO}_{2} \text {, isothermal } \\
\text { molecular diffusion can be modeled by setting } \mathrm{NB}=8\end{array}$ \\
\hline $\begin{array}{l}\text { Primary Variables } \\
\text { single fluid phase (or } \\
\mathrm{P} \text { - pressure } \\
\mathrm{X}_{\mathrm{sm}} \text { - salt mass } \mathrm{f}_{\mathrm{f}} \\
\text { or solid sa } \\
\mathrm{X} 3-\mathrm{CO}_{2} \text { mass } \mathrm{f}_{\mathrm{t}} \\
\text { in the three } \\
\mathrm{T} \text { - temperature } \\
\text { two fluid phases (aq } \\
\mathrm{P} \text { - pressure } \\
\mathrm{X}_{\mathrm{sm}} \text { - salt mass } \mathrm{f}_{\mathrm{f}} \\
\text { or solid sa } \\
\mathrm{S}_{\mathrm{g}} \text { - gas phase sa } \\
\mathrm{T} \text { - temperature }\end{array}$ & $\begin{array}{l}\text { ly aqueous, or only gas })^{\#}\left(\mathrm{P}, \mathrm{X}_{\mathrm{sm}}, \mathrm{X} 3, \mathrm{~T}\right) \\
\text { action } \mathrm{X}_{\mathrm{s}} \text { in two-component water-salt system, } \\
\text { uration } \mathrm{S}_{\mathrm{s}}+10 \\
\text { action in the aqueous phase, or in the gas phase, } \\
\text { component system water-salt- } \mathrm{CO}_{2} \\
\text { eous and gas) } \\
\text { action } \mathrm{X}_{\mathrm{S}} \text { in two-component water-salt system, } \\
\text { uration } \mathrm{S}_{\mathrm{S}}+10 \\
\text { uration }\end{array}$ \\
\hline
\end{tabular}

\# When discussing fluid phase conditions, we refer to the potentially mobile (aqueous and gas) phases only; in all cases solid salt may precipitate or dissolve, adding another active phase to the system.

$$
\mathrm{X}_{\mathrm{s}}=\frac{\mathrm{mM}_{\mathrm{NaCl}}}{1000+\mathrm{mM}_{\mathrm{NaCl}}}
$$

Here $\mathrm{M}_{\mathrm{NaCl}}=58.448$ is the molecular weight of $\mathrm{NaCl}$, and the number 1000 appears in the denominator because molality is defined as moles per $1000 \mathrm{~g}$ of water. For convenience we also list the inverse of Eq. (1).

$$
\mathrm{m}=\frac{1000 \mathrm{X}_{\mathrm{s}} / \mathrm{M}_{\mathrm{NaCl}}}{1-\mathrm{X}_{\mathrm{s}}}
$$


The third primary variable $\mathrm{X} 3$ is $\mathrm{CO}_{2}$ mass fraction $\left(\mathrm{X}_{2}\right)$ for single-phase conditions (only aqueous, or only gas) and is "gas saturation plus ten" $\left(\mathrm{S}_{\mathrm{g}}+10\right)$ for two-phase (aqueous and gas) conditions. The reason for adding 10 to $\mathrm{S}_{\mathrm{g}}$ is analogous to the conventions adopted for the second primary variable, namely, to be able to distinguish single-phase conditions $(0 \leq \mathrm{X} 3 \leq 1)$ from twophase conditions $(10 \leq \mathrm{X} 3 \leq 11)$. In single-phase conditions, the $\mathrm{CO} 2$ concentration variable $\mathrm{X}_{2}$ is "free," i.e., it can vary continuously within certain parameter ranges, while in two-phase aqueous-gas conditions, $\mathrm{X}_{2}$ has a fixed value $\mathrm{X}_{2 \text {,eq }}$ that is a function of temperature, pressure, and salinity (see below). Accordingly, for single-phase conditions $X_{2}$ is included among the independent primary variables $\left(=\mathrm{X} 3\right.$ ), while for two-phase conditions, $\mathrm{X}_{2}$ becomes a "secondary" parameter that is dependent upon primary variables $\left(\mathrm{T}, \mathrm{P}, \mathrm{X}_{\mathrm{S}}\right)$. "Switching" primary variables according to phase conditions present provides a very robust and stable technique for dealing with changing phase compositions; see Section 2.2, below.

Initialization of a simulation with TOUGH2/ECO2N would normally be made with the internally used primary variables as listed in Table 1 . For convenience of the user, additional choices are available for initializing a flow problem; see Section 4, below.

\subsection{Phase Composition}

The partitioning of $\mathrm{H}_{2} \mathrm{O}$ and $\mathrm{CO}_{2}$ among co-existing aqueous and gas phases is calculated from a slightly modified version of the correlations developed in (Spycher and Pruess, 2005). These correlations were derived from the requirement that chemical potentials of all components must be equal in different phases. For two-phase conditions, they predict the equilibrium composition of liquid (aqueous) and gas (CO2-rich) phases as functions of temperature, pressure, and salinity, and are valid in the temperature range $12{ }^{\circ} \mathrm{C} \leq \mathrm{T} \leq 110^{\circ} \mathrm{C}$, for pressures up to 600 bar, and salinity up to saturated $\mathrm{NaCl}$ brines. In the indicated parameter range, mutual solubilities of $\mathrm{H}_{2} \mathrm{O}$ and $\mathrm{CO}_{2}$ are calculated with an accuracy typically within experimental uncertainties. The modification made in $\mathrm{ECO} 2 \mathrm{~N}$ is that $\mathrm{CO}_{2}$ molar volumes are calculated using a tabular EOS based on Altunin's correlation (1975), instead of the Redlich-Kwong equation of state used in (Spycher and Pruess, 2005). This was done to maintain consistency with the temperature and pressure conditions for phase change between liquid and gaseous conditions used elsewhere in ECO2N. Altunin's correlations yield slightly different molar volumes than the Redlich-Kwong EOS whose parameters were fitted by Spycher and Pruess (2005) to obtain the best overall match between observed and predicted $\mathrm{CO}_{2}$ concentrations in the aqueous phase. The (small) differences in Altunin's molar volumes cause predictions for the mutual solubility of water and $\mathrm{CO}_{2}$ to be somewhat different also. However, the differences are generally small, see Figs. 3-5. 


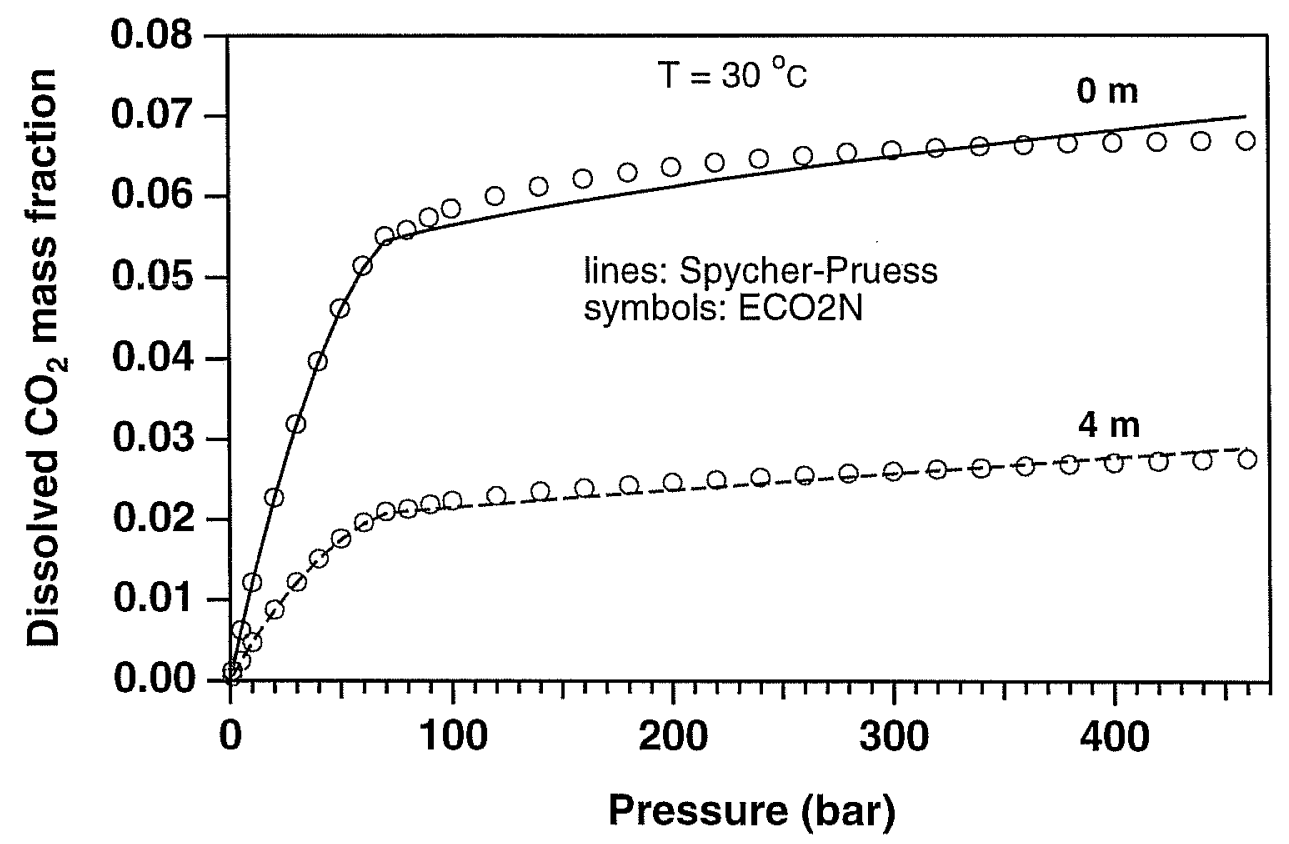

Figure 3. Dissolved $\mathrm{CO}_{2}$ mass fractions in two-phase system at $\mathrm{T}=30^{\circ} \mathrm{C}$ for pure water $(0 \mathrm{~m})$ and 4-molal $\mathrm{NaCl}$ brine. Lines represent the original correlation of Spycher and Pruess (2005) that uses a Redlich-Kwong EOS for molar volume of $\mathrm{CO}_{2}$. Symbols represent data calculated by ECO2N in which the molar volume of $\mathrm{CO}_{2}$ is obtained from the correlations of Altunin (1975).

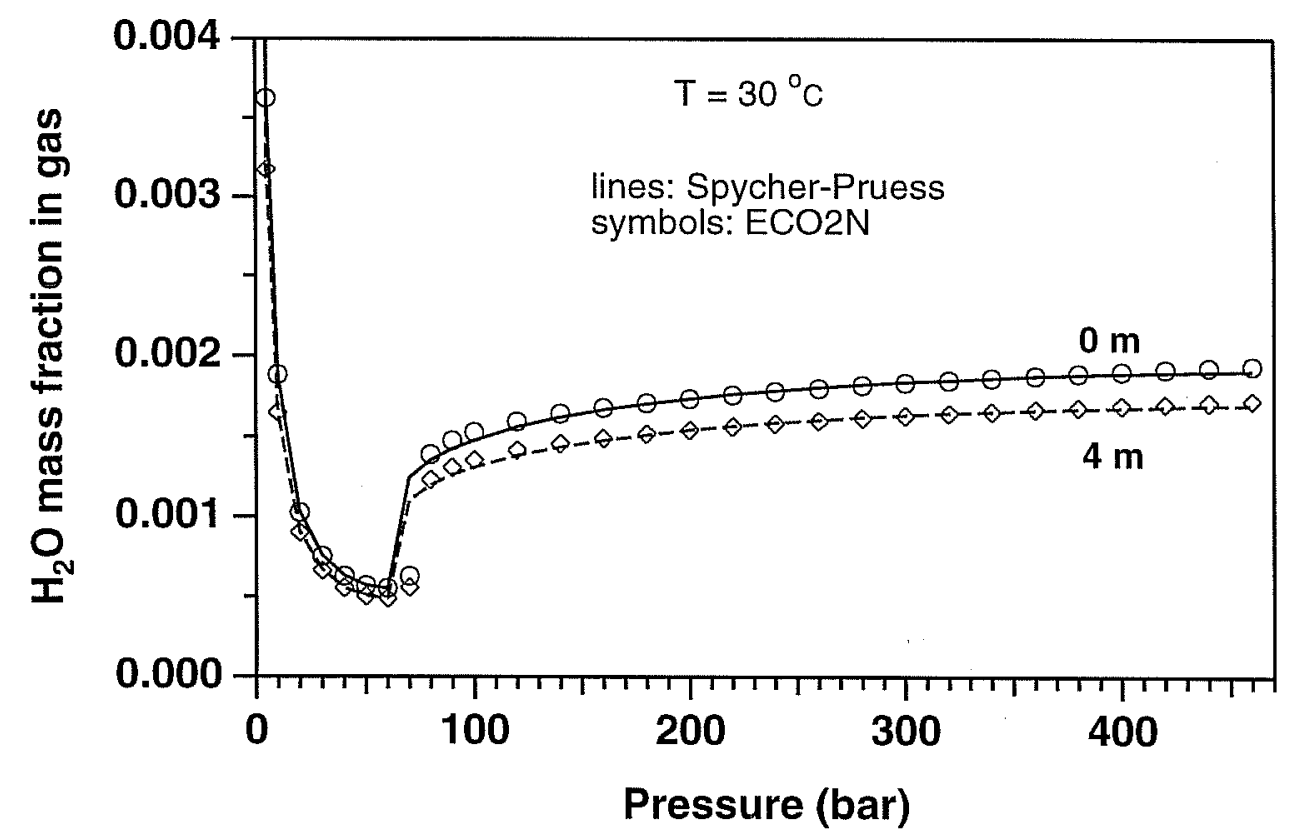

Figure 4. $\mathrm{H}_{2} \mathrm{O}$ mass fractions in gas in two-phase system at $\mathrm{T}=30^{\circ} \mathrm{C}$ for pure water $(0 \mathrm{~m})$ and 4 molal $\mathrm{NaCl}$ brine. Lines represent the original correlation of Spycher and Pruess (2005) that uses a Redlich-Kwong EOS for molar volume of $\mathrm{CO}_{2}$. Symbols represent data calculated by ECO2N in which the molar volume of $\mathrm{CO}_{2}$ is obtained from the correlations of Altunin (1975). 


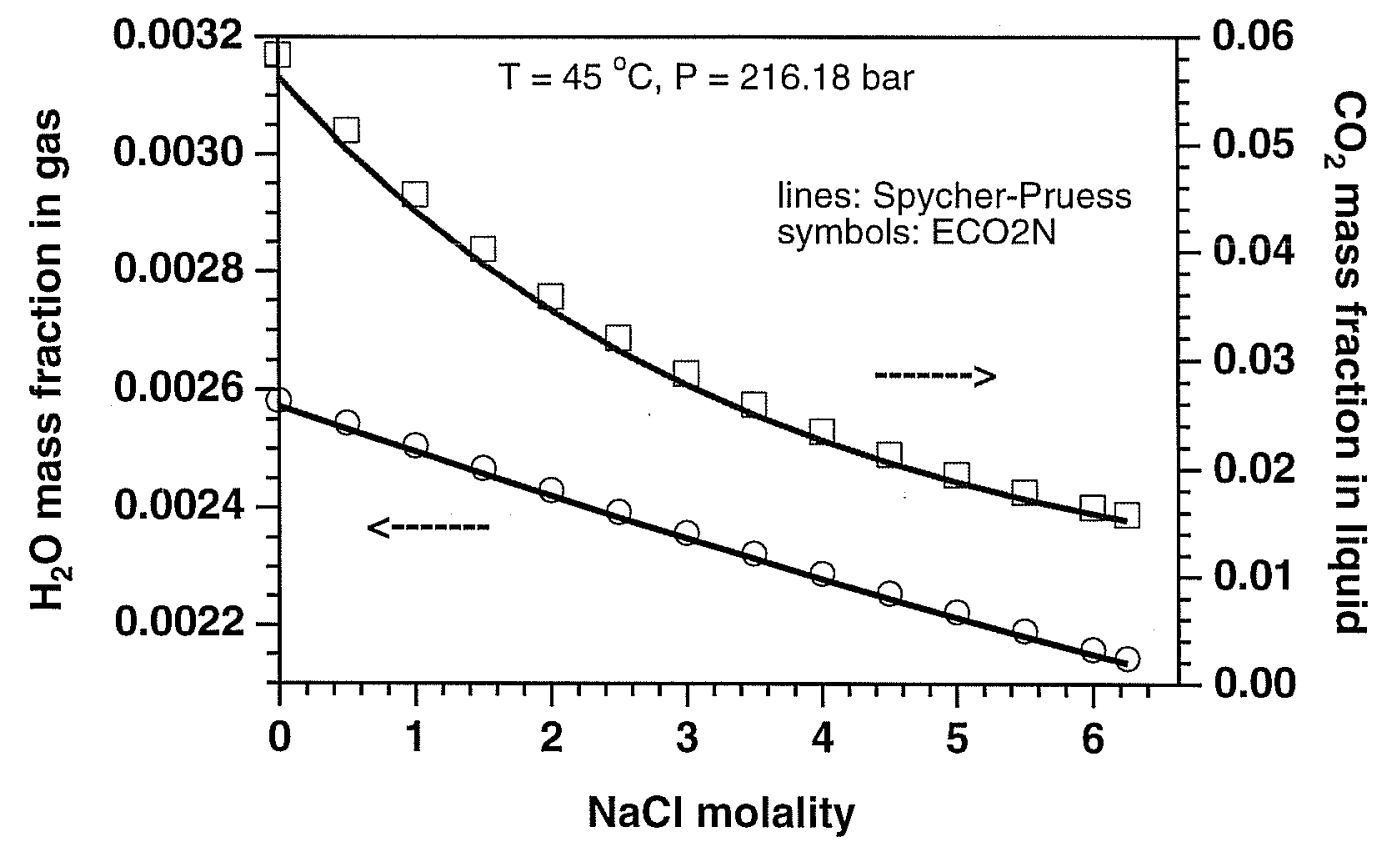

Figure 5. Concentration of water in gas and $\mathrm{CO}_{2}$ in the liquid (aqueous) phase at $(\mathrm{T}, \mathrm{P})=\left(45^{\circ} \mathrm{C}\right.$, $216.18 \mathrm{bar}$ ), for salinities ranging from zero to fully saturated. Lines were calculated from the correlation of Spycher and Pruess (2005) that uses a Redlich-Kwong EOS for molar volume of $\mathrm{CO}_{2}$. Symbols represent data calculated by ECO2N from a modified correlation in which the molar volume of $\mathrm{CO}_{2}$ is obtained from the correlations of Altunin (1975).

For conditions of interest to geologic dispoal of $\mathrm{CO}_{2}$, equilibrium between aqueous and gas phases corresponds to a dissolved $\mathrm{CO}_{2}$ mass fraction in the aqueous phase, $\mathrm{X}_{2 \text {,eq }}$, on the order of a few percent, while the mass fraction of water in the gas phase, $\mathrm{Y}_{1 \text {,eq, }}$, is a fraction of a percent, so that gas phase $\mathrm{CO}_{2}$ mass fraction $\mathrm{Y}_{2 \text {,eq }}=1-\mathrm{Y}_{1 \text {,eq }}$ is larger than 0.99 . The relationship between $\mathrm{CO}_{2}$ mass fraction $\mathrm{X} 3$ and phase composition of the fluid mixture is as follows (see Fig. 6)

- $\mathrm{X} 3<\mathrm{X}_{2, \mathrm{eq}}$ corresponds to single-phase liquid conditions;

- $\mathrm{X} 3>\mathrm{Y}_{2, \text { eq }}$ corresponds to single-phase gas;

- intermediate values $\left(\mathrm{X}_{2, \mathrm{eq}} \leq \mathrm{X} 3 \leq \mathrm{Y}_{2, \mathrm{eq}}\right)$ correspond to two-phase conditions with different proportions of aqueous and gas phases.

Dissolved $\mathrm{NaCl}$ concentrations may for typical sequestration conditions range as high as 6.25 molal. This corresponds to mass fractions of up to $\mathrm{X}_{\mathrm{sm}}=26.7 \%$ in the two-component system water-salt. Phase conditions as a function of $\mathrm{X}_{\mathrm{sm}}$ are as follows.

- $\mathrm{X}_{\mathrm{Sm}} \leq \mathrm{XEQ}$ corresponds to dissolved salt only;

- $\quad \mathrm{X}_{\mathrm{sm}}>\mathrm{XEQ}$ corresponds to conditions of a saturated $\mathrm{NaCl}$ brine and solid salt. 
Here XEQ denotes the equilibrium solubility of $\mathrm{NaCl}$, which in ECO2N is evaluated as in EWASG (Battistelli et a., 1997) as a function of temperature, using an equation by Potter cited in Chou (1987). No dependence of XEQ on $\mathrm{CO}_{2}$ concentration is taken into account.

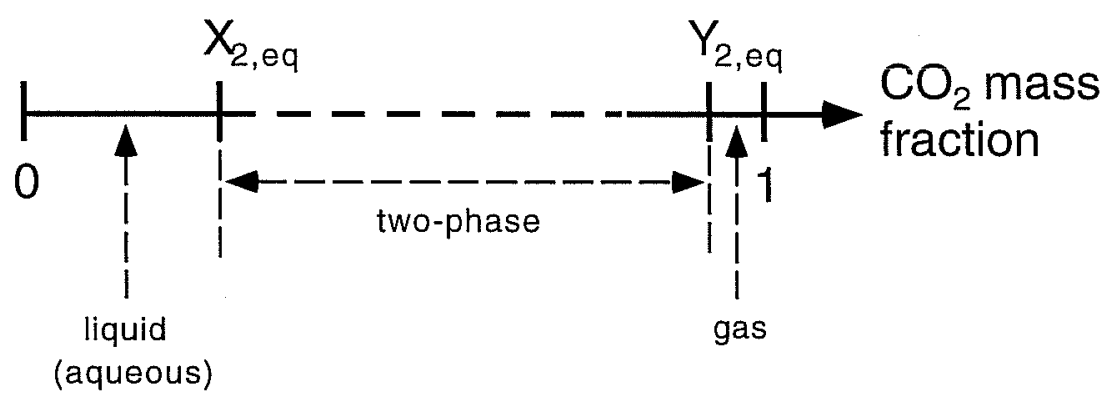

Figure 6. $\mathrm{CO}_{2}$ phase partitioning in the system $\mathrm{H}_{2} \mathrm{O}-\mathrm{NaCl}-\mathrm{CO}_{2}$. The $\mathrm{CO}_{2}$ mass fraction in brine- $\mathrm{CO}_{2}$ mixtures can vary in the range from $0\left(\right.$ no $\left.\mathrm{CO}_{2}\right)$ to 1 (no brine). $\mathrm{X}_{2 \text {,eq }}$ and $\mathrm{Y}_{2 \text {,eq }}$ denote, respectively, the $\mathrm{CO}_{2}$ mass fractions in aqueous and gas phases corresponding to equilibrium phase partitioning in two-phase conditions. Mass fractions less than $X_{2 \text {,eq }}$ correspond to conditions in

which only an aqueous phase is present, while mass fractions larger than $Y_{2 \text {,eq }}$ correspond to single-phase gas conditions. Mass fractions intermediate between $X_{2 \text {,eq }}$ and $Y_{2 \text {,eq }}$ correspond to two-phase conditions with different proportions of aqueous and gas phases.

\subsection{Phase Change}

In single-phase (aqueous or gas) conditions, the third primary variable $\mathrm{X} 3$ is the $\mathrm{CO}_{2}$ mass fraction in that phase. In single-phase aqueous conditions, we must have $X 3 \leq X_{2, e q}$, while in

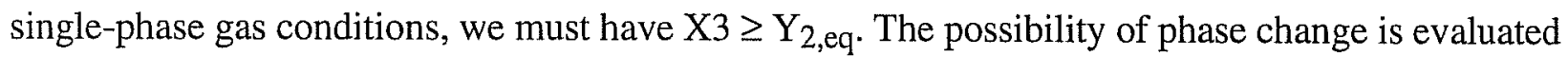
during a simulation by monitoring $\mathrm{X} 3$ in each grid block. The criteria for phase change from singlephase to two-phase conditions may be written as follows.

- single-phase aqueous conditions: a transition to two-phase conditions (evolution of a gas phase) will occur when $\mathrm{X} 3>\mathrm{X}_{2 \text {,eq; }}$;

- single-phase gas conditions: a transition to two-phase conditions (evolution of an aqueous phase) will occur when $\mathrm{X} 3<\mathrm{Y}_{2, \mathrm{eq}}=1-\mathrm{Y}_{1, \mathrm{eq}}$.

When two-phase conditions evolve in a previously single-phase grid block, the third primary variable is switched to $\mathrm{X} 3=\mathrm{S}_{\mathrm{g}}+10$. If the transition occurred from single-phase liquid conditions, the starting value of $S_{\mathrm{g}}$ is chosen as $10^{-6}$; if the transition occurred from single-phase gas, the starting value is chosen as $1-10^{-6}$.

In two-phase conditions, the third primary variable is $\mathrm{X} 3=\mathrm{S}_{\mathrm{g}}+10$. For two-phase conditions to persist, $\mathrm{X} 3$ must remain in the range $\left(10,11-\mathrm{S}_{\mathrm{S}}\right)$. Transitions to single-phase conditions are recognized as follows. 
- if $\mathrm{X} 3<10$ (i.e., $\mathrm{S}_{\mathrm{g}}<0$ ): gas phase disappears; make a transition to single-phase liquid conditions;

- if $\mathrm{X} 3>11-\mathrm{S}_{\mathrm{s}}$ (i.e., $\mathrm{S}_{\mathrm{g}}>1-\mathrm{S}_{\mathrm{S}}$ ): liquid phase disappears; make a transition to singlephase gas conditions.

Phase change involving (dis-)appearance of solid salt is recognized as follows. When no solid salt is present, the second primary variable $\mathrm{X}_{\mathrm{sm}}$ is the concentration (mass fraction referred to total water plus salt) of dissolved salt in the aqueous phase. The possibility of precipitation starting is evaluated by comparing $\mathrm{X}_{\mathrm{sm}}$ with $\mathrm{XEQ}$, the equilibrium solubility of $\mathrm{NaCl}$ at prevailing temperature. If $\mathrm{X}_{\mathrm{sm}} \leq \mathrm{XEQ}$ no precipitation occurs, whereas for $\mathrm{X}_{\mathrm{sm}}>\mathrm{XEQ}$ precipitation starts. In the latter case, variable $X_{\mathrm{sm}}$ is switched to $S_{\mathrm{s}}+10$, where solid saturation $S_{\mathrm{s}}$ is initialized with a small non-zero value $\left(10^{-6}\right)$. If a solid phase is present, the variable $X_{s m}=S_{s}+10$ is monitored. Solid phase disappears if $X_{\mathrm{sm}}<10$, in which case primary variable $X_{\mathrm{sm}}$ is switched to salt concentration, and is initialized as slightly below saturation, $\mathrm{X}_{\mathrm{sm}}=\mathrm{XEQ}-10^{-6}$.

\subsection{Conversion of Units}

The Spycher and Pruess (2005) model for phase partitioning in the system $\mathrm{H}_{2} \mathrm{O}-\mathrm{NaCl}-$ $\mathrm{CO}_{2}$ is formulated in molar quantities (mole fractions and molalities), while TOUGH2/ECO2N describes phase compositions in terms of mass fractions. This section presents the equations and parameters needed for conversion between the two sets of units. The conversion between various concentration variables (mole fractions, molalities, mass fractions) does not depend upon whether or not concentrations correspond to equilibrium between liquid and gas phases; accordingly, the relations given below are valid regardless of the magnitude of concentrations.

Let us consider an aqueous phase with dissolved $\mathrm{NaCl}$ and $\mathrm{CO}_{2}$. For a solution that is $\mathrm{m}$ molal in $\mathrm{NaCl}$ and $\mathrm{n}$-molal in $\mathrm{CO}_{2}$, total mass per $\mathrm{kg}$ of water is

$$
\mathrm{M}=1000\left(\mathrm{~g} \mathrm{H}_{2} \mathrm{O}\right)+\mathrm{m} \mathrm{M}_{\mathrm{NaCl}}(\mathrm{g} \mathrm{NaCl})+\mathrm{n} \mathrm{M}_{\mathrm{CO} 2}\left(\mathrm{~g} \mathrm{CO}_{2}\right)
$$

where $\mathrm{M}_{\mathrm{NaCl}}$ and $\mathrm{M}_{\mathrm{CO} 2}$ are the molecular weights of $\mathrm{NaCl}$ and $\mathrm{CO}_{2}$, respectively (see Table 2). Assuming $\mathrm{NaCl}$ to be completely dissociated, the total moles per $\mathrm{kg}$ of water are

$$
\mathrm{m}_{\mathrm{T}}=1000 / \mathrm{M}_{\mathrm{H} 2 \mathrm{O}}+2 \mathrm{~m}+\mathrm{n}
$$

The Spycher and Pruess (2005) correlations provide $\mathrm{CO}_{2}$ mole fraction $\mathrm{x}_{2}$ in the aqueous phase and $\mathrm{H}_{2} \mathrm{O}$ mole fraction $\mathrm{y}_{1}$ in the gas phase as functions of temperature, pressure, and salt 
concentration (molality). For a $\mathrm{CO}_{2}$ mole fraction $\mathrm{x}_{2}$ we have $\mathrm{n}=\mathrm{x}_{2} \mathrm{~m}_{\mathrm{T}}$ from which, using Eq. (4), we obtain

$$
\mathrm{n}=\frac{\mathrm{x}_{2}\left(2 \mathrm{~m}+1000 / \mathrm{M}_{\mathrm{H} 2 \mathrm{O}}\right)}{1-\mathrm{x}_{2}}
$$

$\mathrm{CO}_{2}$ mass fraction $\mathrm{X}_{2}$ in the aqueous phase is obtained by dividing the $\mathrm{CO}_{2}$ mass in $\mathrm{n}$ moles by the total mass,

$$
X_{2}=\frac{n M_{\mathrm{CO} 2}}{1000+\mathrm{mM}_{\mathrm{NaCl}}+\mathrm{nM}_{\mathrm{CO} 2}}
$$

Water mass fraction $\mathrm{Y}_{1}$ in the $\mathrm{CO}_{2}$-rich phase is simply

$$
\mathrm{Y}_{1}=\frac{\mathrm{y}_{1} \cdot \mathrm{M}_{\mathrm{H} 2 \mathrm{O}}}{\mathrm{y}_{1} \cdot \mathrm{M}_{\mathrm{H} 2 \mathrm{O}}+\left(1-\mathrm{y}_{1}\right) \mathrm{M}_{\mathrm{CO} 2}}
$$

The molecular weights of the various species are listed in Table 2 (Evans, 1982).

Table 2. Molecular weights in the system $\mathrm{H}_{2} \mathrm{O}-\mathrm{NaCl}-\mathrm{CO}_{2}$.

\begin{tabular}{|c|c|}
\hline species & mol. weight \\
\hline \hline $\mathrm{H}_{2} \mathrm{O}$ & 18.016 \\
\hline $\mathrm{Na}$ & 22.991 \\
\hline $\mathrm{Cl}$ & 35.457 \\
\hline $\mathrm{NaCl}$ & 58.448 \\
\hline $\mathrm{CO}_{2}$ & 44.0 \\
\hline
\end{tabular}




\section{Thermophysical Properties of Water-NaCl- $\mathrm{CO}_{2}$ Mixtures}

Thermophysical properties needed to model the flow of water-salt- $\mathrm{CO}_{2}$ mixtures in porous media include density, viscosity, and specific enthalpy of the fluid phases as functions of temperature, pressure, and composition, and partitioning of components among the fluid phases. Many of the needed parameters are obtained from the same correlations as were used in the EWASG property module of TOUGH2 (Battistelli et al., 1997). EWASG was developed for geothermal applications, and consequently considered conditions of elevated temperatures $>100{ }^{\circ} \mathrm{C}$, and modest $\mathrm{CO}_{2}$ partial pressures of order 1-10 bar. The present ECO2N module targets the opposite end of the temperature and pressure range, namely, modest temperatures below $110^{\circ} \mathrm{C}$, and high $\mathrm{CO}_{2}$ pressures up to several hundred bar.

Water properties in TOUGH2/ECO2N are calculated, as in other members of the TOUGH family of codes, from the steam table equations as given by the International Formulation Committee (1967). Properties of pure $\mathrm{CO}_{2}$ are obtained from correlations developed by Altunin et al. (1975). We began using Altunin's correlations in 1999 when a computer program implementing them was conveniently made available to us by Victor Malkovsky of the Institute of Geology of Ore Deposits, Petrography, Mineralogy and Geochemistry (IGEM) of the Russian Academy of Sciences, Moscow. Altunin's correlations were subsequently extensively cross-checked against experimental data and alternative PVT formulations, such as Span and Wagner (1996). They were found to be very accurate (García, 2003), so there is no need to change to a different formulation.

Altunin's correlations are not used directly in the code, but are used ahead of a TOUGH2/ECO2N simulation to tabulate density, viscosity, and specific enthalpy of pure $\mathrm{CO}_{2}$ on a regular grid of ( $\mathrm{T}, \mathrm{P})$-values. These tabular data are provided to the ECO2N module in a file called "CO2TAB," and property values are obtained during the simulation by means of bivariate interpolation. Fig. 7 shows the manner in which $\mathrm{CO}_{2}$ properties are tabulated, intentionally showing a coarse (T, P)-grid so that pertinent features of the tabulation may be better seen. (For actual calculations, we use finer grid spacings; the $\mathrm{CO} 2 \mathrm{TAB}$ data file distributed with $\mathrm{ECO} 2 \mathrm{~N}$ covers the range $3.04{ }^{\circ} \mathrm{C} \leq \mathrm{T} \leq 103.04{ }^{\circ} \mathrm{C}$ with $\Delta \mathrm{T}=2{ }^{\circ} \mathrm{C}$ and 1 bar $\leq \mathrm{P} \leq 600$ bar with $\Delta \mathrm{P} \leq 4$ bar in most cases. The $\mathrm{ECO} 2 \mathrm{~N}$ distribution includes a utility program for generating $\mathrm{CO} 2 \mathrm{TAB}$ files if users desire a different T,P-range or different increments.) As shown in Fig. 7, the tabulation is made in such a way that for sub-critical conditions the saturation line is given by diagonals of the interpolation quadrangles. On the saturation line, two sets of data are provided, for liquid and gaseous $\mathrm{CO}_{2}$, respectively, and in quadrangles that include points on both sides of the saturation line, points on the "wrong" side are excluded from the interpolation. This scheme provides for an efficient and accurate determination of thermophysical properties of $\mathrm{CO}_{2}$. 


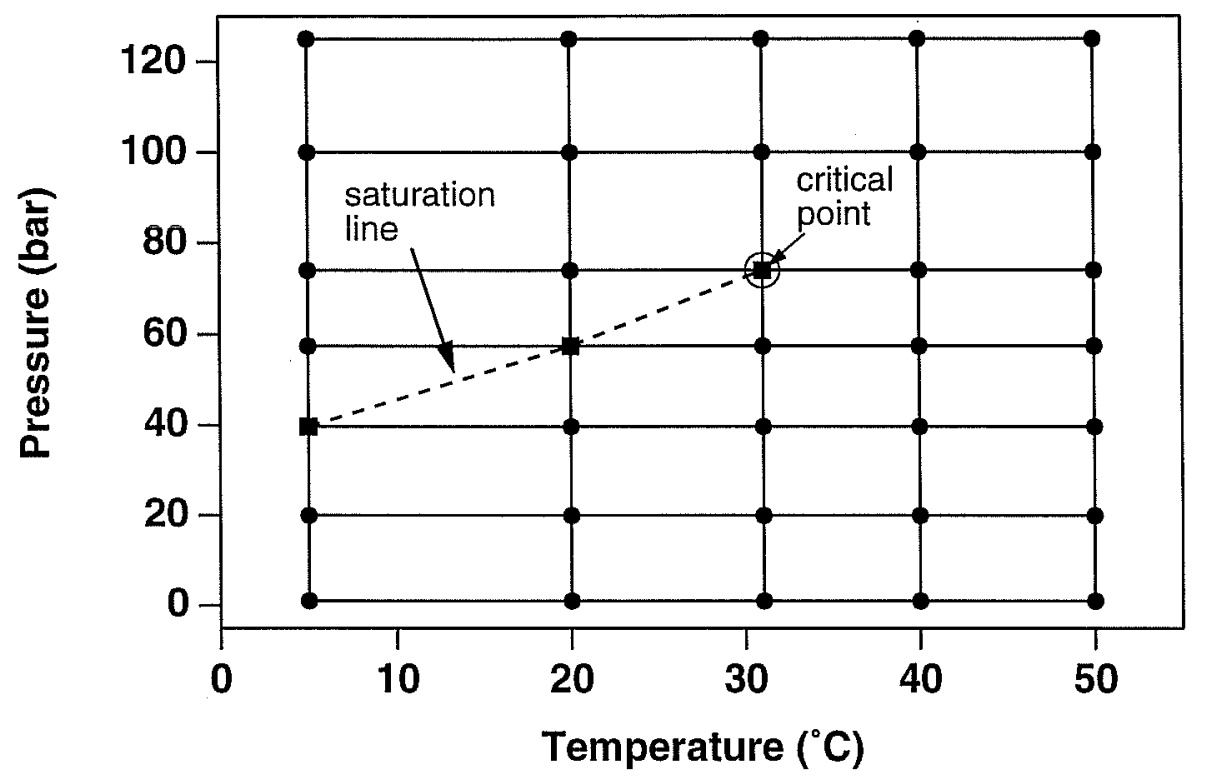

Figure 7. Schematic of the temperature-pressure tabulation of $\mathrm{CO}_{2}$ properties. The saturation line (dashed) is given by the diagonals of interpolation rectangles.

An earlier version of ECO2N explicitly associated partial pressures of water (vapor) and $\mathrm{CO}_{2}$ with the gas phase, and calculated $\mathrm{CO}_{2}$ dissolution in the aqueous phase from the $\mathrm{CO}_{2}$ partial pressure, using an extended version of Henry's law (Pruess and García, 2002). The present version uses a methodology for calculating mutual solubilities of water and $\mathrm{CO}_{2}$ (Spycher and Pruess, 2005) that is much more accurate, but has a drawback insofar as no partial pressures are associated with the individual fluid components. This makes it less straightforward to calculate thermophysical properties of the gas phase in terms of individual fluid components. We are primarily interested in the behavior of water-salt- $\mathrm{CO}_{2}$ mixtures at moderate temperatures, $\mathrm{T}<100{ }^{\circ} \mathrm{C}$, say, where water vapor pressure is a negligibly small fraction of total pressure. Under these conditions the amount of water present in the $\mathrm{CO}_{2}$-rich phase, henceforth referred to as "gas," is small. Accordingly, we approximate density, viscosity, and specific enthalpy of the gas phase by the corresponding properties of pure $\mathrm{CO}_{2}$, without water present.

\subsection{Density}

Brine density $\rho_{b}$ for the binary system water-salt is calculated as in Battistelli et al. (1997) from the correlations of Haas (1976) and Andersen et al. (1992). The calculation starts from aqueous phase density without salinity at vapor-saturated conditions, which is obtained from the correlations given by the International Formulation Committee (1967). Corrections are then applied 
to account for effects of salinity and pressure. The density of aqueous phase with dissolved $\mathrm{CO}_{2}$ is calculated assuming additivity of the volumes of brine and dissolved $\mathrm{CO}_{2}$.

$$
\frac{1}{\rho_{\mathrm{aq}}}=\frac{1-\mathrm{X}_{2}}{\rho_{\mathrm{b}}}+\frac{\mathrm{X}_{2}}{\rho_{\mathrm{CO} 2}}
$$

where $\mathrm{X}_{2}$ is the mass fraction of $\mathrm{CO}_{2}$ in the aqueous phase. Partial density of dissolved $\mathrm{CO}_{2}, \rho_{\mathrm{CO}}$, is calculated as a function of temperature from the correlation for molar volume of dissolved $\mathrm{CO}_{2}$ at infinite dilution developed by García (2001).

$$
V_{\phi}=a+b T+c T^{2}+d T^{3}
$$

In Eq. (9), molar volume of $\mathrm{CO}_{2}$ is in units of $\mathrm{cm}^{3}$ per gram-mole, temperature $\mathrm{T}$ is in ${ }^{\circ} \mathrm{C}$, and a-d are fit parameters given in Table 3.

Table 3. Parameters for molar volume of dissolved $\mathrm{CO}_{2}$ (Eq. 9)

\begin{tabular}{|c|c|}
\hline $\mathrm{a}$ & 37.51 \\
\hline $\mathrm{b}$ & $-9.585 \mathrm{e}-2$ \\
\hline $\mathrm{c}$ & $8.740 \mathrm{e}-4$ \\
\hline $\mathrm{d}$ & $-5.044 \mathrm{e}-7$ \\
\hline
\end{tabular}

Partial density of dissolved $\mathrm{CO}_{2}$ in units of $\mathrm{kg} / \mathrm{m}^{3}$ is then

$$
\rho_{\mathrm{CO} 2}=\frac{\mathrm{M}_{\mathrm{CO} 2}}{\mathrm{~V}_{\phi}} * 10^{3}
$$

where $\mathrm{M}_{\mathrm{CO} 2}=44.0$ is the molecular weight of $\mathrm{CO}_{2}$.

Dissolved $\mathrm{CO}_{2}$ amounts at most to a few percent of total aqueous density. Accordingly, dissolved $\mathrm{CO}_{2}$ is always dilute, regardless of total fluid pressure. It is then permissible to neglect the pressure dependence of partial density of dissolved $\mathrm{CO}_{2}$, and to use the density corresponding to infinite dilution. 
As had been mentioned above, the density of the $\mathrm{CO}_{2}$-rich (gas) phase is obtained by neglecting effects of water, and approximating the density by that of pure $\mathrm{CO}_{2}$ at the same temperature and pressure conditions. Density is obtained through bivariate interpolation from a tabulation of $\mathrm{CO}_{2}$ densities as function of temperature and pressure, that is based on the correlations developed by Altunin (1975).

\subsection{Viscosity}

Brine viscosity is obtained as in EWASG from a correlation presented by Phillips et al. (1981), that reproduces experimental data in the temperature range from $10-350{ }^{\circ} \mathrm{C}$ for salinities up to 5 molal and pressures up to 500 bar within $2 \%$. No allowance is made for dependence of brine viscosity on the concentration of dissolved $\mathrm{CO}_{2}$. Viscosity of the $\mathrm{CO}_{2}$-rich phase is approximated as being equal to pure $\mathrm{CO}_{2}$, and is obtained through tabular interpolation from the correlations of Altunin (1975).

\subsection{Specific Enthalpy}

Specific enthalpy of brine is calculated from the correlations developed by Lorenz et al. (2000), which are valid for all salt concentrations in the temperature range from $25^{\circ} \mathrm{C} \leq \mathrm{T} \leq 300^{\circ} \mathrm{C}$. The enthalpy of aqueous phase with dissolved $\mathrm{CO}_{2}$ is obtained by adding the enthalpies of the $\mathrm{CO}_{2}$ and brine (pseudo-) components, and accounting for the enthalpy of dissolution of $\mathrm{CO}_{2}$.

$$
\mathrm{h}_{\mathrm{aq}}=\left(1-\mathrm{X}_{2}\right) \mathrm{h}_{\mathrm{b}}+\mathrm{X}_{2} \mathrm{~h}_{\mathrm{CO} 2, \mathrm{aq}}
$$

$\mathrm{h}_{\mathrm{CO} 2 \text {,aq }}=\mathrm{h}_{\mathrm{CO} 2}+\mathrm{h}_{\text {dis }}$ is the specific enthalpy of aqueous (dissolved) $\mathrm{CO}_{2}$, which includes heat of dissolution effects that are a function of temperature and salinity. For gas-like (low pressure) $\mathrm{CO}_{2}$, the specific enthalpy of dissolved $\mathrm{CO}_{2}$ is

$$
\mathrm{h}_{\mathrm{CO} 2, \mathrm{aq}}\left(\mathrm{T}, \mathrm{P}, \mathrm{X}_{\mathrm{s}}\right)=\mathrm{h}_{\mathrm{CO} 2, \mathrm{~g}}(\mathrm{~T}, \mathrm{P})+\mathrm{h}_{\mathrm{dis}, \mathrm{g}}\left(\mathrm{T}, \mathrm{X}_{\mathrm{s}}\right)
$$

where $h_{\text {dis,g }}$ is obtained as in Battistelli et al. (1997) from an equation due to Himmelblau (1959). For geologic sequestration we are primarily interested in liquid-like (high-pressure) $\mathrm{CO}_{2}$, for which the specific enthalpy of dissolved $\mathrm{CO}_{2}$ may be written

$$
\mathrm{h}_{\mathrm{CO} 2, \mathrm{aq}}\left(\mathrm{T}, \mathrm{P}, \mathrm{X}_{\mathrm{s}}\right)=\mathrm{h}_{\mathrm{CO} 2,1}(\mathrm{~T}, \mathrm{P})+\mathrm{h}_{\mathrm{dis}, 1}\left(\mathrm{~T}, \mathrm{X}_{\mathrm{s}}\right)
$$


Here $h_{\text {dis, }}$ is the specific heat of dissolution for liquid-like $\mathrm{CO}_{2}$. Along the $\mathrm{CO}_{2}$ saturation line, liquid and gaseous $\mathrm{CO}_{2}$ phases may co-exist, and the expressions Eqs. $(12,13)$ must be equal there. We obtain

$$
\mathrm{h}_{\mathrm{dis}, 1}\left(\mathrm{~T}, \mathrm{X}_{\mathrm{s}}\right)=\mathrm{h}_{\mathrm{dis}, \mathrm{g}}\left(\mathrm{T}, \mathrm{X}_{\mathrm{s}}\right)+\mathrm{h}_{\mathrm{CO} 2, \mathrm{gl}}(\mathrm{T})
$$

where $h_{\mathrm{CO} 2, \mathrm{gl}}(\mathrm{T})=\mathrm{h}_{\mathrm{CO} 2, \mathrm{~g}}\left(\mathrm{~T}, \mathrm{P}_{\mathrm{s}}\right)-\mathrm{h}_{\mathrm{CO} 2,1}\left(\mathrm{~T}, \mathrm{P}_{\mathrm{s}}\right)$ is the specific enthalpy of vaporization of $\mathrm{CO}_{2}$, and $\mathrm{P}_{\mathrm{S}}=\mathrm{P}_{\mathrm{S}}(\mathrm{T})$ is the saturated vapor pressure of $\mathrm{CO}_{2}$ at temperature $\mathrm{T}$. Depending upon whether $\mathrm{CO}_{2}$ is in gas or liquid conditions, we use Eq.(12) or (13) in Eq. (11) to calculate the specific enthalpy of dissolved $\mathrm{CO}_{2}$. At the temperatures of interest here, $\mathrm{h}_{\text {dis, }}$ is a negative quantity, so that dissolution of low-pressure $\mathrm{CO}_{2}$ is accompanied by an increase in temperature. $\mathrm{h}_{\mathrm{CO}, \mathrm{gl}}$ is a positive quantity, which will reduce or cancel out the heat-of-dissolution effects. This indicates that dissolution of liquid $\mathrm{CO}_{2}$ will produce less temperature increase than dissolution of gaseous $\mathrm{CO}_{2}$, and may even cause a temperature decline if $\mathrm{h}_{\mathrm{CO} 2, \mathrm{gl}}$ is sufficiently large.

Application of Eq. (11) is straightforward for single-phase gas and two-phase conditions, where $\mathrm{h}_{\mathrm{CO} 2}$ is obtained as a function of temperature and pressure through bivariate interpolation from a tabulation of Altunin's correlation (1975). A complication arises in evaluating $\mathrm{h}_{\mathrm{CO} 2}$ for single-phase aqueous conditions. We make the assumption that $\mathrm{h}_{\mathrm{CO} 2}\left(\mathrm{P}, \mathrm{X}_{\mathrm{S}}, \mathrm{X}_{2}, \mathrm{~T}\right)$ for single-phase liquid is identical to the value in a two-phase system with the same composition of the aqueous phase. To determine $\mathrm{h}_{\mathrm{CO} 2}$, it is then necessary to invert the Spycher and Pruess (2005) phase partitioning relation $\mathrm{X}_{2}=\mathrm{X}_{2}\left(\mathrm{P} ; \mathrm{T}, \mathrm{X}_{\mathrm{s}}\right)$, in order to obtain the pressure $\mathrm{P}$ in a two-phase aqueous-gas system that would correspond to a dissolved $\mathrm{CO}_{2}$ mass fraction $\mathrm{X}_{2}$ in the aqueous phase, $\mathrm{P}=\mathrm{P}\left(\mathrm{X}_{2}\right.$; $\mathrm{X}_{\mathrm{s}}, \mathrm{T}$ ). The inversion is accomplished by Newtonian iteration, using a starting guess $\mathrm{P}_{0}$ for $\mathrm{P}$ that is obtained from Henry's law. Specific enthalpy of gaseous $\mathrm{CO}_{2}$ in the two-phase system is then calculated as $\mathrm{h}_{\mathrm{CO} 2}=\mathrm{h}_{\mathrm{CO} 2}(\mathrm{~T}, \mathrm{P})$, and specific enthalpy of dissolved $\mathrm{CO}_{2}$ is $\mathrm{h}_{\mathrm{CO} 2}+\mathrm{h}_{\text {dis }}$. 


\section{Preparation of Input Data}

Most of TOUGH2/ECO2N input specifications correspond to the general TOUGH2 input formats as given in the TOUGH2 user's guide (Pruess et al., 1999). This information is not duplicated in the present report; here we discuss only parameter choices specific to $E C O 2 N$.

\subsection{Initialization Choices}

Flow problems in TOUGH2/ECO2N will generally be initialized with the primary thermodynamic variables as used in the code, but some additional choices are available for the convenience of users. The internally used variables are $\left(\mathrm{P}, \mathrm{X}_{\mathrm{sm}}, \mathrm{X} 3, \mathrm{~T}\right)$ for grid blocks in singlephase (liquid or gas) conditions and $\left(\mathrm{P}, \mathrm{X}_{\mathrm{sm}}, \mathrm{S}_{\mathrm{g}}+10, \mathrm{~T}\right)$ for two-phase (liquid and gas) grid blocks (see Table 1). Here $\mathrm{X} 3$ is the mass fraction of $\mathrm{CO}_{2}$ in the fluid. As had been discussed above, for conditions of interest to geologic sequestration of $\mathrm{CO}_{2}, \mathrm{X} 3$ is restricted to small values $0 \leq \mathrm{X} 3 \leq$ $\mathrm{X}_{2 \text {,eq }}$ (a few percent) for single-phase liquid conditions, or to values near $1\left(\mathrm{Y}_{2, \mathrm{eq}} \leq \mathrm{X} 3 \leq 1\right.$, with $Y_{2, \text { eq }}>0.99$ typically) for single-phase gas (Fig. 6). Intermediate values $X_{2, \text { eq }}<X 3<Y_{2, \text { eq }}$ correspond to two-phase conditions, and thus should be initialized by specifying $S_{\mathrm{g}}+10$ as third primary variable. As a convenience to users, ECO2N allows initial conditions to be specified in the full range $0 \leq X 3 \leq 1$. During the initialization phase of a simulation, a check is made whether $X 3$ is in fact within the range of mass fractions that correspond to single-phase (liquid or gas) conditions. If this is found not to be the case, the conditions are recognized as being two-phase, and the corresponding gas saturation is calculated from the phase equilibrium constraint.

$$
X 3\left(S_{1} \rho_{1}+S_{g} \rho_{g}\right)=S_{1} \rho_{1} X_{2, \text { eq }}+S_{g} \rho_{g} Y_{2, \text { eq }}
$$

Using $S_{1}=1-S_{g}-S_{S}$, with $S_{S}$ the "solid saturation" (fraction of pore space occupied by solid salt), we obtain

$$
S_{g}=A \times\left(1-S_{S}\right)
$$

and the third primary variable is reset internally to $\mathrm{X} 3=\mathrm{S}_{\mathrm{g}}+10$. Here the parameter $\mathrm{A}$ is given by

$$
A=\frac{\left(X 3-X_{2, e q}\right) \rho_{1}}{\left(X 3-X_{2, e q}\right) \rho_{1}+\left(Y_{2, e q}-X 3\right) \rho_{g}}
$$

Users may think of specifying single-phase liquid (aqueous) conditions by setting $\mathrm{X} 3=10$ (corresponding to $S_{g}=0$ ), and single-phase gas conditions by setting $X 3=11-S_{\mathrm{S}}$ (corresponding 
to $S_{l}=0$ ). Strictly speaking this is not permissible, because two-phase initialization requires that both $S_{g}>0$ and $S_{1}>0$. Single-phase states should instead be initialized by specifying primary variable $\mathrm{X} 3$ as $\mathrm{CO}_{2}$ mass fraction. However, as a user convenience, $\mathrm{ECO} 2 \mathrm{~N}$ accepts initialization of single-phase liquid conditions by specifying $\mathrm{X} 3=10\left(\mathrm{~S}_{\mathrm{g}}=0\right)$. Such specification will be converted internally to two-phase in the initialization phase by adding a small number $\left(10^{-11}\right)$ to the third primary variable, changing conditions to two-phase with a small gas saturation $S_{g}=10^{-11}$.

Salt concentration or saturation of solid salt, if present, is characterized in ECO2N by means of the second primary variable $X_{\mathrm{sm}}$. When no solid phase is present, $\mathrm{X}_{\mathrm{sm}}$ denotes $\mathrm{X}_{\mathrm{s}}$, the mass fraction of $\mathrm{NaCl}$ referred to the two-component system water- $\mathrm{NaCl}$. This is restricted to the range 0 $\leq \mathrm{X}_{\mathrm{sm}} \leq \mathrm{XEQ}$, where $\mathrm{XEQ}=\mathrm{XEQ}(\mathrm{T})$ is the solubility of salt. For $\mathrm{X}_{\mathrm{sm}}>10$ this variable means $\mathrm{S}_{\mathrm{s}}$ +10 , solid saturation plus 10 . Users also have the option to specify salt concentration by means of molality $m$ by assigning $X_{\mathrm{sm}}=-\mathrm{m}$. Such specification will in the initialization phase be internally converted to $X_{s}$ by using Eq. (1). When salt concentration (as a fraction of total $\mathrm{H}_{2} \mathrm{O}+\mathrm{NaCl}$ mass) exceeds $\mathrm{XEQ}$, this corresponds to conditions in which solid salt will be present in addition to dissolved salt in the aqueous phase. Such states should be initialized with a second primary variable $\mathrm{X}_{\mathrm{sm}}=\mathrm{S}_{\mathrm{s}}+10$. However, ECO2N accepts initialization with $\mathrm{X}_{\mathrm{sm}}>\mathrm{XEQ}$, recognizes this as corresponding to presence of solid salt, and converts the second primary variable internally to the appropriate solid saturation that will result in total salt mass fraction in the binary system water-salt being equal to $\mathrm{X}_{\mathrm{sm}}$. The conversion starts from the following equation.

$$
X_{\mathrm{sm}}=\frac{\mathrm{XEQ} \times \mathrm{S}_{1} \rho_{1}\left(1-\mathrm{X}_{2}\right)+\mathrm{S}_{\mathrm{s}} \rho_{\mathrm{s}}}{\mathrm{S}_{1} \rho_{1}\left(1-\mathrm{X}_{2}\right)+\mathrm{S}_{\mathrm{s}} \rho_{\mathrm{s}}}
$$

where the numerator gives the total salt mass per unit volume, in liquid and solid phases, while the denominator gives the total mass of salt plus water. Substituting $S_{I}=1-S_{g}-S_{S}$, this can be solved for $S_{\mathrm{s}}$ to yield

$$
S_{s}=\frac{B \times\left(1-S_{g}\right)}{1+B}
$$

where the parameter $\mathrm{B}$ is given by

$$
B=\frac{\left(X_{s m}-X E Q\right) \rho_{1}\left(1-X_{2}\right)}{\rho_{s}\left(1-X_{s m}\right)}
$$


The most general conditions arise when both the second and third primary variables are initialized as mass fractions, nominally corresponding to single-phase fluid conditions with no solid phase present, but both mass fractions being in the range corresponding to two-phase fluid conditions with precipitated salt. Under these conditions, Eqs. (16) and (19) are solved simultaneously in ECO2N for $S_{\mathrm{S}}$ and $\mathrm{S}_{\mathrm{g}}$, yielding

$$
S_{g}=\frac{A}{1+B-A \times B}
$$

and

$$
S_{s}=\frac{B \times(1-A)}{1+B-A \times B}
$$

Then both second and third primary variables are converted to phase saturations, $\mathrm{S}_{\mathrm{s}}+10$ and $\mathrm{S}_{\mathrm{g}}+$ 10, respectively. Examples of different initialization choices are given in sample problem 1, below.

\subsection{Permeability Change from Precipitation and Dissolution of Salt}

ECO2N offers several choices for the functional dependence of relative change in permeability, $\mathrm{k} / \mathrm{k}_{0}$, on relative change in active flow porosity.

$$
\frac{\mathrm{k}}{\mathrm{k}_{0}}=\mathrm{f}\left(\frac{\phi_{\mathrm{f}}}{\phi_{0}}\right) \equiv \mathrm{f}\left(1-\mathrm{S}_{\mathrm{s}}\right)
$$

The simplest model that can capture the converging-diverging nature of natural pore channels consists of alternating segments of capillary tubes with larger and smaller radii, respectively; see Fig. 8. While in straight capillary tube models permeability remains finite as long

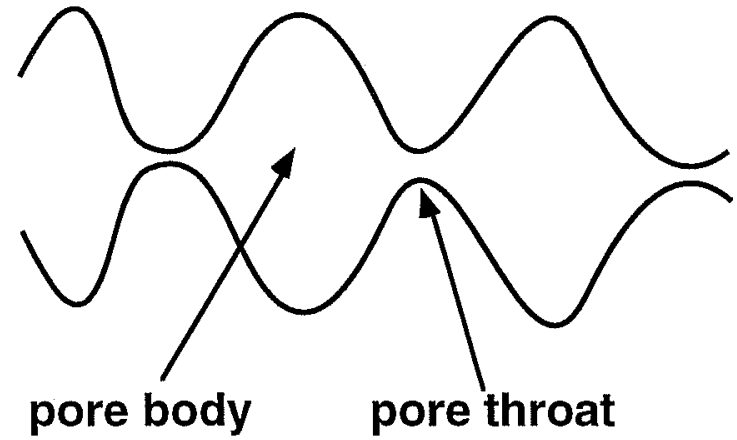

(a) conceptual model

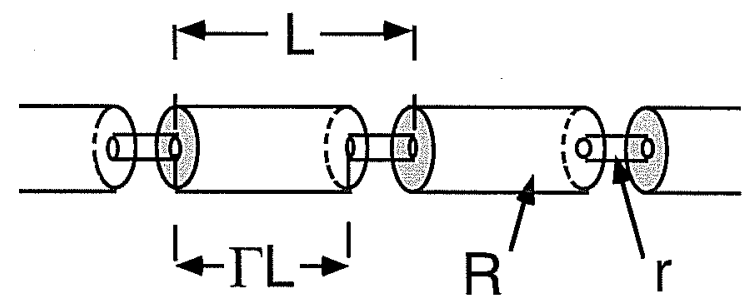

(b) tubes-in-series

Figure 8. Model for converging-diverging pore channels. 
as porosity is non-zero, in models of tubes with different radii in series, permeability is reduced to zero at a finite porosity. From the tubes-in-series model shown in Fig. 8, the following relationship can be derived (Verma and Pruess, 1988)

$$
\frac{\mathrm{k}}{\mathrm{k}_{0}}=\theta^{2} \frac{1-\Gamma+\Gamma / \omega^{2}}{1-\Gamma+\Gamma[\theta /(\theta+\omega-1)]^{2}}
$$

Here

$$
\theta=\frac{1-S_{\mathrm{S}}-\phi_{\mathrm{r}}}{1-\phi_{\mathrm{r}}}
$$

depends on the fraction $1-S_{s}$ of original pore space that remains available to fluids, and on a parameter $\phi_{\mathrm{r}}$, which denotes the fraction of original porosity at which permeability is reduced to zero. $\Gamma$ is the fractional length of the pore bodies, and the parameter $\omega$ is given by

$$
\omega=1+\frac{1 / \Gamma}{1 / \phi_{\mathrm{r}}-1}
$$

Therefore, Eq. (24) has only two independent geometric parameters that need to be specified, $\phi_{\mathrm{r}}$ and $\Gamma$. As an example, Fig. 9 shows the permeability reduction factor from Eq. (24), plotted against $\phi / \phi_{0} \equiv\left(1-S_{s}\right)$, for parameters of $\phi_{\mathrm{r}}=\Gamma=0.8$.

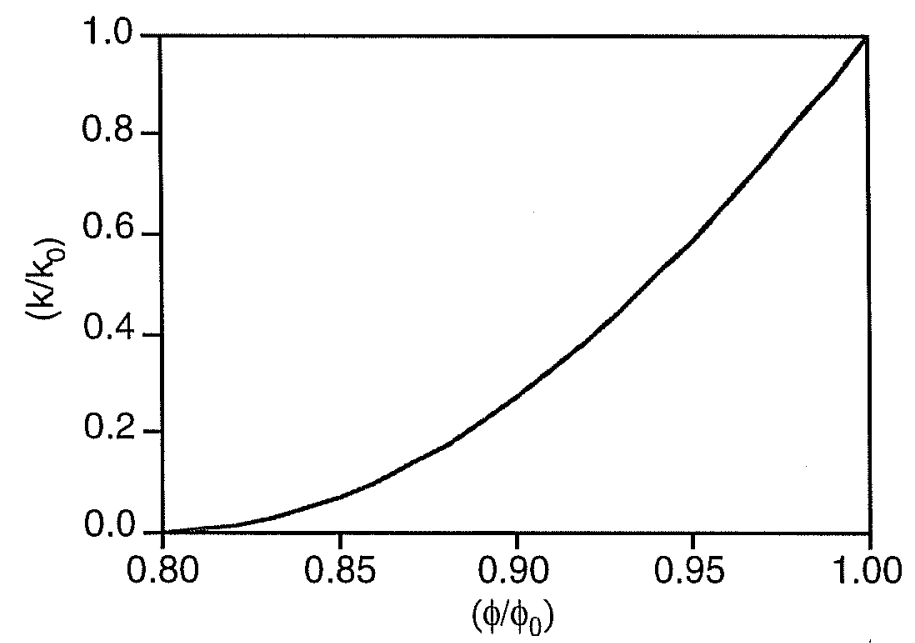

Figure 9. Porosity-permeability relationship for tubes-in-series model, after Verma and Pruess (1988). 
For parallel-plate fracture segments of different aperture in series, a relationship similar to Eq. (24) is obtained, the only difference being that the exponent 2 is replaced everywhere by 3 (Verma and Pruess, 1988). If only straight capillary tubes of uniform radius are considered, we have $\phi_{\mathrm{r}}=0, \Gamma=$ 0 , and Eq. (24) simplifies to

$$
\mathrm{k} / \mathrm{k}_{0}=\left(1-\mathrm{S}_{\mathrm{s}}\right)^{2}
$$

\subsection{Choice of Program Options}

Various options for ECO2N can be selected through parameter specifications in data block SELEC. Default choices corresponding to various selection parameters set equal to zero provide the most comprehensive thermophysical property model. Certain functional dependencies can be turned off or replaced by simpler and less accurate models, see below. These options are offered to enable users to identify the role of different effects in a flow problem, and to facilitate comparison with other simulation programs that may not include full dependencies of thermophysical properties.

SELECTION keyword to introduce a data block with parameters for ECO2N.

\section{Record SELEC. 1}

$$
\begin{aligned}
& \text { Format(16I5) } \\
& \mathbb{I E}(\mathrm{I}), \mathrm{I}=1,16
\end{aligned}
$$

$\mathrm{IE}(1) \quad$ set equal to 1 , to read one additional data record (a larger value with more data records is acceptable, but only one additional record will be used by ECO2N).

IE(11) selects dependence of permeability on the fraction $\phi_{\mathrm{f}} / \phi_{0}=\left(1-\mathrm{S}_{\mathrm{S}}\right)$ of original pore space that remains available to fluids.

0 : permeability does not vary with $\phi_{\mathrm{f}}$.

1: $\mathrm{k} / \mathrm{k}_{0}=\left(1-\mathrm{S}_{\mathrm{s}}\right)^{\gamma}$, with $\gamma=\mathrm{FE}(1)$ (record SELEC. 2$)$.

2: fractures in series, i.e., Eq. (24) with exponent 2 everywhere replaced by 3 .

3: tubes-in-series, i.e., Eq. (24).

$\mathrm{IE}(12) \quad$ allows choice of model for water solubility in $\mathrm{CO}_{2}$

0: after Spycher and Pruess (2005).

1: evaporation model; i.e., water density in the $\mathrm{CO}_{2}$-rich phase is calculated as density of saturated water vapor at prevailing temperature and salinity.

$\mathrm{IE}(13) \quad$ allows choice of dependence of brine density on dissolved $\mathrm{CO}_{2}$ 
0 : brine density varies with dissolved $\mathrm{CO}_{2}$ concentration, according to García's (2001) correlation for temperature dependence of molar volume of dissolved $\mathrm{CO}_{2}$.

1: brine density is independent of $\mathrm{CO}_{2}$ concentration.

$\mathrm{IE}(14) \quad$ allows choice of treatment of thermophysical properties as a function of salinity

0 : full dependence.

1: no salinity dependence of thermophysical properties (except for brine enthalpy; salt solubility constraints are maintained).

IE(15) allows choice of correlation for brine enthalpy at saturated vapor pressure

0: after Lorenz et al. (2000).

1: after Michaelides (1981).

2: after Miller (1978).

Record SELEC.2 introduces parameters for functional dependence of permeability on solid saturation

Format(8E10.4)

$\mathrm{FE}(1), \mathrm{FE}(2)$

$\mathrm{FE}(1) \quad$ parameter $\gamma($ for $\mathrm{IE}(11)=1)$; parameter $\phi_{\mathrm{r}}($ for $\mathrm{IE}(11)=2,3)$

$\mathrm{FE}(2) \quad$ parameter $\Gamma$ (for $\mathrm{IE}(11)=2,3$ )

The ECO2N module includes a customized version of a subroutine FGTAB that can write data files FOFT, COFT, and GOFT with time series of conditions at user-selected grid blocks and connections for plotting. The parameters written out in comma-delimited format at each time step are as follows.

FOFT: (gas) pressure, dissolved $\mathrm{CO}_{2}$ mass fraction in liquid, gas saturation, dissolved salt mass fraction and solid saturation (fraction of void space taken up by solid precipitate);

COFT: flow rates of gas, liquid, and total $\mathrm{CO}_{2}$ (as free phase and dissolved in aqueous phase);

GOFT: well flow rate, flowing enthalpy, flowing $\mathrm{CO}_{2}$ mass fraction, gas mass fraction of well flow, flowing wellbore pressure (production wells only). 


\section{Sample Problems}

This section presents a number of sample problems for TOUGH2/ECO2N. The problems were chosen to demonstrate the preparation of input data, to illustrate code capabilities, and to provide benchmarks for proper code installation. Three of the problems were taken from a recent code intercomparison study, in which ten groups from six countries exercised different simulation codes to generate results for a suite of test problems (Pruess et al., 2002, 2004). These problems include a basic injection problem (Section 5.2), a basic fault leakage problem (Section 5.3), and a $\mathrm{CO}_{2}$ storage problem with 2-D geometry loosely patterned after the Sleipner Vest $\mathrm{CO}_{2}$ injection project (Kongsjorden et al., 1997; Lindeberg et al., 2002) in the Norwegian sector of the North Sea (Section 5.4). In order to provide some context and perspective the current TOUGH2/ECO2N results are compared with results previously obtained in the $\mathrm{CO}_{2}$ code intercomparison project.

\subsection{Problem No. 1 (*rtab*) - Demonstration of Initialization Options}

The input file as given in Fig. 10 performs just a single infinitesimal time step $\left(\Delta t=10^{-9} \mathrm{~s}\right)$ and includes neither flow connections between grid blocks nor sinks or sources. Therefore, there is no flow and no changes in the initially specified thermodynamic conditions. The purpose of this problem is simply to demonstrate different options for initializing thermodynamic conditions.

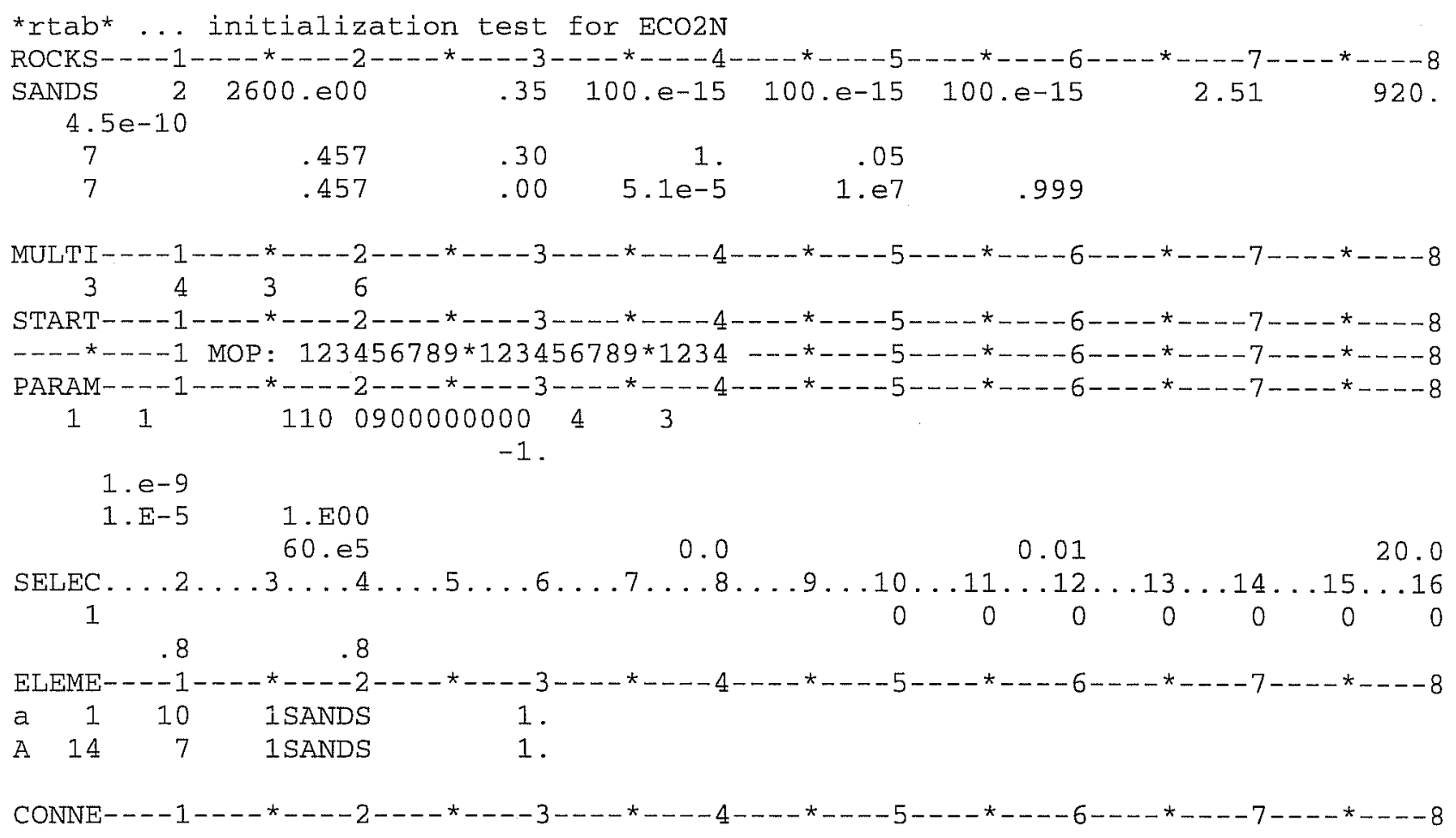

Figure 10. TOUGH2/ECO2N input file (first part) for sample problem 1 - demonstration of initialization options. 


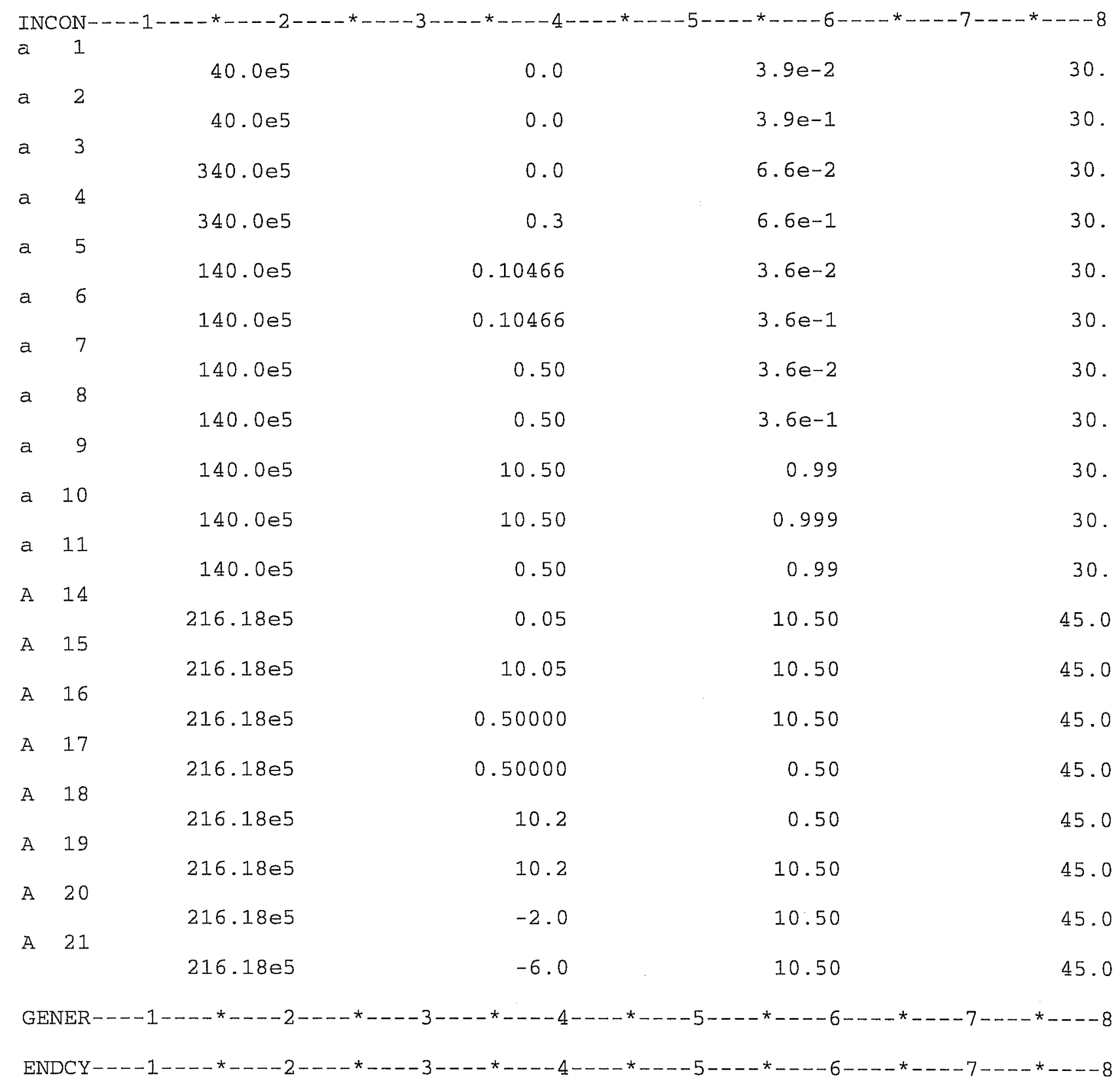

Figure 10. (continued)

Standard initialization with internally used primary variables (Table 1 ) is made for a number of grid blocks in single-phase liquid conditions (*a $1^{*}$, *a $3^{*}, *^{*} 5^{*}$ ), single-phase gas (*a $10^{*}$ ), and two-phase fluid (*A 14*, *A 15*,*A 19*). Several grid blocks are initialized with single-phase type primary variables, but with a $\mathrm{CO}_{2}$ mass fraction (primary variable \#3) that is larger than can be dissolved in the aqueous phase, and smaller than required for single-phase gas conditions $\left(* \mathrm{a} \quad 2 *, * \mathrm{a} \quad 6^{*}, * \mathrm{a} \quad 9 *\right.$, * $\mathrm{A} \quad 18 *$ ). The $\mathrm{CO}_{2}$ mass fractions for these blocks correspond to two-phase (liquid-gas) fluid conditions (see Fig. 6 and Section 4.1), and are 
internally converted to the appropriate gas saturation in the initialization phase. Primary variable \#3 is then re-set to $S_{g}+10$, as can be seen from the list of internally used primary variables that is generated by this problem (Fig. 11). Grid block *A $16 *$ is initialized with primary variable \#3 corresponding to internal ECO2N useage, but primary variable \#2 is larger than saturated salt mass fraction in the binary system water-salt. This specification corresponds to presence of solid salt, and is internally converted to $S_{s}+10$. In some grid blocks both primary variables \#2 and \#3 are specified with conventions applicable for single-phase liquid conditions, but with salt mass fraction exceeding the solubility limit, and $\mathrm{CO}_{2}$ mass fraction being in the intermediate range between the liquid and gas phase limits (*a $4^{*}, *^{*} 7^{*}, * a 8^{*}, * a 11^{*}, *^{*}$ A $17^{*}$ ). Salt as well as $\mathrm{CO}_{2}$ mass fractions for these blocks are converted to the appropriate internally used saturation variables. Finally, there are grid blocks (*A $20^{*}, * A 21 *$ ) in which primary variable \#2 is specified as salt molality (counted by convention as undissociated) in the binary water-salt system, which is internally converted to salt mass fraction. The internally used primary variables generated from the INCON data given in Fig. 10 are shown in Fig. 11. Fig. 12 shows part of the printed output for this problem.

We emphasize that the preferred and recommended option is to initialize flow problems by means of the internally used primary variables (Table 1). The options of allowing salt and $\mathrm{CO}_{2}$ mass fractions that are out of range were created as a convenience to users, to avoid "erroneous initialization" errors when running TOUGH2/ECO2N.

\begin{tabular}{|c|c|c|c|c|c|c|c|c|}
\hline $\mathrm{AT}$ & ELEMENT & $\star_{a}$ & $1 *$ & -- & $.400000 E+07$ & $.000000 E+00$ & $.390000 \mathrm{E}-01$ & $.300000 \mathrm{E}+02$ \\
\hline $\mathrm{AT}$ & ELEMENT & *a & 2 * & --- & $.400000 \mathrm{E}+07$ & $.000000 \mathrm{E}+00$ & $.108654 E+02$ & $.300000 E+02$ \\
\hline $\mathrm{AT}$ & ELEMENT & *a & $3 *$ & --- & $.340000 E+08$ & $.000000 \mathrm{E}+00$ & $.660000 \mathrm{E}-01$ & $.300000 E+02$ \\
\hline $\mathrm{AT}$ & ELEMENT & ${ }^{\star} a$ & $4^{*}$ & --- & $.340000 E+08$ & $.100080 \mathrm{E}+02$ & $.106980 \mathrm{E}+02$ & $.300000 E+02$ \\
\hline AT & ELEMENT & *a & $5 *$ & --- & $.140000 E+08$ & $.104660 \mathrm{E}+00$ & $.360000 \mathrm{E}-01$ & $.300000 E+02$ \\
\hline AT & ELEMENT & *a & $6 *$ & --- & $.140000 E+08$ & $.104660 \mathrm{E}+00$ & $.103947 \mathrm{E}+02$ & $.300000 \mathrm{E}+02$ \\
\hline $\mathrm{AT}$ & ELEMENT & *a & $7 *$ & --- & $.140000 \mathrm{E}+08$ & $.101996 \mathrm{E}+02$ & $.100239 E+02$ & $.300000 \mathrm{E}+02$ \\
\hline $\mathrm{AT}$ & ELEMENT & *a & $8 *$ & --- & $.140000 \mathrm{E}+08$ & $.101265 E+02$ & $.103812 \mathrm{E}+02$ & $.300000 E+02$ \\
\hline $\mathrm{AT}$ & ELEMENT & *a & $9 *$ & --- & $.140000 E+08$ & $.105000 \mathrm{E}+02$ & $.104969 E+02$ & $.300000 \mathrm{E}+02$ \\
\hline $\mathrm{AT}$ & ELEMENT & *a & $10^{*}$ & -- & $.140000 \mathrm{E}+08$ & $.105000 \mathrm{E}+02$ & $.999000 \mathrm{E}+00$ & $.300000 \mathrm{E}+02$ \\
\hline $\mathrm{AT}$ & ELEMENT & *a & $11 *$ & --- & $.140000 \mathrm{E}+08$ & $.100016 \mathrm{E}+02$ & $.109923 E+02$ & $.300000 E+02$ \\
\hline $\mathrm{AT}$ & ELEMENT & ${ }^{*} \mathrm{~A}$ & $14 *$ & --- & $.216180 E+08$ & $.500000 \mathrm{E}-01$ & $.105000 \mathrm{E}+02$ & $.450000 \mathrm{E}+02$ \\
\hline $\mathrm{AT}$ & ELEMENT & ${ }^{*} \mathrm{~A}$ & $15 *$ & --- & $.216180 E+08$ & $.100500 E+02$ & $.105000 E+02$ & $.450000 \mathrm{E}+02$ \\
\hline $\mathrm{AT}$ & ELEMENT & ${ }^{*} \mathrm{~A}$ & $16 *$ & --- & $.216180 \mathrm{E}+08$ & $.101016 \mathrm{E}+02$ & $.105000 \mathrm{E}+02$ & $.450000 E+02$ \\
\hline AT & ELEMENT & ${ }^{*} \mathrm{~A}$ & $17 *$ & --- & $.216180 \mathrm{E}+08$ & $.100957 E+02$ & $.105287 E+02$ & $.450000 E+02$ \\
\hline $\mathrm{AT}$ & ELEMENT & ${ }^{*} \mathrm{~A}$ & 18 * & --- & $.216180 E+08$ & $.102000 E+02$ & $.104677 \mathrm{E}+02$ & $.450000 E+02$ \\
\hline $\mathrm{AT}$ & ELEMENT & ${ }^{*} \mathrm{~A}$ & $19 *$ & --- & $.216180 \mathrm{E}+08$ & $.102000 \mathrm{E}+02$ & $.105000 \mathrm{E}+02$ & $.450000 \mathrm{E}+02$ \\
\hline $\mathrm{AT}$ & ELEMENT & ${ }^{*} \mathrm{~A}$ & $20^{*}$ & --- & $.216180 E+08$ & $.104661 \mathrm{E}+00$ & $.105000 \mathrm{E}+02$ & $.450000 E+02$ \\
\hline & ELEMENT & ${ }^{\star A} \mathrm{~A}$ & $21 *$ & --- & $.216180 E+08$ & $.259637 E+00$ & $.105000 \mathrm{E}+02$ & $.450000 E+02$ \\
\hline
\end{tabular}

Figure 11. Primary variables internally used in ECO2N for the INCON data given in Fig. 10. 
${ }^{\star} r t a b * \ldots$ initialization test for ECO2N

OUTPUT DATA AFTER (1, 1)-2-TIME STEPS

THE TIME IS , 115741E-13 DAYS

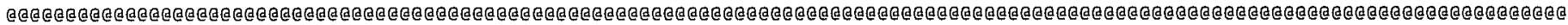

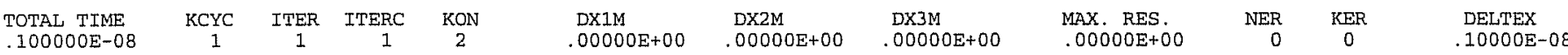

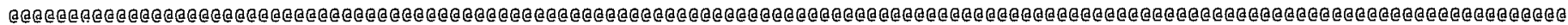

\begin{tabular}{|c|c|c|c|c|c|c|c|c|c|c|c|c|c|}
\hline \multicolumn{2}{|c|}{ ELEM. } & INDEX & $\stackrel{\mathrm{P}}{(\mathrm{Pa})}$ & $\stackrel{\mathrm{T}}{(\mathrm{deg}-\mathrm{c})}$ & SG & SS & XNACL & YH2OG & sc02aq & $\begin{array}{l}\mathrm{PCAP} \\
(\mathrm{Pa})\end{array}$ & \multicolumn{2}{|c|}{$\begin{array}{c}D G \\
(\mathrm{~kg} / \mathrm{m} 3)\end{array}$} & $\begin{array}{l}\mathrm{DL} \\
(\mathrm{kg} / \mathrm{m} 3)\end{array}$ \\
\hline a & 1 & 1 & $.40000 \mathrm{E}+07$ & 0.00 & $.00000 \mathrm{E}+00$ & $.00000 E+00$ & $.00000 E+00$ & $63683 E-03$ & $.39000 \mathrm{E}-01$ & $.00000 \mathrm{E}+00$ & $.10000 \mathrm{E}+01$ & .00 & .004 .89 \\
\hline $\mathrm{a}$ & 2 & 2 & $.40000 \mathrm{E}+07$ & & $.86541 E+00$ & $000 E+00$ & $.00000 E+00$ & .6 & $36 \mathrm{E}-01$ & $21079 E+06$ & $E+01$ & 89.85 & 5.03 \\
\hline$a$ & 3 & 3 & $.34000 E+08$ & 30.00 & $.00000 \mathrm{E}+00$ & $\pm+\infty$ & +00 & & 1 & & & 00 & U. \\
\hline 1 & 4 & 4 & $.34000 E+08$ & 30.00 & $E+00$ & $8 E-02$ & $17 E+00$ & & & -.79 & & 166.06 & 9.49 \\
\hline 国 & 5 & 5 & $.14000 E+08$ & & $E+00$ & .0 & .10 & .1 & & $\mathrm{E}+00$ & 01 & 00 & .59 \\
\hline$a$ & 6 & 6 & $E+08$ & & .35 & .00 & .1 & & & -.2 & & 836. & \\
\hline a & 7 & 7 & $2+08$ & & & & & & & -.4 & & & \\
\hline a & 8 & 8 & .14 & & & & & & & -.3 & & & \\
\hline $\mathrm{a}$ & 9 & 9 & +08 & 30 & 00 & .5 & .2 & & & -.8 & & & 12 \\
\hline a & 10 & 10 & $E+08$ & 30.0 & +00 & .5 & +00 & & 01 & -.1 & 1 & 83 & \\
\hline a & 11 & 11 & +08 & & $=00$ & .1 & .2 & & & -.8 & & 83 & \\
\hline A & 14 & 12 & +08 & & +00 & & .4 & & & -.3 & & & \\
\hline A & 15 & 13 & & & & & & & & -.4 & & & \\
\hline A & 16 & 14 & .21 & & & & & & & -.4 & & & \\
\hline A & 17 & 15 & $E+08$ & 0 & $6 E+00$ & .95 & $2 \mathrm{E}+00$ & .2 & $a-01$ & - & & 82 & \\
\hline A & 18 & 16 & $E+08$ & 45.00 & $71 E+00$ & .20 & +00 & $0 E-02$ & $E-01$ & -.5 & 10 & 829 & \\
\hline A & 19 & 17 & & & & & & & & -.5 & & & \\
\hline A & 20 & 18 & & & & & & & & & & & \\
\hline 7 & 21 & 19 & $1618 \mathrm{E}+08$ & 5.00 & $0000 \mathrm{E}+00$ & $00000 \mathrm{E}+00$ & $.25536 \mathrm{E}+00$ & $.21594 \mathrm{E}-02$ & $16490 \mathrm{E}-01$ & $7 E+05$ & $10000 E \div 01$ & 829.68 & 1194. \\
\hline
\end{tabular}

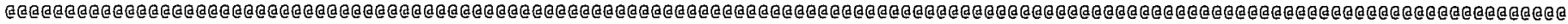

Figure 12. Output data for sample problem 1. 


\subsection{Problem No. 2 ("*cc3*) - Radial Flow from a $\mathrm{CO}_{2}$ Injection Well}

This is a basic problem of $\mathrm{CO}_{2}$ injection into a saline aquifer, examining two-phase flow with $\mathrm{CO}_{2}$ displacing (saline) water under conditions that may be encountered in brine aquifers at a depth of the order of $1.2 \mathrm{~km}$. A CO 2 injection well fully penetrates a homogeneous, isotropic, infinite-acting aquifer of $100 \mathrm{~m}$ thickness (Fig. 13), at conditions of 120 bar pressure, $45{ }^{\circ} \mathrm{C}$ temperature, and a salinity of $15 \%$ by weight. $\mathrm{CO}_{2}$ is injected uniformly at a constant rate of 100 $\mathrm{kg} / \mathrm{s}$. This problem had been included as test problem \#3 in a recent code intercomparison project (Pruess et al., 2002, 2004); full specifications are given in Appendix A.

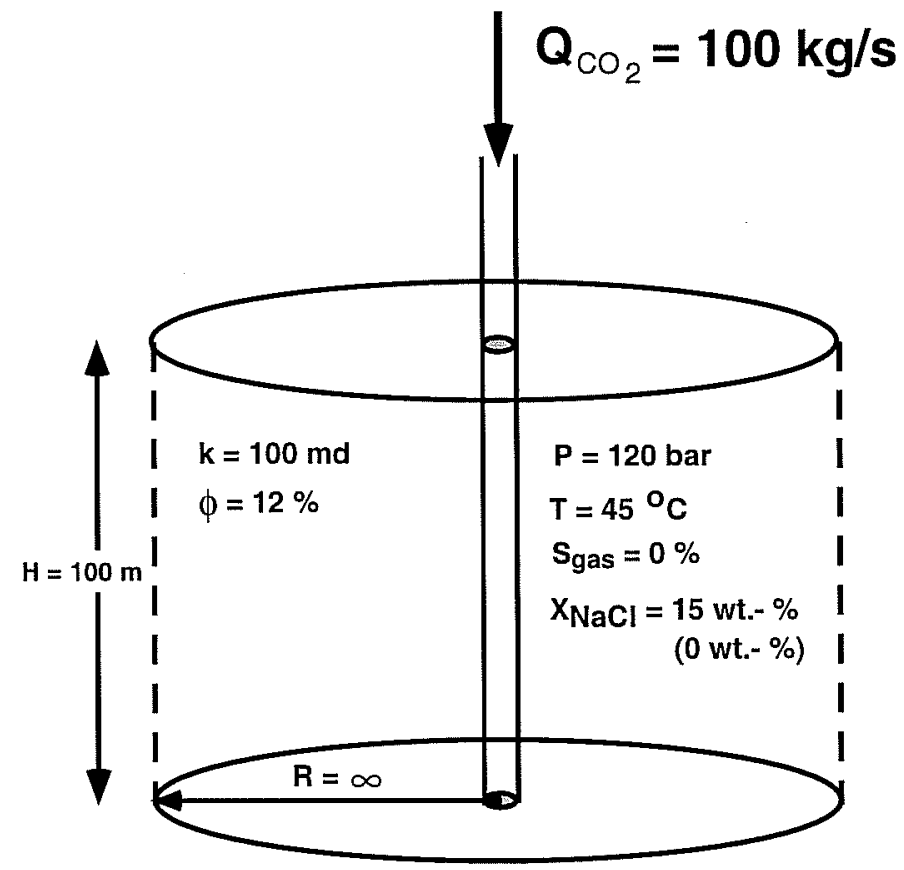

Figure 13. Schematic of sample problem 2.

The TOUGH2 input file used for grid generation is shown in Fig. 14. The well is modeled as a circular grid element of $\mathrm{R}=0.3 \mathrm{~m}\left(\approx 12^{\prime \prime}\right)$. The numerical grid is extended to a large distance of $100 \mathrm{~km}$, so that the system would be infinite-acting for the time period simulated $(10,000$ days, 27.38 years). Prior to the flow simulation, a minor amount of editing is performed on the MESH file. The well block is assigned to a domain \#2, with a view on facilitating running of a nonisothermal variation of the problem. Further, the nodal distance corresponding to the well block was changed to an infinitesimal value. A fragment of the modified MESH file is shown in Fig. 15, and the TOUGH2 input file used for the simulation is shown in Fig. 16. The simulation is performed in isothermal mode (NEQ = 3 in data block MULTI). A separate ROCKS domain 'well ' with "infinite" rock grain density was included in the input file to enable running of a non-isothermal 


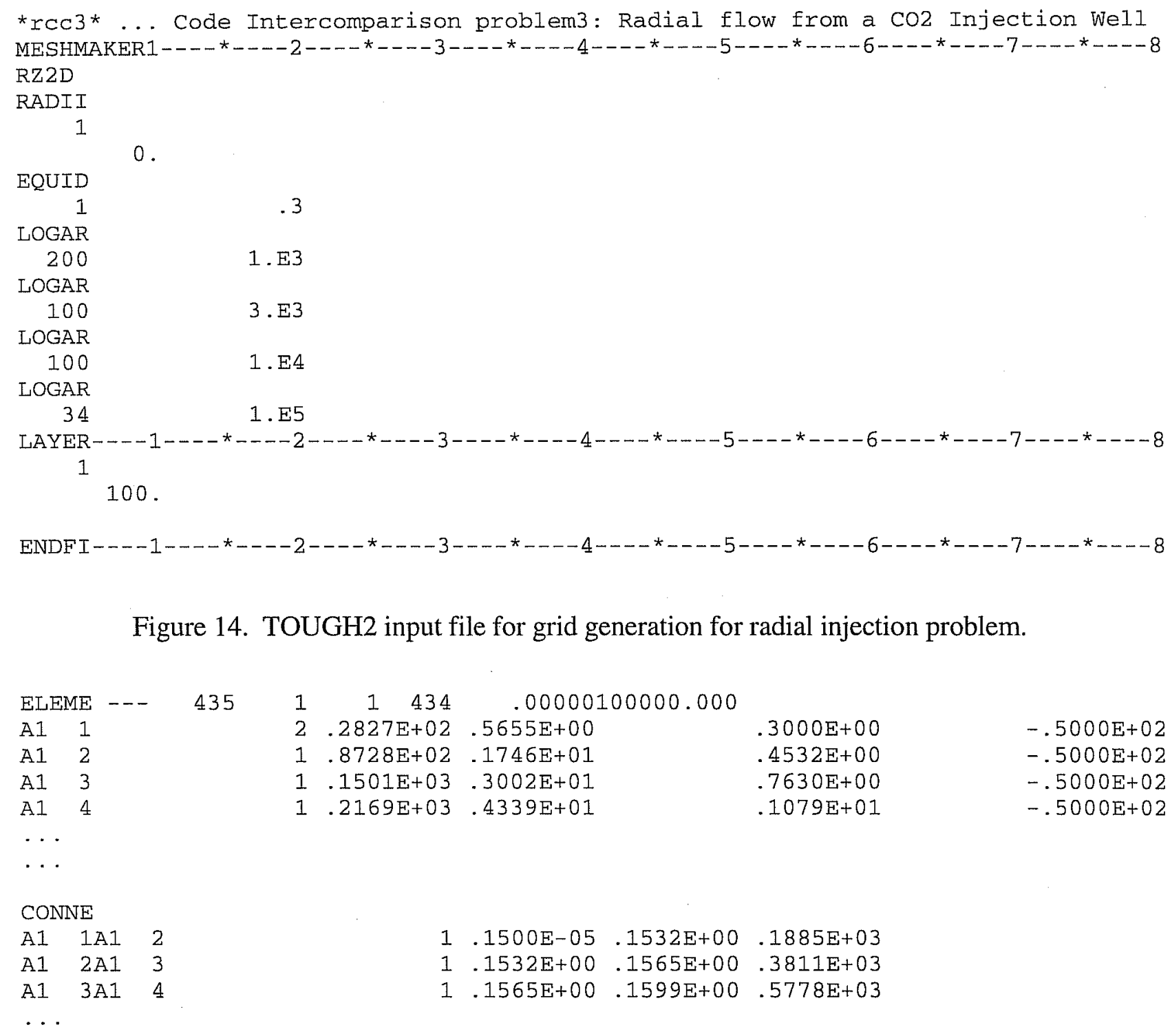

Figure 15. Modified MESH file for radial injection problem.

variation simply by setting NEQ $=4$; the well block "A1 1 " is assigned to domain 'well ' with "infinite" rock grain density, so that $\mathrm{CO}_{2}$ injection would effectively occur at initial temperature of $45^{\circ} \mathrm{C}$, obviating the need for specifying an injection enthalpy. Part of the output generated from this problem is shown in Fig. 17. As can be seen salt is precipitating around the injection well, but associated permeability reduction is turned off $(\mathbb{E}(11)=0)$.

An important advantage of the radial flow problem considered here is that it admits a similarity solution. Specifically, the solution depends on radial distance $\mathrm{R}$ and time tonly through the similarity variable $\xi=\mathrm{R}^{2} / \mathrm{t}$, even when taking into account all the non-linearities due to PVT 


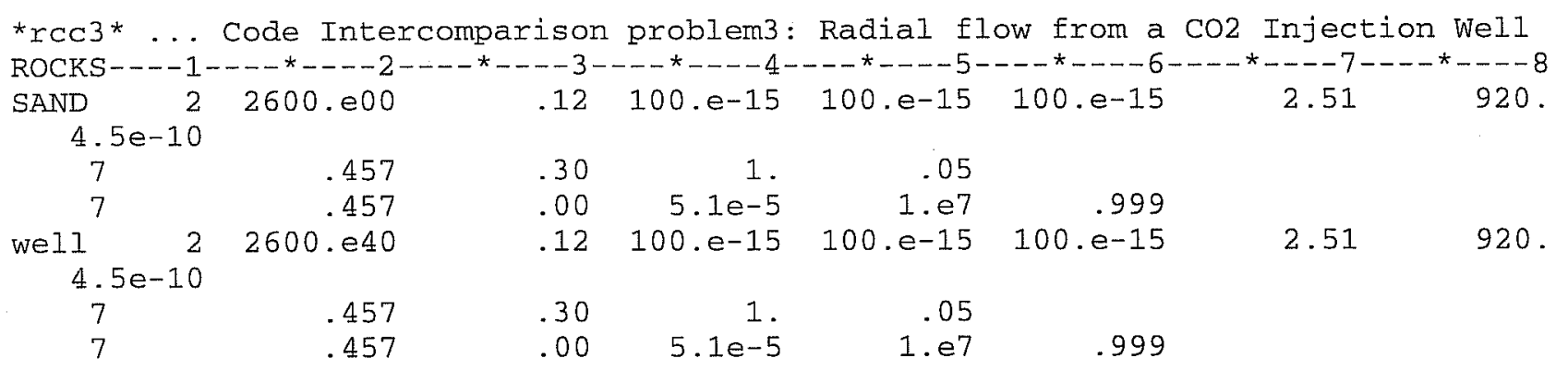

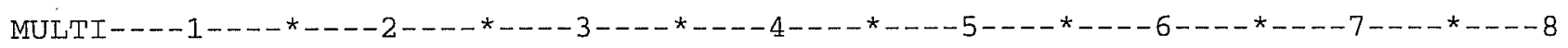
$\begin{array}{llll}3 & 3 & 3 & 6\end{array}$

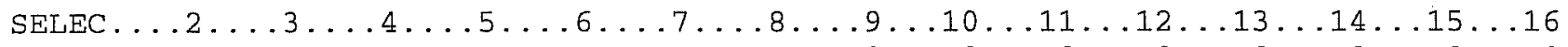

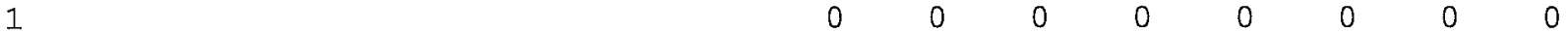

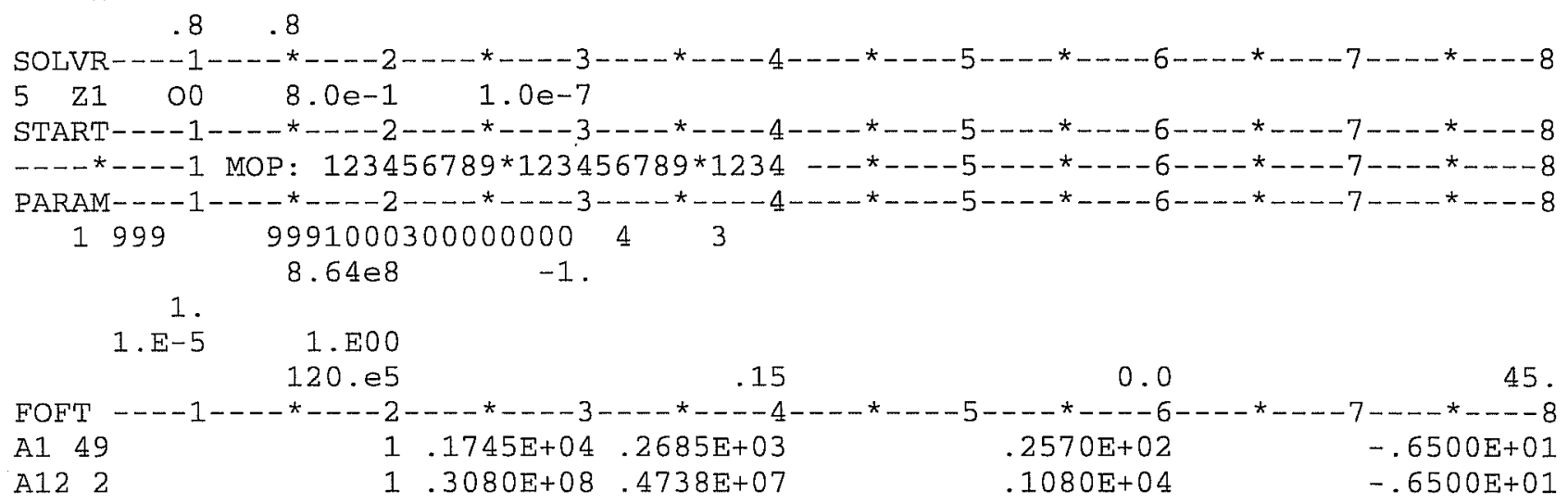

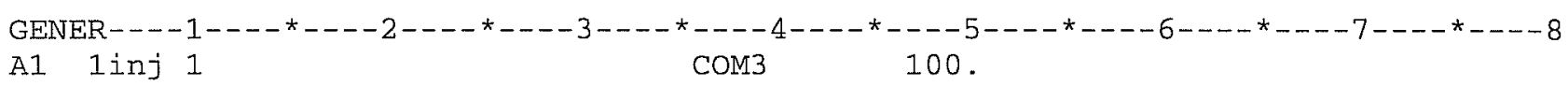

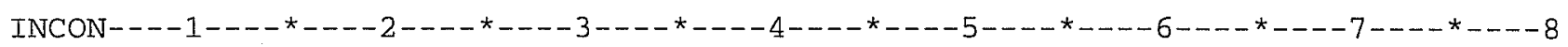

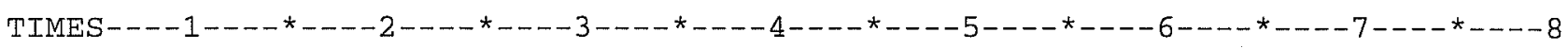
4

$2.592 \mathrm{E}+06 \quad 8.64 \mathrm{E}+06 \quad 8.64 \mathrm{E}+07 \quad 8.64 \mathrm{E}+08$

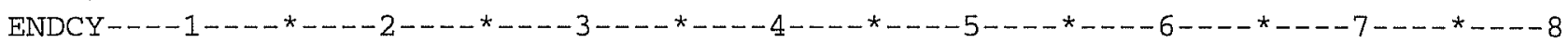

Figure 16. TOUGH2 input file for radial injection problem.

properties and two-phase flow (O'Sullivan, 1981; Doughty and Pruess, 1992). The space and time discretization employed for finite difference simulation will violate the rigorous $\mathrm{R}^{2} / \mathrm{t}$ invariance, so that the similarity property will be maintained only approximately. The accuracy of the numerical simulation can be checked by plotting the results as a function of the similarity variable $\mathrm{R}^{2} / \mathrm{t}$ (Figs. 18 - 23). Fig. 18 shows the results for pressure as a function of the similarity variable. Data were plotted from the pressure profile obtained at a simulation time of $\mathrm{t}=8.64 \times 10^{7} \mathrm{~s}$, and from the time series data for grid block A1 49, at a radial distance of $\mathrm{R}=25.25 \mathrm{~m}$, that were generated by means of FOFT specifications in the input file (Fig. 16). The agreement between the profile data (shown as thick solid lines) and the time series data (shown as thick dashed lines) is excellent, 
.. ITERATING... AT [ 1,1$]-$ DELTEX $=.100000 \mathrm{E}+01$ \$\$\$\$\$\$\$\$ GAS PHASE EVOLVES AT ELEMENT *A1 $1 *$ $\$ \$ \$ \$$ .ITERATING... AT $[1,2]-10$ DELTEX $=.100000 \mathrm{E}+01$

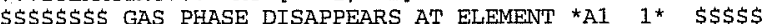
\$\$\$\$\$\$\$\$ GAS PHASE EVOLVES AT ELEMENT *AI $1 *$ *\$\$\$ ...ITERATING... AT $[1,1,3]--$ DELTEX $=.100000 E+01$ $\$ \$ \$ \$ \$ \$$ GAS PHASE DISAPPEARS AT ELEMENT *A1 $1 *$ *\$\$\$ ITERATING. . A AT [ 1,4$]-10$ DELTEX $=.10000 \mathrm{E}+01$ ..ITERATING. . AT [ 1,5$]--$ DELTEX $=.100000 E+01$

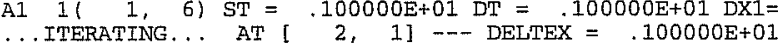

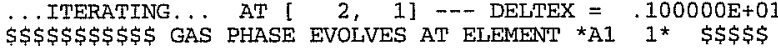
...ITERATING. . A AT $[2,2]--$ DELTEX $=.100000 \mathrm{E}+01$ ...ITERATING... AT $[2,3]-$-- DELTEX $=.100000 \mathrm{E}+01$ $\ldots$ ITERATTNG . . A AT $[2,4] \ldots$ DELTEX $=.100000 E+01$ ITPRATING... AT [ 2,5$]-$. DELTEX $=.100000 \mathrm{E}+01$ $\ldots$ ITERATING... AT $[12,6]-$. DELTEX $=.100000 \mathrm{E}+01$ AI $2(2,7) \mathrm{ST}=.200000 \mathrm{E}+01 \mathrm{DT}=.100000 \mathrm{E}+01 \mathrm{DX} 1=$ ...ITERATING... AT $[3,1]-$ DELTEX $=.100000 \mathrm{E}+01$ $\ldots$ ITERATING. . . AT $[3,2] \ldots$ DELTEX $=.100000 \mathrm{E}+01$ $\therefore$ ITERATING $\ldots$ AT $[3,3]-{ }_{3 T}=$ DELTEX $=0.100000 \mathrm{E}+01$ A1 I 3 . 4) ST $=.300000 \mathrm{E}+01$ DT $=.100000 \mathrm{E}+01 \mathrm{DX} 1=$

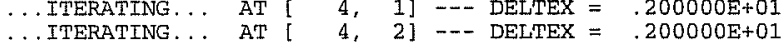
$\ldots$ ITERATING. .. AT $[4,3]-$. DELTEX $=.200000 \mathrm{E}+01$ $\ldots$ ITERATING... AT [ 4, 4] -.. DELTEX $=.200000 \mathrm{E}+01$ $\mathrm{A} 12(4,5) \mathrm{ST}=.500000 \mathrm{E}+01 \mathrm{DT}=.200000 \mathrm{E}+01 \mathrm{DX} 1=$
MAX. RES. $=.353732 \mathrm{E}+01$ AT ELEMENT AI 1 EQUATION 3 $\mathrm{X} 3=.267978 \mathrm{E}-01 \quad \mathrm{XCO2aq}=.262042 \mathrm{E}-01 \mathrm{PX}=.136627 \mathrm{E}+08 \mathrm{PA}$ MAX. RES. $=.246611$ E-01 AT ELEMENT A1 2 EQUATION 3 $S G=-.892323 E-04$

$\mathrm{X} 3=.262042 \mathrm{E}-01 \quad \mathrm{XCO2aq}=.261503 \mathrm{E}-01 \mathrm{PX}=.135439 \mathrm{E}+08 \mathrm{PA}$ MAX. RES. $=.121096 \mathrm{E}-01$ AT ELEMENT A1 1 EQUATION 3 $S G=-.993540 \mathrm{E}-04$

MAX. RES. $=.882447 \mathrm{E}-02$ AT ELEMENT AI 1 EQUATION 3 MAX RES $=315412 \mathrm{E}-04$ AT ELEMENT A1 1 EOUATTON 3 $166338 \mathrm{E}+07 \mathrm{DX}=-303162 \mathrm{E}-15 \mathrm{~T}=45.000 \mathrm{P}=13663377 . \mathrm{S}=000000 \mathrm{E}+00$ MAX RES $=100000 \mathrm{E}+01$ AT ELEMENT A1 1 EOUATTON 3 $\mathrm{X3}=.515157 \mathrm{E}-01 \quad \mathrm{XCO2aq}=.264071 \mathrm{E}-01 \mathrm{PX} \stackrel{141315 \mathrm{E}+0 \mathrm{BA}}{=}$ MAX. RES. $=.986648 \mathrm{E}+00$ AT ELEMENT A.1 1 EQUATION 3 MAX. RES. $=.913019 \mathrm{E}+00$ AT ELEMENT AI 2 EQUATION 3 MAX. RES. $=.154995 \mathrm{E}+00$ AT ELEMENT A1 2 EQUATION 3 MAX. RES. $=.106964 \mathrm{E}-01$ AT ELEMENT A1 2 EQUATION 3 MAX. RES. $=.117013 \mathrm{E}-03$ AT ELEMENT A1 2 EQUATION 3 $.111163 \mathrm{E}+07 \mathrm{DX} 2=.974739 \mathrm{E}-07 \mathrm{~T}=45.000 \mathrm{P}=14270694 . \mathrm{S}=.000000 \mathrm{E}+00$ MAX. RES. $=.496177 \mathrm{E}+00$ AI ELEMENT A1 1 EQUATION MAX. RES. $=.121128 \mathrm{E}-01$ AT ELEMENT A1 1 EQUATION 3 MAX. RES. $=.242397 \mathrm{E}-04$ AT ELEMENT A1 2 EQUATION 3 $158378 \mathrm{E}+07 \mathrm{DX} 2=972620 \mathrm{E}-05 \mathrm{~T}=45.000 \mathrm{P}=17949134 . \mathrm{S}=.722202 \mathrm{E}-01$ MAX. RES. $=.661797$ E+00 AT ELEMENT A1 1 EQUATION 3 MAX. RES. $=.745003 E+00$ AT ELEMENT AI 2 EQUATION 3 MAX. RES. $=.671985 E-01$ AT ELEMENT A1 2 EQUATION 3 $.259506 \mathrm{E}+06 \mathrm{DX} 2=-.564015 \mathrm{E}-06 \mathrm{~T}=45.000 \mathrm{P}=14951326 . \mathrm{S}=.000000 \mathrm{E}+00$

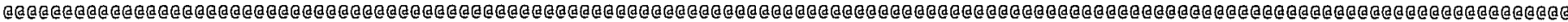

TOTAI, TTME

$.864000 \mathrm{E}+0$

KCYC ITER ITERC KON

$\mathrm{DX} 1 \mathrm{M}$

DX2M

$\begin{array}{lc}\text { DX3M } & \text { MAX. RES. } \\ .91553 \mathrm{E}-01 & .29116 \mathrm{E}-07\end{array}$

NEF

$4 \quad \mathrm{KER}$

3

DELTEX

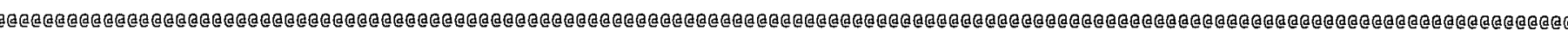

\begin{tabular}{|c|c|c|c|c|c|c|}
\hline \multicolumn{2}{|c|}{ ELEM. } & INDEX & $\stackrel{\mathrm{P}}{(\mathrm{Pa})}$ & $\begin{array}{c}T \\
\langle\operatorname{deg}-C\rangle\end{array}$ & SG & SS \\
\hline$A 1$ & 1 & 1 & $.22320 \mathrm{E} \div 08$ & 45.00 & $.93208 \mathrm{E}+00$ & $67918 \mathrm{E}$ \\
\hline A1 & 2 & 2 & $.22243 E+08$ & & $19 \mathrm{E}$ & \\
\hline A1 & 3 & 3 & $.22167 \mathrm{E}+08$ & 45.00 & $.95895 \mathrm{E}+00$ & $.41047 \mathrm{E}-01$ \\
\hline $\mathrm{A} 1$ & 4 & 4 & $.22115 \mathrm{E}+08$ & 45 & $.95915 \mathrm{E}+00$ & $.40850 \mathrm{E}-01$ \\
\hline 1 & 5 & 5 & $.22076 \mathrm{E}+08$ & 45 & $E+00$ & \\
\hline AI & 6 & 6 & $.22045 \mathrm{E}+08$ & 45 . & .96 & \\
\hline AI & 7 & 7 & $.22018 \mathrm{E}+08$ & 45.00 & $.96230 \mathrm{E}+00$ & $.37702 \mathrm{E}-01$ \\
\hline A1 & 8 & 8 & $.21995 \mathrm{E}+08$ & 45.00 & $.96157 \mathrm{E}+00$ & $430 \mathrm{E}-01$ \\
\hline A.1 & 9 & 9 & $.21975 \mathrm{E}+08$ & & $E+00$ & $32 \mathrm{E}-01$ \\
\hline A. 1 & 10 & 10 & .219 & 45 & $E+00$ & $7-01$ \\
\hline A1 1 & 11 & 11 & $.21940 E+08$ & 45 & $E+\infty 0$ & 3 \\
\hline A.1. & 12 & 12 & $.21925 E+08$ & 45. & $.96088 \mathrm{E}+00$ & $.39119 \mathrm{E}-01$ \\
\hline A1 1 & 13 & 13 & $.21911 \mathrm{E}+08$ & 45.00 & $.96376 \mathrm{E}+00$ & $.36238 \mathrm{E}-01$ \\
\hline & 10 & 14 & $8 E+0$ & 45.00 & $309 E+00$ & $913 \mathrm{E}-\mathrm{C}$ \\
\hline & 15 & 1.5 & $.21885 E+08$ & 45.00 & $.96087 \mathrm{E}+00$ & $.39133 E-01$ \\
\hline
\end{tabular}

XNACL
$.00000 \mathrm{E}+00$
$.00000 \mathrm{E}+00$
$.00000 \mathrm{E}+00$
$.00000 \mathrm{E}+00$
$.00000 \mathrm{E}+00$
$.00000 \mathrm{E}+00$
$.00000 \mathrm{E}+00$
$.00000 \mathrm{E}+00$
$.00000 \mathrm{E}+00$
$.00000 \mathrm{E}+00$
$.00000 \mathrm{E}+00$
$.00000 \mathrm{E}+00$
$.00000 \mathrm{E}+00$
$.00000 \mathrm{E}+00$
$.00000 \mathrm{E}+00$

$\mathrm{YH} 20 \mathrm{G}$
$.00000 \mathrm{E}+00$
$.00000 \mathrm{E}+00$
$.00000 \mathrm{E}+00$
$.00000 \mathrm{E}+00$
$.00000 \mathrm{E}+00$
$.00000 \mathrm{E}+00$
$.00000 \mathrm{E}+00$
$.00000 \mathrm{E}+00$
$.00000 \mathrm{E}+00$
$.00000 \mathrm{E}+00$
$.00000 \mathrm{E}+00$
$.00000 \mathrm{E}+00$
$.00000 \mathrm{E}+00$
$.00000 \mathrm{E}+00$
$.00000 \mathrm{E}+00$

$\begin{array}{lc}\text { XCO2aq } & \begin{array}{c}\text { PCAP } \\ (\mathrm{Pa})\end{array} \\ .15973 \mathrm{E}-01 & -.10000 \mathrm{E}+08 \\ .15960 \mathrm{E}-01 & -.10000 \mathrm{E}+08 \\ .15947 \mathrm{E}-01 & -.10000 \mathrm{E}+08 \\ .15938 \mathrm{E}-01 & -.10000 \mathrm{E}+08 \\ .15931 \mathrm{E}-01 & -.10000 \mathrm{E}+08 \\ .15926 \mathrm{E}-01 & -.10000 \mathrm{E}+08 \\ .15921 \mathrm{E}-01 & -.10000 \mathrm{E}+08 \\ .15917 \mathrm{E}-01 & -.10000 \mathrm{E}+08 \\ .15914 \mathrm{E}-01 & -.10000 \mathrm{E}+08 \\ .15911 \mathrm{E}-01 & -.10000 \mathrm{E}+08 \\ .15908 \mathrm{E}-01-.10000 \mathrm{E}+08 \\ .15905 \mathrm{E}-01-.10000 \mathrm{E}+08 \\ .15903 \mathrm{E}-01-.10000 \mathrm{E}+08 \\ .15901 \mathrm{E}-01-.10000 \mathrm{E}+08 \\ .15899 \mathrm{E}-01-.10000 \mathrm{E}+08\end{array}$

$\begin{array}{lc}\text { k-red. } & \begin{array}{c}\mathrm{DG} \\ (\mathrm{kg} / \mathrm{mI})\end{array} \\ .10000 \mathrm{E}+01 & 836.08 \\ .10000 \mathrm{E}+01 & 835.38 \\ .10000 \mathrm{E}+01 & 834.69 \\ .10000 \mathrm{E}+01 & 834.22 \\ .10000 \mathrm{E}+01 & 833.86 \\ .10000 \mathrm{E}+01 & 833.57 \\ .10000 \mathrm{E}+01 & 833.33 \\ .10000 \mathrm{E}+01 & 833.12 \\ .10000 \mathrm{E}+01 & 832.94 \\ .10000 \mathrm{E}+01 & 832.77 \\ .10000 \mathrm{E}+01 & 832.62 \\ .10000 \mathrm{E}+01 & 832.48 \\ .10000 \mathrm{E}+01 & 832.35 \\ .10000 \mathrm{E}+01 & 832.23 \\ .10000 \mathrm{E}+01 & 832.12\end{array}$

$\underset{(\mathrm{kg} / \mathrm{m} 3)}{\mathrm{DL}}$

Figure 17. Part of printed output for radial flow problem.

confirming the approximate preservation of the similarity property in the numerical solution. Minor deviations in the time series data at values $\mathrm{R}^{2} / \mathrm{t}<10^{-5} \mathrm{~m}^{2} / \mathrm{s}$ correspond to conditions at very large times, where effects of the finite system size are beginning to be felt. Fig. 19 presents simulated results for gas saturation as a function of the similarity variable, showing three distinct regions emerging from the $\mathrm{CO}_{2}$ injection process. The first region with $\mathrm{R}^{2} / \mathrm{t} \leq 1.3 \times 10^{-5} \mathrm{~m}^{2} / \mathrm{s}$ corresponds to a zone where complete dry-out of aqueous phase has occurred. Gas saturation in this region is slightly less than 1, however, due to the presence of solid precipitate (Fig. 20). The dry-out zone is followed by an intermediate zone extending to $\mathrm{R}^{2} / \mathrm{t} \approx 10^{-2} \mathrm{~m}^{2} / \mathrm{s}$ where liquid and gas phases coexist. Finally, there is an outer region with $R^{2} / t>10^{-2} \mathrm{~m}^{2} / \mathrm{s}$ in which single-phase liquid conditions prevail. 
For comparison Figs. 18 - 22 also include results generated by LBNL for the code intercomparison project with an earlier version of the ECO2N-module. The main difference to the present simulation is that the earlier version used an evaporation model for $\mathrm{H}_{2} \mathrm{O}$ partitioning into the $\mathrm{CO}_{2}$-rich phase. We ran a problem variation using the evaporation model with the present ECO2N module $(\operatorname{IE}(12)=1)$, and obtained results that were virtually identical to the previous LBNL results in the code intercomparison project. Fig. 23 shows that the evaporation model strongly underestimates the amount of water dissolving into the $\mathrm{CO}_{2}$-rich phase. The Spycher and Pruess (2005) model for phase partitioning produces a more vigorous drying process, accelerating the growth of a dry-out zone around the injection well (Fig. 19), and giving rise to increased salt precipitation (Fig. 20). The larger extent of the dry-out zone and increased salt precipitation there are the only significant differences in comparison to the earlier LBNL results. The peculiar behavior of $\mathrm{NaCl}$ mass fraction in liquid seen in Fig. 22 is due to dissolution of $\mathrm{CO}_{2}$. At large $\mathrm{R}^{2} / \mathrm{t}>10^{-2}$ $\mathrm{m}^{2} / \mathrm{s}, \mathrm{NaCl}$ mass fraction is unchanged from the initial value of 0.15 . The modest reduction of $\mathrm{NaCl}$ mass fraction to approximately 0.146 in the two-phase zone $\left(1.3 \times 10^{-5} \mathrm{~m}^{2} / \mathrm{s}<\mathrm{R}^{2} / \mathrm{t}<10^{-2} \mathrm{~m}^{2} / \mathrm{s}\right)$ is due to the volume increase of the aqueous phase upon $\mathrm{CO}_{2}$ dissolution. The sharp peak in $\mathrm{NaCl}$ concentration at the inner boundary of the two-phase zone $\left(\mathrm{R}^{2} / \mathrm{t} \approx 1.3 \times 10^{-5} \mathrm{~m}^{2} / \mathrm{s}\right)$ occurs because conditions are approaching dry-out there. 


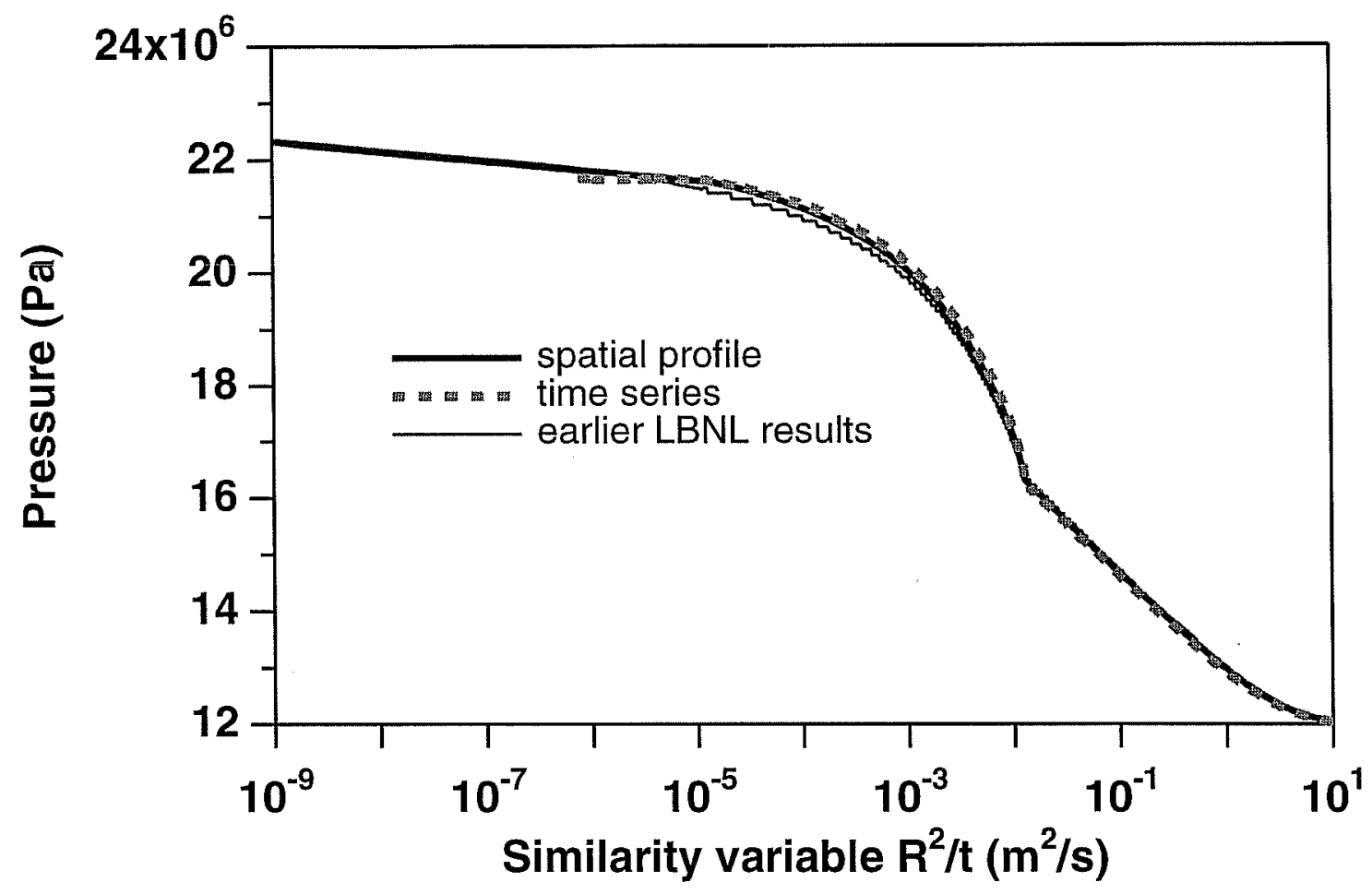

Figure 18. Simulated pressures as a function of the similarity variable. The thick solid line represents a spatial profile at a simulation time of $8.64 \times 10^{7} \mathrm{~s}$, while the thick dashed line represents a time series of data for a grid block at a radial distance of $R=25.25 \mathrm{~m}$. The thin line gives the results previously submitted by LBNL to the code intercomparison project, that were obtained with an earlier version of the ECO2N module. 


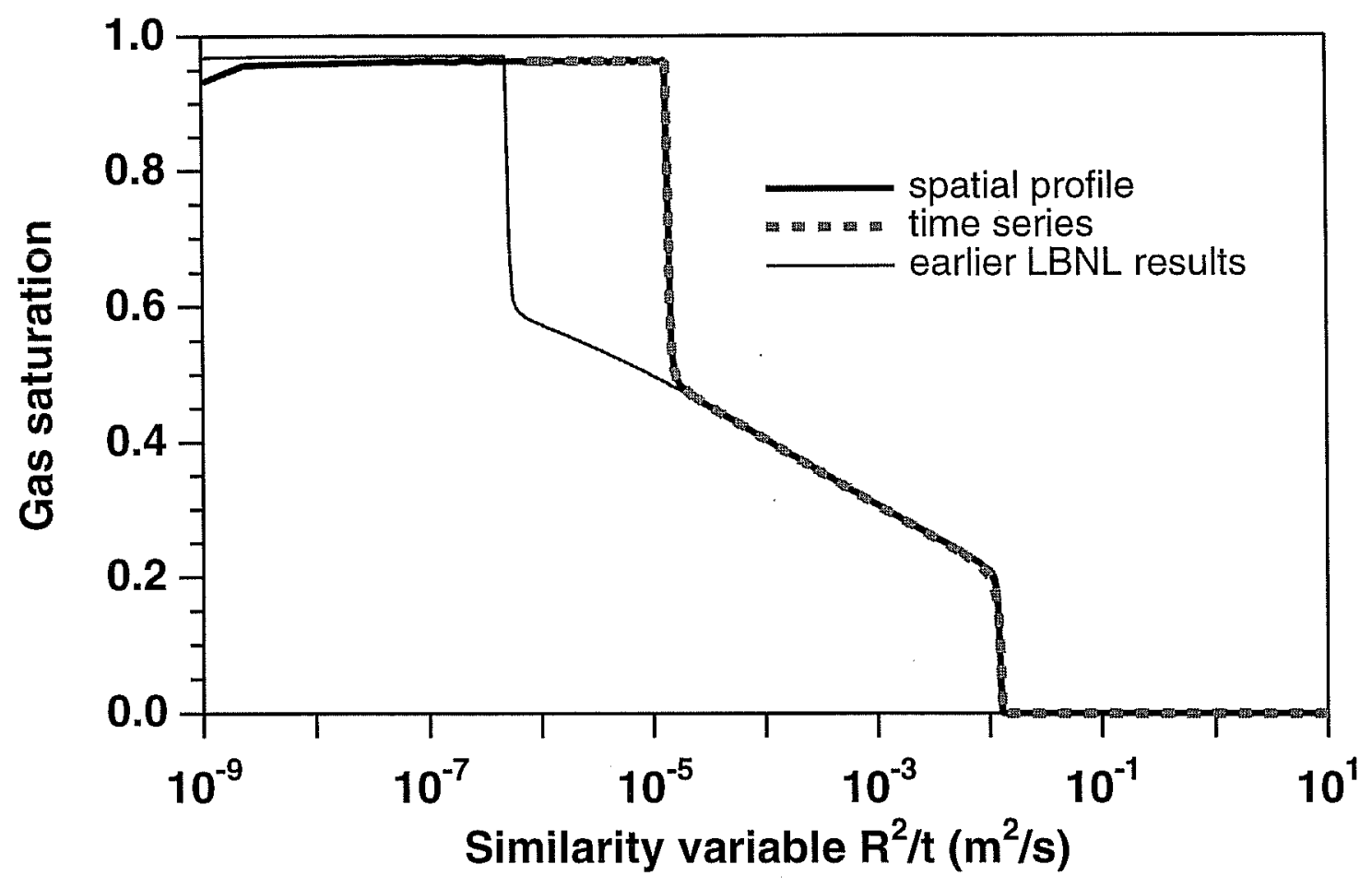

Figure 19. Simulated gas saturations.

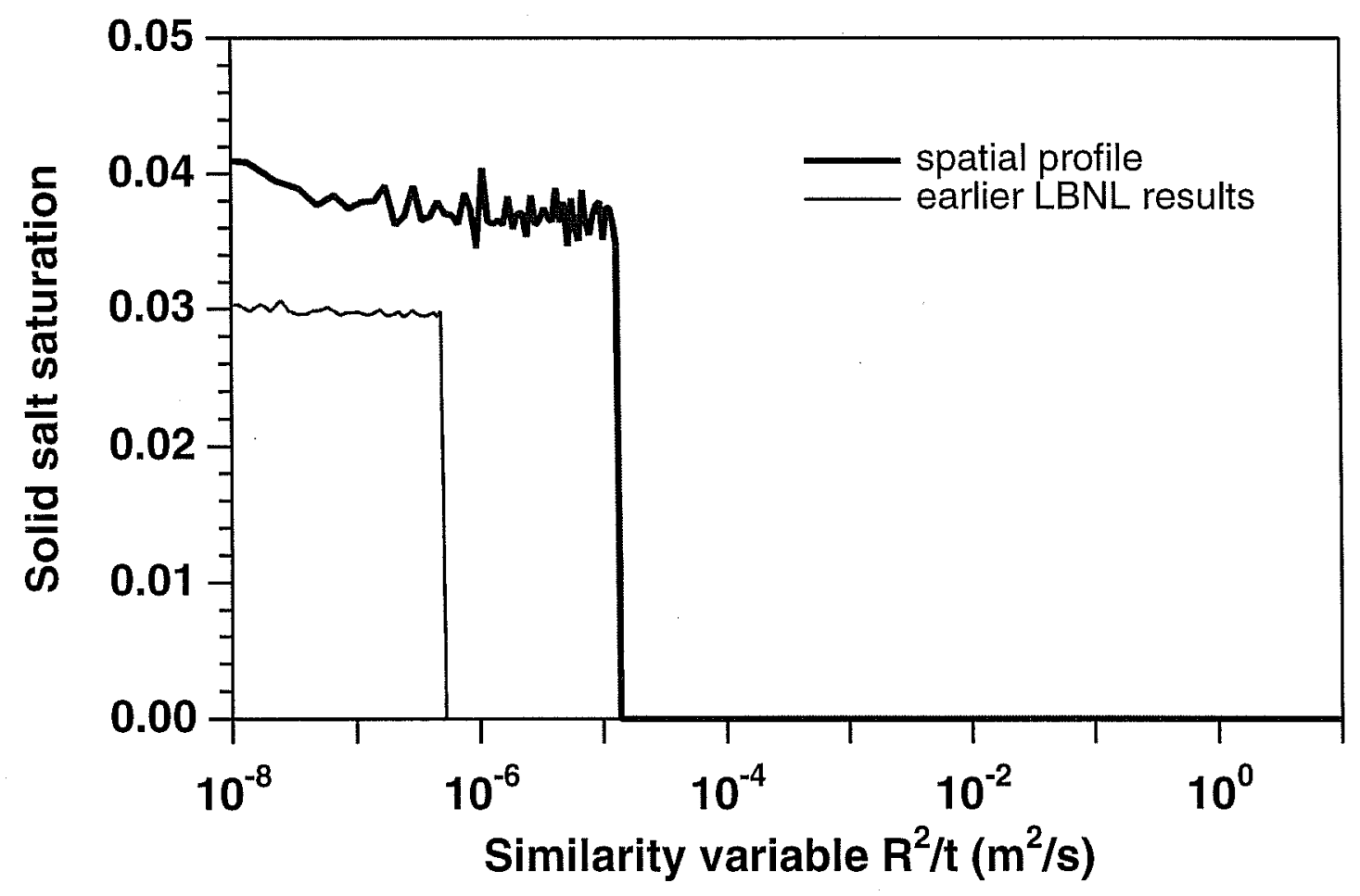

Figure 20. Simulated solid saturations. 


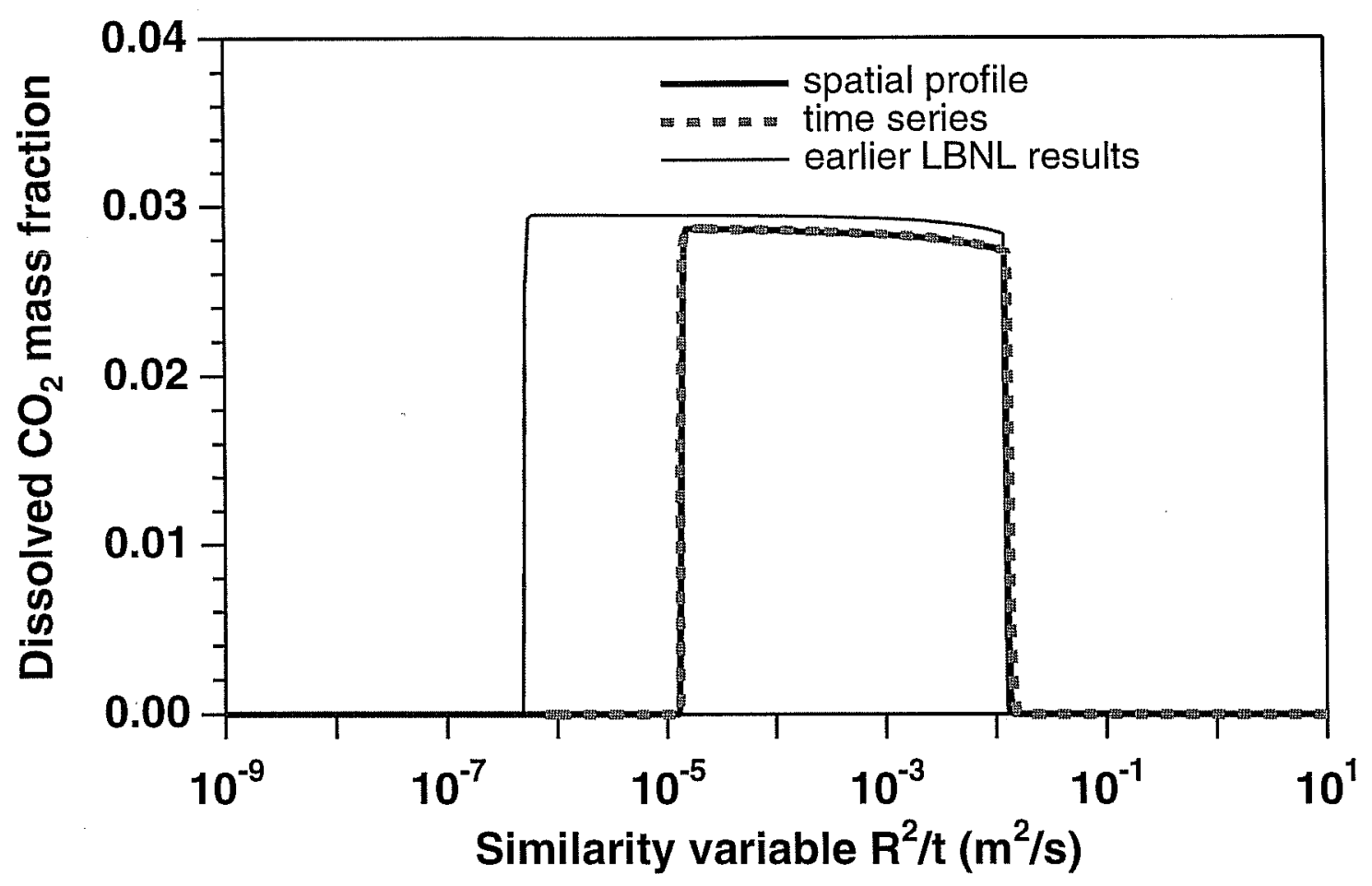

Figure 21. Simulated $\mathrm{CO}_{2}$ mass fraction in aqueous phase.

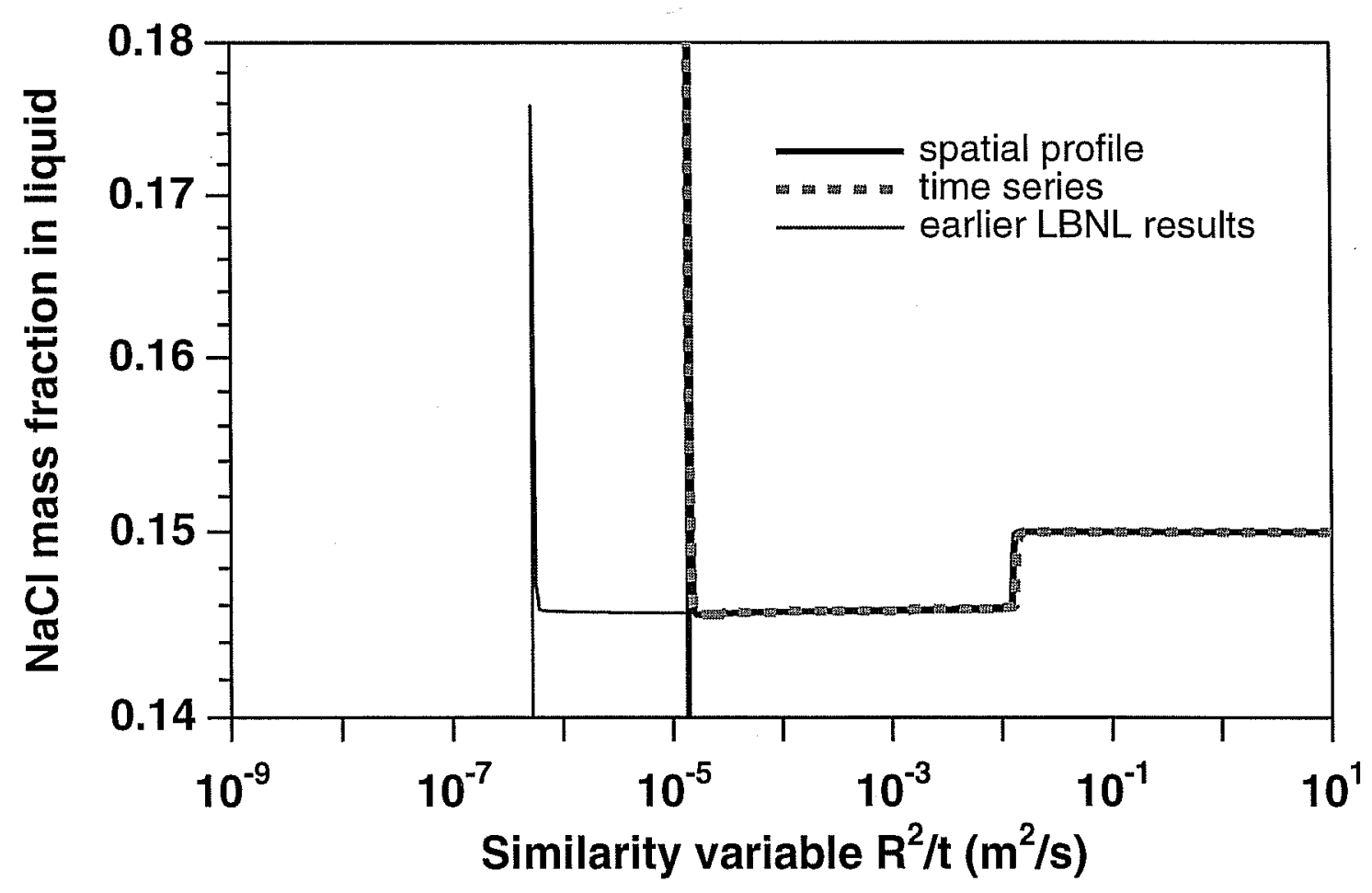

Figure 22. Simulated $\mathrm{NaCl}$ mass fraction in aqueous phase. 


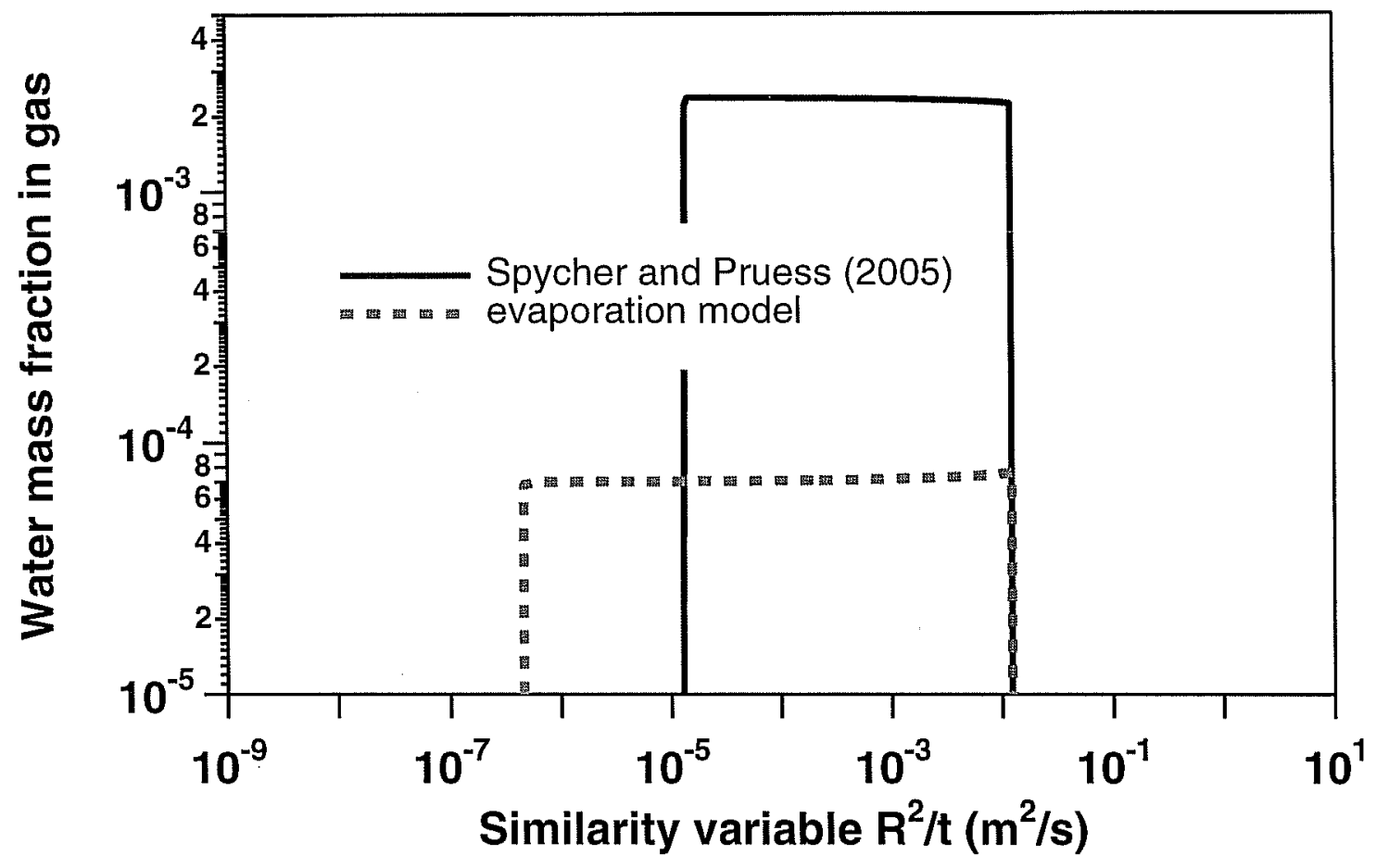

Figure 23. Simulated water mass fraction in $\mathrm{CO}_{2}$-rich phase. 


\subsection{Problem No. 3 (*r1dv*) - $\mathrm{CO}_{2}$ Discharge Along a Fault Zone}

The amounts of $\mathrm{CO}_{2}$ that would need to be disposed of at fossil-fueled power plants are very large. A coal-fired plant with a capacity of 1,000 MWe generates approximately 30,000 tonnes of $\mathrm{CO}_{2}$ per day (Hitchon 1996). When disposed of into brine formations, $\mathrm{CO}_{2}$ injection plumes would over time extend to large distances of the order of ten kilometers or more, making it likely that geologic discontinuities such as faults and fractures will be encountered, with an associated potential for $\mathrm{CO}_{2}$ losses from the primary disposal aquifer. $\mathrm{CO}_{2}$ leaks through caprock discontinuities have a potential for self-enhancement, because pressures can actually decrease and/or flow rates increase as escaping $\mathrm{CO}_{2}$ creates a pathway towards shallower strata. It is not known whether or not it may be possible for a runaway process to develop where an initially "small" leak could accelerate and grow over time to the point of an eruptive release.

Migration of $\mathrm{CO}_{2}$ along a water-saturated fault zone would be subject to gravitational and viscous instabilities, and would likely involve complex two- and three-dimensional flow effects. As a first approximation to this kind of problem, we consider here a highly simplified situation in which a potential $\mathrm{CO}_{2}$ leakage path is modeled as a 1-D column (Fig. B.1). This problem was also included as \#4 in the code intercomparison project (Pruess et al., 2002, 2004); specifications are given in Appendix B.

The problem is run in two segments. A first run segment obtains gravity equilibrium relative to a pressure of 100 bar prescribed at the top boundary. The gravity-equilibrated conditions are then used as initial conditions in a second run segment, where conditions of $\mathrm{P}=240$ bar and a mass fraction $\mathrm{X}_{\mathrm{CO} 2}=1$ are maintained at the lower boundary, while upper boundary conditions are unchanged. Note that the $\mathrm{CO}_{2}$ discharge conditions correspond to a large overpressure, exceeding initial hydrostatic pressure by approximately $60 \%$. It is unlikely that overpressures this large would be used in practical $\mathrm{CO}_{2}$ storage systems. All runs are performed for pure water (no salinity) in isothermal mode at $\mathrm{T}=45^{\circ} \mathrm{C}$. A length of $1 \mathrm{~m}$ of fault zone is simulated and a constant vertical grid spacing of $5 \mathrm{~m}$ is used. Capillary pressure parameters were chosen so that maximum $\mathrm{P}_{\text {cap }}$ is $10^{7} \mathrm{~Pa}$, and $\mathrm{P}_{\text {cap }}$ vanishes for small gas saturations of $\mathrm{S}_{\mathrm{g}} \leq 0.001$. These and other simulation parameters can be seen from the TOUGH2 input file shown in Fig. 24. For this simple 1-D problem, the calculational mesh is generated simply by directly specifying "repeat" elements and connections in the TOUGH2 input file. The $500 \mathrm{~m}$ vertical extent of the fault zone is evenly divided into 100 grid blocks of $5 \mathrm{~m}$ height. Additional blocks *top $0 *$ and *bot $0 *$ are used to represent boundary conditions. For the $1 \mathrm{~m}$ length of the $25 \mathrm{~m}$ wide fault zone modeled, interface areas are $25 \mathrm{~m}^{2}$. Input data also include COFT and FOFT blocks for generating output data for plotting. For reference we list representative fluid properties used in the simulation in Table 4. 
${ }^{*} r 1 \mathrm{dv} * \ldots$ 1-D vertical column; CO2 migration up a fault zone

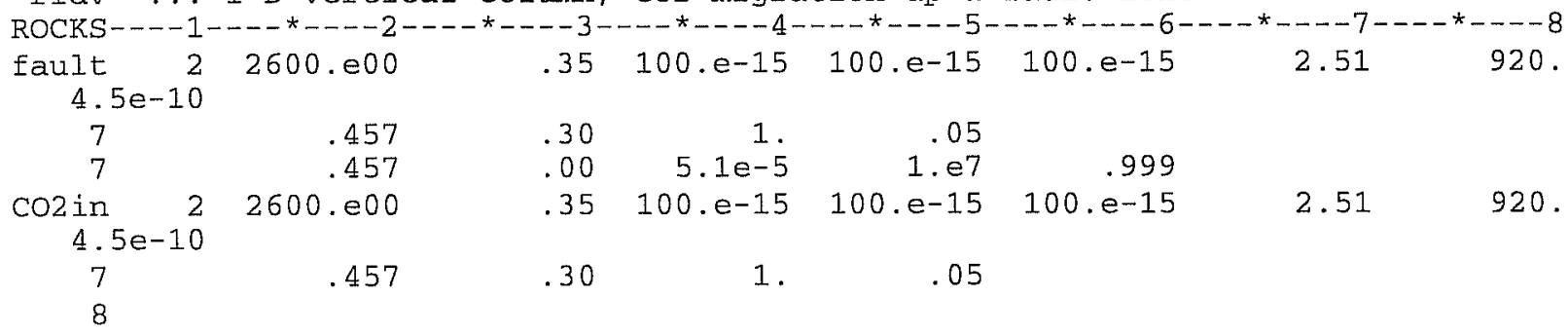

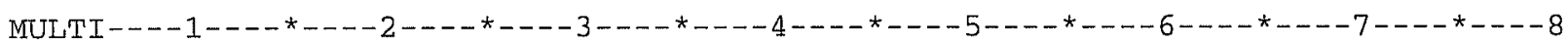
$\begin{array}{llll}3 & 3 & 3 & 6\end{array}$

SELEC $\ldots 2 \ldots 3 \ldots 4 \ldots 5 \ldots 6 \ldots 7 \ldots 8 \ldots 9 \ldots 10 \ldots 11 \ldots 12 \ldots 13 \ldots 14 \ldots 15 \ldots 16$ 1

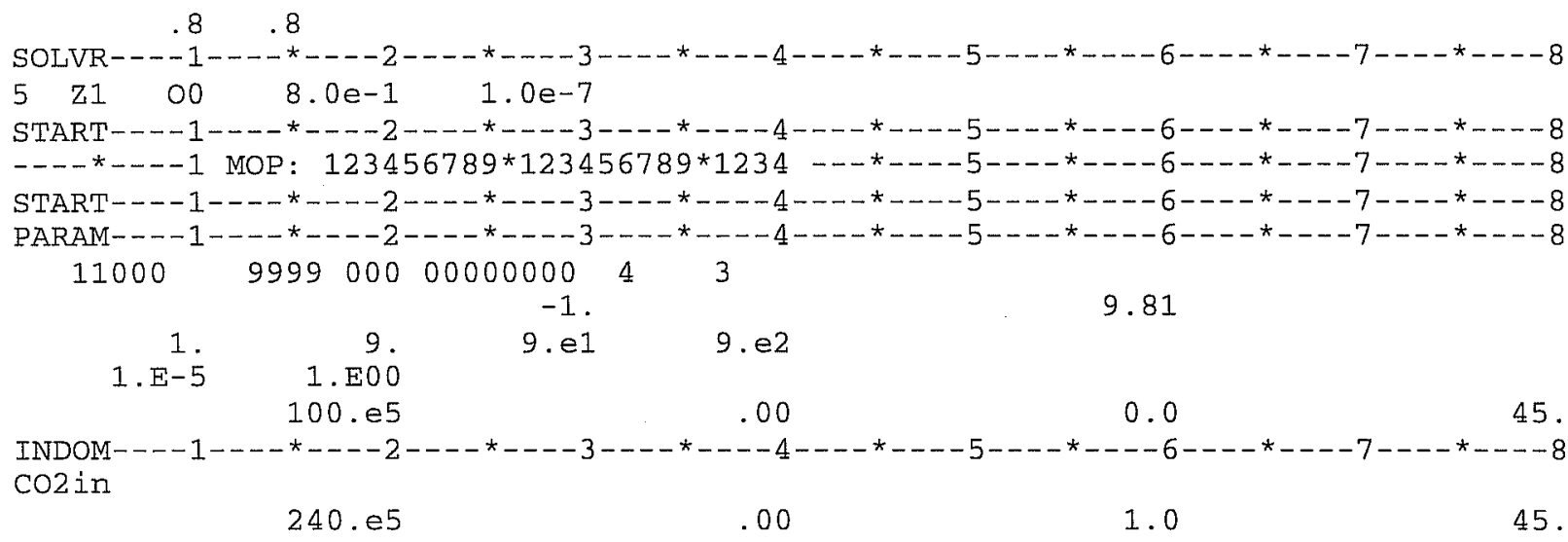

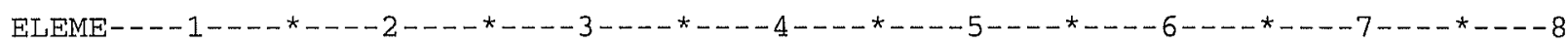
flt $0 \quad 99 \quad$ ifault 125 .

ina

top 0

bot 0

co2in

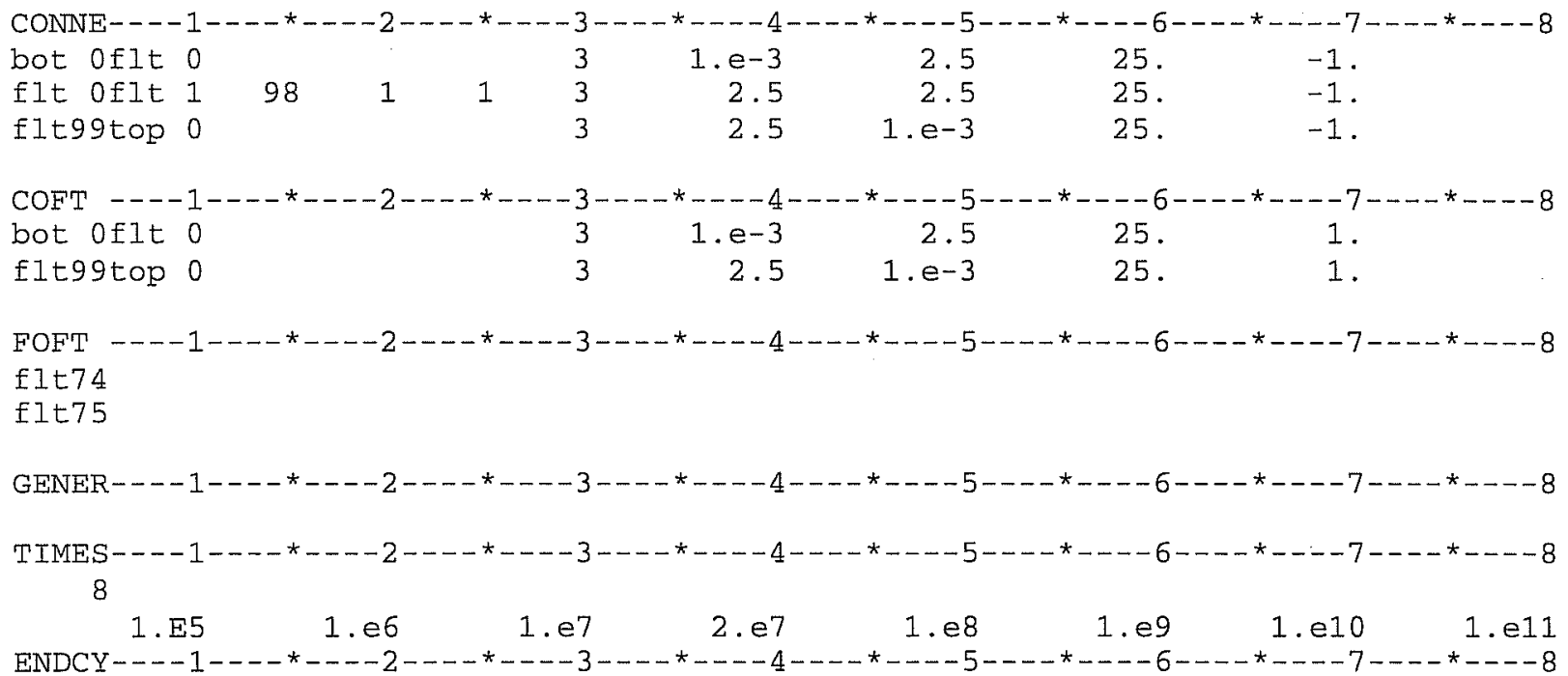

Figure 24. TOUGH2 input file for fault zone problem. 
Table 4. PVT properties at a temperature of $45^{\circ} \mathrm{C}$ at selected pressures, as used in the TOUGH2/ECO2N simulation.

\begin{tabular}{|r|c|c|c|c|}
\hline $\begin{array}{c}\text { Pressure (bar) } \\
\text { fluid phase }\end{array}$ & 120 & 160 & 200 & 240 \\
\hline \hline $\begin{array}{r}\text { pure water } \\
\text { density }\left(\mathrm{kg} / \mathrm{m}^{3}\right)\end{array}$ & 994.768 & 996.292 & 997.821 & 999.354 \\
\hline viscosity (Pa s) & $5.97778 \mathrm{e}-4$ & $5.98341 \mathrm{e}-4$ & $5.98929 \mathrm{e}-4$ & $5.99540 \mathrm{e}-4$ \\
\hline $\begin{array}{r}\text { water with } \mathbf{C O}_{2} \\
\text { density }\left(\mathrm{kg} / \mathrm{m}^{3}\right)\end{array}$ & 1005.79 & 1008.00 & 1009.94 & 1011.74 \\
\hline viscosity $(\mathrm{Pa} \mathrm{s})$ & $5.97778 \mathrm{e}-4$ & $5.98341 \mathrm{e}-4$ & $5.98929 \mathrm{e}-4$ & $5.99540 \mathrm{e}-4$ \\
\hline $\mathrm{CO}_{2}$ mass fraction & $5.20592 \mathrm{e}-2$ & $5.55092 \mathrm{e}-2$ & $5.76593 \mathrm{e}-2$ & $5.91875 \mathrm{e}-2$ \\
\hline gas & & & & \\
\hline density $\left(\mathrm{kg} / \mathrm{m}^{3}\right)$ & 659.261 & 760.931 & 813.504 & 850.176 \\
\hline viscosity $(\mathrm{Pa} \mathrm{s})$ & $5.17641 \mathrm{e}-5$ & $6.56503 \mathrm{e}-5$ & $7.45231 \mathrm{e}-5$ & $8.15904 \mathrm{e}-5$ \\
\hline water mass fraction & $2.14658 \mathrm{e}-3$ & $2.41648 \mathrm{e}-3$ & $2.54446 \mathrm{e}-3$ & $2.62678 \mathrm{e}-3$ \\
\hline
\end{tabular}

\subsubsection{Gravity Equilibration}

Gravity-equilibrated initial conditions are obtained from a simulation in which the element *bot $0 *$ is removed from the input file. Larger time steps $\left(\Delta t_{1}=1 . e 3, \Delta t_{2}=9 . e 3 \mathrm{~s}\right)$ are used, along with a tight convergence tolerance of RE1 $1=1 . \mathrm{e}-10$. Pore compressibility is set to 0 in this part of the simulation, so that porosity remains a constant $35 \%$ throughout as fluid pressures change. After 22 time steps and a simulation time of $\mathrm{t}=4.72 \times 10^{9}$ seconds an accurate hydrostatic equilibrium is obtained, with maximum pore velocities of $2 \times 10^{-19} \mathrm{~m} / \mathrm{s}$. Pressure in the lowest grid block, $2.5 \mathrm{~m}$ above the lower boundary, is computed as 148.56 bar.

\subsection{2 $\mathrm{CO}_{2}$ Displacement}

Migration of $\mathrm{CO} 2$ up the fault zone is simulated with the input file as given in Fig. 24, and using the SAVE file from the gravity equilibration as INCON. The main process in this problem is immiscible displacement of water by $\mathrm{CO}_{2}$. In response to the applied step change in pressure at the bottom of the fault, $\mathrm{CO}_{2}$ enters the system at the lower boundary and migrates up the fault, displacing some of the water and also partially dissolving in residual water, while some water also dissolves in the $\mathrm{CO}_{2}$. The problem is run in two variations, (1) using the Spycher and Pruess (2005) phase partitioning model, and (2) using an evaporation model for water partitioning into the gas phase (parameter $\operatorname{IE}(12)=1$ ). 


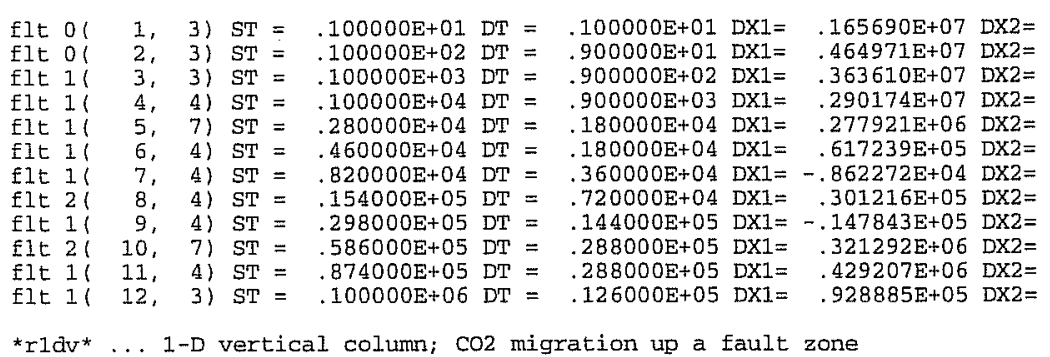

OUTPUT DATA AFTER (12, 3)-2-TIME STEPS

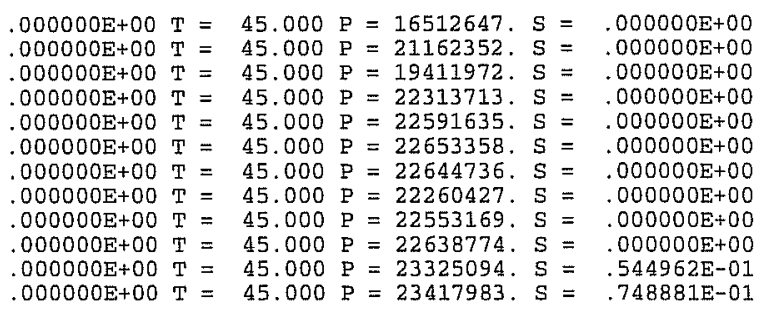

THE TIME IS .115741E+01 DAYS

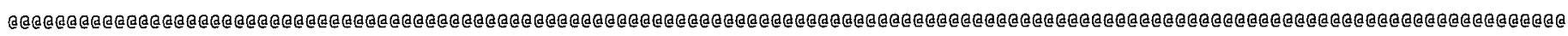

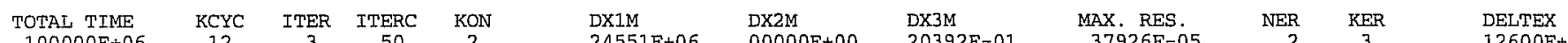

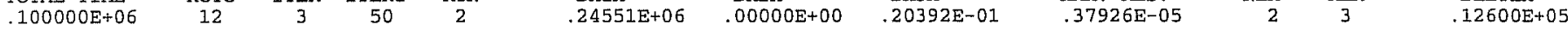

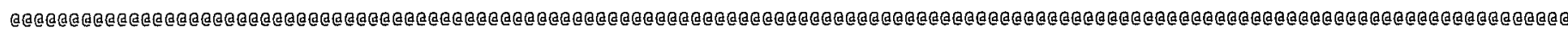

\begin{tabular}{|c|c|c|c|c|c|c|c|c|c|c|c|c|}
\hline ELEM. & INDEX & $\begin{array}{l}\mathrm{P} \\
(\mathrm{Pa})\end{array}$ & $\stackrel{\mathrm{T}}{(\mathrm{deg}-\mathrm{C})}$ & SG & SS & XINACL & YH2OG & xCO2aq & $\begin{array}{l}\mathrm{PCAP} \\
\text { (Pa) }\end{array}$ & $\mathrm{k}$-red. & $\begin{array}{c}\text { DG } \\
(\mathrm{kg} / \mathrm{m} 3)\end{array}$ & $\begin{array}{l}\mathrm{DL} \\
(\mathrm{kg} / \mathrm{m} 3)\end{array}$ \\
\hline $\begin{array}{ll}\text { Elt } & 0 \\
\text { flt } & 1 \\
\text { flt } & 2 \\
\text { flt } & 3 \\
\text { Elt } & 4\end{array}$ & $\begin{array}{l}1 \\
2 \\
3 \\
4 \\
5\end{array}$ & $\begin{array}{l}.23971 E+08 \\
23418 E+08 \\
.22886 E+08 \\
.22725 E+08 \\
.22564 E+08\end{array}$ & $\begin{array}{l}45.00 \\
45.00 \\
45.00 \\
45.00 \\
45.00\end{array}$ & $\begin{array}{l}.20235 \mathrm{E}+00 \\
.74888 \mathrm{E}-01 \\
.00000 \mathrm{E}+00 \\
.00000 \mathrm{E}+00 \\
.00000 \mathrm{E}+00\end{array}$ & $\begin{array}{l}.00000 \mathrm{E}+00 \\
.00000 \mathrm{E}+00 \\
.00000 \mathrm{E}+00 \\
.00000 \mathrm{E}+00 \\
.00000 \mathrm{E}+00\end{array}$ & $\begin{array}{l}.00000 \mathrm{E}+00 \\
.00000 \mathrm{E}+00 \\
.00000 \mathrm{E}+00 \\
.00000 \mathrm{E}+00 \\
.00000 \mathrm{E}+00\end{array}$ & $\begin{array}{l}.26293 \mathrm{E}-02 \\
.26189 \mathrm{E}-02 \\
.10000 \mathrm{E}+01 \\
.10000 \mathrm{E}+01 \\
.10000 \mathrm{E}+01\end{array}$ & $\begin{array}{l}59178 \mathrm{E}-01 \\
.58995 \mathrm{E}-01 \\
.10509 \mathrm{E}-01 \\
.13021 \mathrm{E}-02 \\
.13793 \mathrm{E}-03\end{array}$ & $\begin{array}{r}-.15342 \mathrm{E}+05 \\
-.77996 \mathrm{E}+04 \\
.00000 \mathrm{E}+00 \\
.00000 \mathrm{E}+00 \\
.00000 \mathrm{E}+00\end{array}$ & $\begin{array}{l}10000 E+01 \\
.10000 E+01 \\
.10000 E+01 \\
.10000 E+01 \\
.10000 E+01\end{array}$ & $\begin{array}{r}849.95 \\
845.47 \\
.00 \\
.00 \\
.00\end{array}$ & $\begin{array}{r}1011.73 \\
1011.48 \\
1001.11 \\
999.13 \\
998.83\end{array}$ \\
\hline
\end{tabular}

Figure 25. Part of printed output for fault leakage problem.

Part of the printed output is shown in Fig. 25. Simulation results are plotted in Figs. 26 30 , with thick solid lines representing variation (1), thick dashed lines representing variation (2), and thin dotted lines showing results from various groups that participated in the code intercomparison study. Variation (1) is considered the most accurate, while variation (2) strongly underestimates the uptake of water by the $\mathrm{CO}_{2}$ rich phase. Variation (2) was included here to bring out effects of water dissolution in the gas phase that are missed in the simplistic evaporation model, and to offer a comparison to results submitted in the code intercomparison project, all of which employ an evaporation model. The variation (2) results agree closely with the LBNL submission to the code intercomparison project.

The simulated evolution of the system proceeds through four stages (Figs. 26, 27). In Stage $1, \mathrm{CO}_{2}$ enters the first grid block above the lower boundary, evolving a gas phase there and causing rapid pressurization that migrates up the fault. Stage 1 ends at approximately $10^{4}$ seconds when the pressure pulse reaches the top of the fault, causing outflow of water to commence. During the subsequent Stage 2 the $\mathrm{CO}_{2}$ displacement front migrates up the fault until, after about $3 \times 10^{7}$ seconds, the front reaches the top. At this time $\mathrm{CO}_{2}$ discharge from the fault begins, while water discharge is reduced because of relative permeability effects, and also because capillary effects reduce the effective pressure gradient for the aqueous phase at the top of the fault. Stage 3 lasts from approximately $3 \times 10^{7}$ to $3 \times 10^{9}$ seconds, and is characterized by two-phase outflow of liquid and gas from the fault. Water continues to be removed from the fault not only by advection, but also by dissolution into the flowing gas phase, causing gas relative permeabilities and flow rates to 
increase. As gas saturations increase capillary pressures get stronger, and at $3.1 \times 10^{9}$ seconds the effective pressure gradient for the aqueous phase at the top of the fault reverses, leading to downflow of water from the top boundary. The water dissolves into the flowing $\mathrm{CO}_{2}$ stream and is carried right back out at the top. Eventually the entire flow system dries out, and in Stage 4 we have a steady single-phase gas flow up the fault. TOUGH2 recognizes a steady state, and the simulation terminates after 395 time steps and a simulation time of $1.0 \times 10^{11}$ seconds.

Simulation progress and time stepping reflect non-linearities of the flow processes. Many relatively small time steps are required toward the end of Stage 2 as the two-phase front approaches the upper boundary (Fig. 26). Smaller time steps again occur towards the end of Stage 3 when the dryout front approaches the top boundary.

Gas saturations are shown at times of $10^{7}$ and $10^{9}$ seconds in Fig. 28. At earlier time there is little difference between the profiles calculated with the two alternative models for water partitioning into gas, while at later time the more accurate Spycher and Pruess (2005) model gives rise to more vigorous dry-out. The pressure profile at $10^{7}$ seconds has a change in slope at an elevation of $215 \mathrm{~m}$, due to the transition from two-phase conditions below to single-phase conditions above (Fig. 29). The pressure gradient in the two-phase zone is larger than in the singlephase region, indicating that mobility loss from relative permeability effects dominates over mobility gain from the lower viscosity of $\mathrm{CO}_{2}$ as compared to water. At late time pressure gradients are smaller in the single-phase dry-out region, due to increased fluid mobility there, while gradients are larger in the overlying two-phase zone. Upward movement of the dry-out zone results in increasing pressure gradients at the top of the fault, giving rise to a local maximum in water outflow rate at about $3 \times 10^{9} \mathrm{~s}$ (Fig. 27). Simulated phase partitioning after $10^{7}$ seconds is shown in Fig. 30.

Results for the simulated $\mathrm{CO}_{2}$ inventory of the system at $\mathrm{t}=10^{7}$ and $2 \times 10^{7}$ seconds are given in Table 5.

Table 5. $\mathrm{CO}_{2}$ inventory.

\begin{tabular}{|l|r|l|}
\hline time & \multicolumn{1}{|c|}{$10^{7}$ seconds } & $2 \times 10^{7}$ seconds \\
\hline \hline gas phase & 401.498 tonnes & 692.639 tonnes \\
\hline liquid phase & 85.340 tonnes & 147.258 tonnes \\
\hline total & 486.838 tonnes & 839.897 tonnes \\
\hline
\end{tabular}



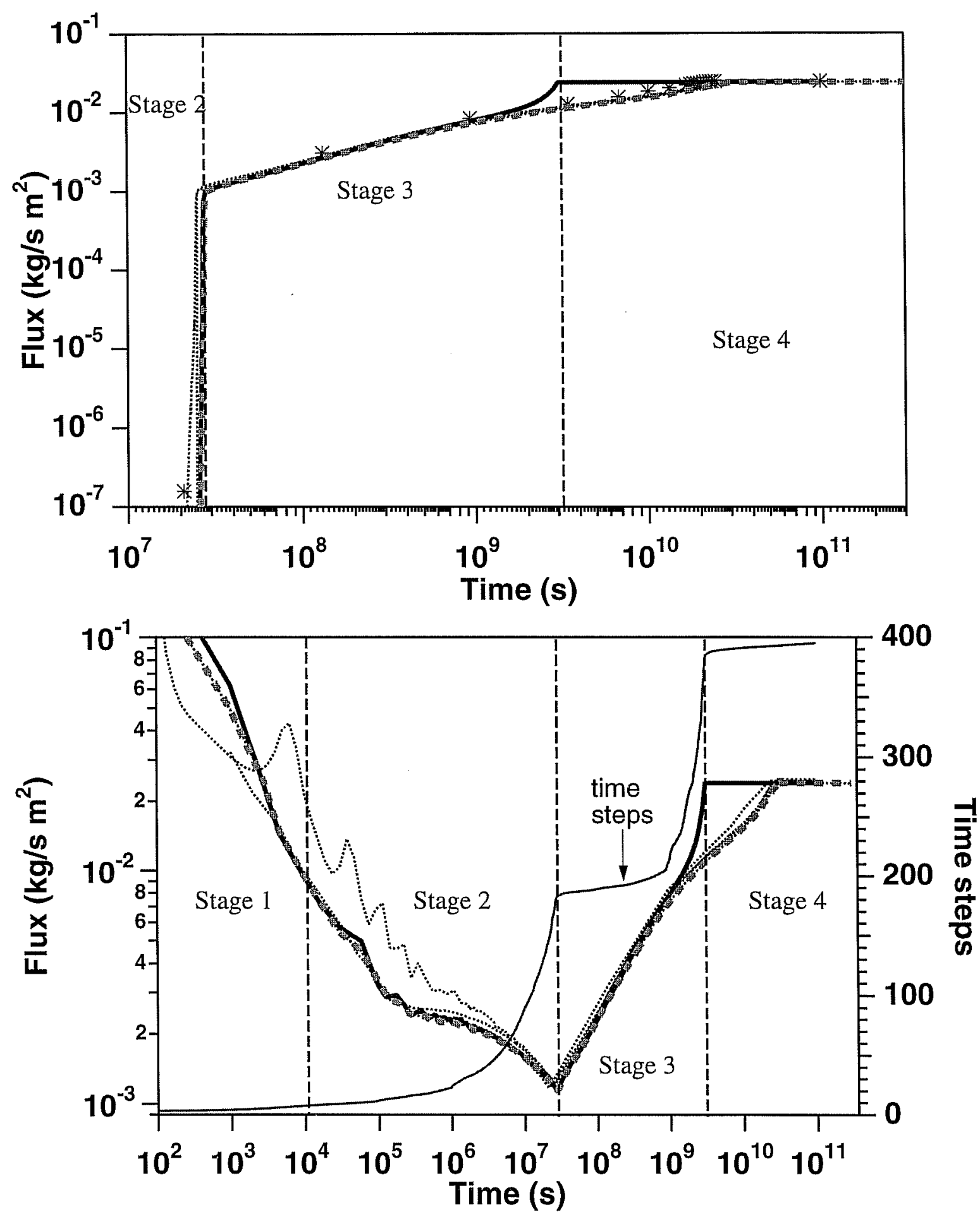

Figure 26. Simulated $\mathrm{CO}_{2}$ fluxes at bottom (lower frame) and top (upper frame) of fault zone. Thick lines are for variation (1) - rigorous $\mathrm{H}_{2} \mathrm{O}-\mathrm{CO}_{2}$ phase partitioning, while dashed lines are for variation (2) - evaporation model for $\mathrm{H}_{2} \mathrm{O}$ partitioning into the $\mathrm{CO}_{2}$-rich phase. Thin lines and symbols represent results submitted in the code intercomparison project. The dashed vertical lines mark the different stages in the evolution of the system. 




Figure 27. Simulated water flux at top of fault zone. Thick line is for variation (1), dashed line for variation (2), and thin lines represent results submitted in the code intercomparison project.

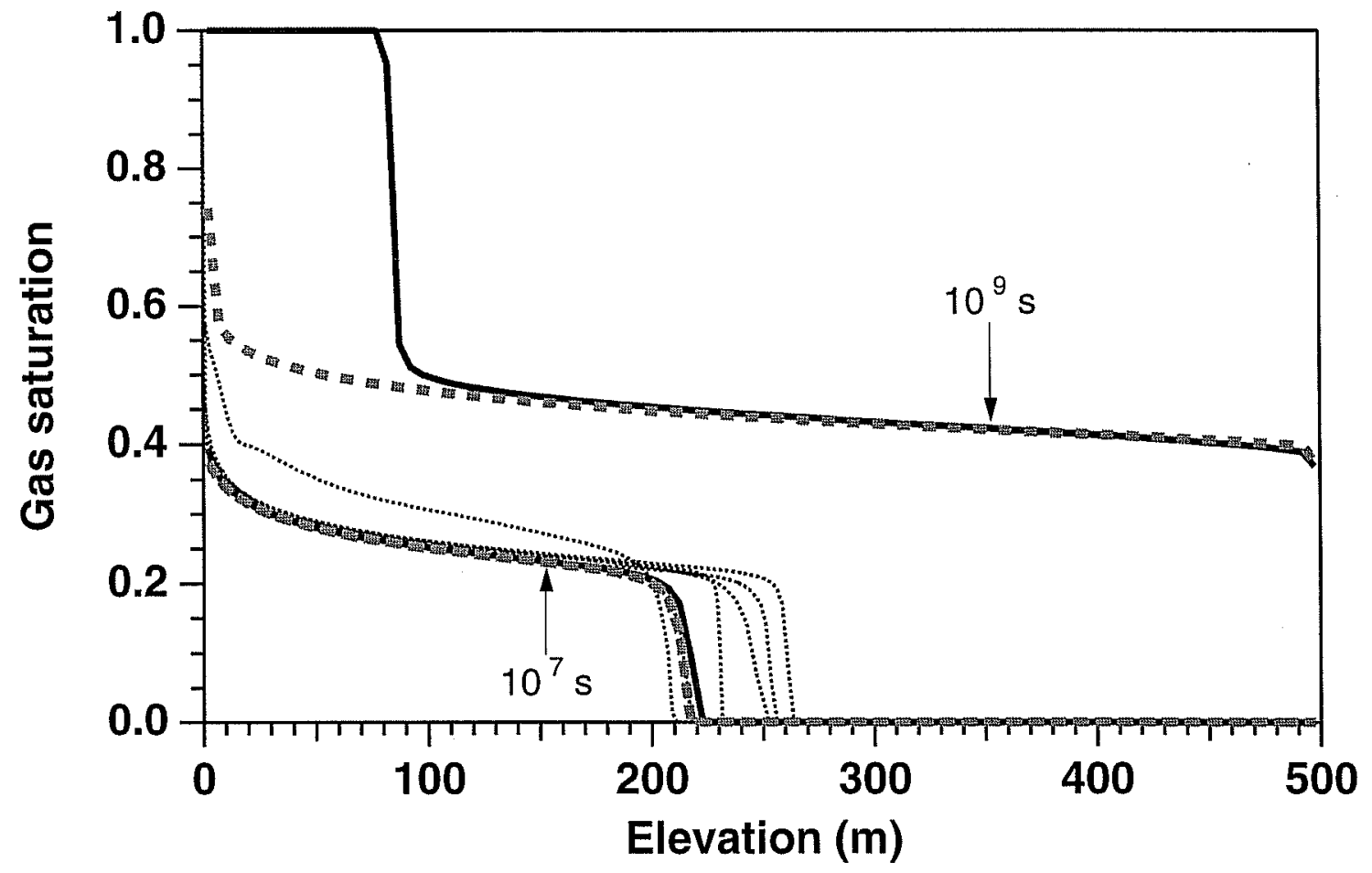

Figure 28. Gas saturation profiles at times of $10^{7}$ and $10^{9}$ seconds. Thick line is for variation (1), dashed line for variation (2), and thin lines represent results from the code intercomparison project. 


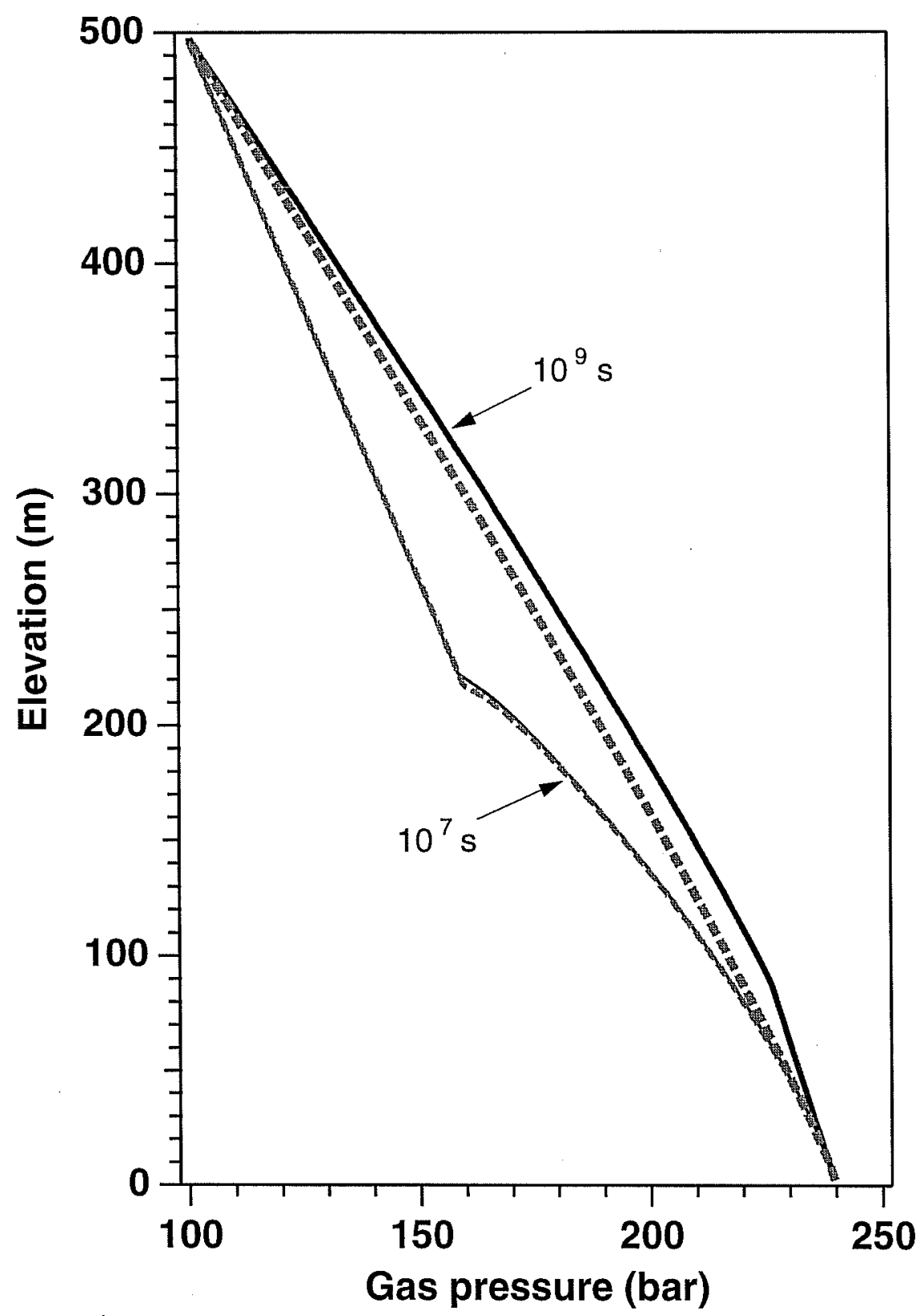

Figure 29. Pressure profiles at times of $10^{7}$ and $10^{9}$ seconds. Solid lines are for variation (1), dashed lines for variation (2). 

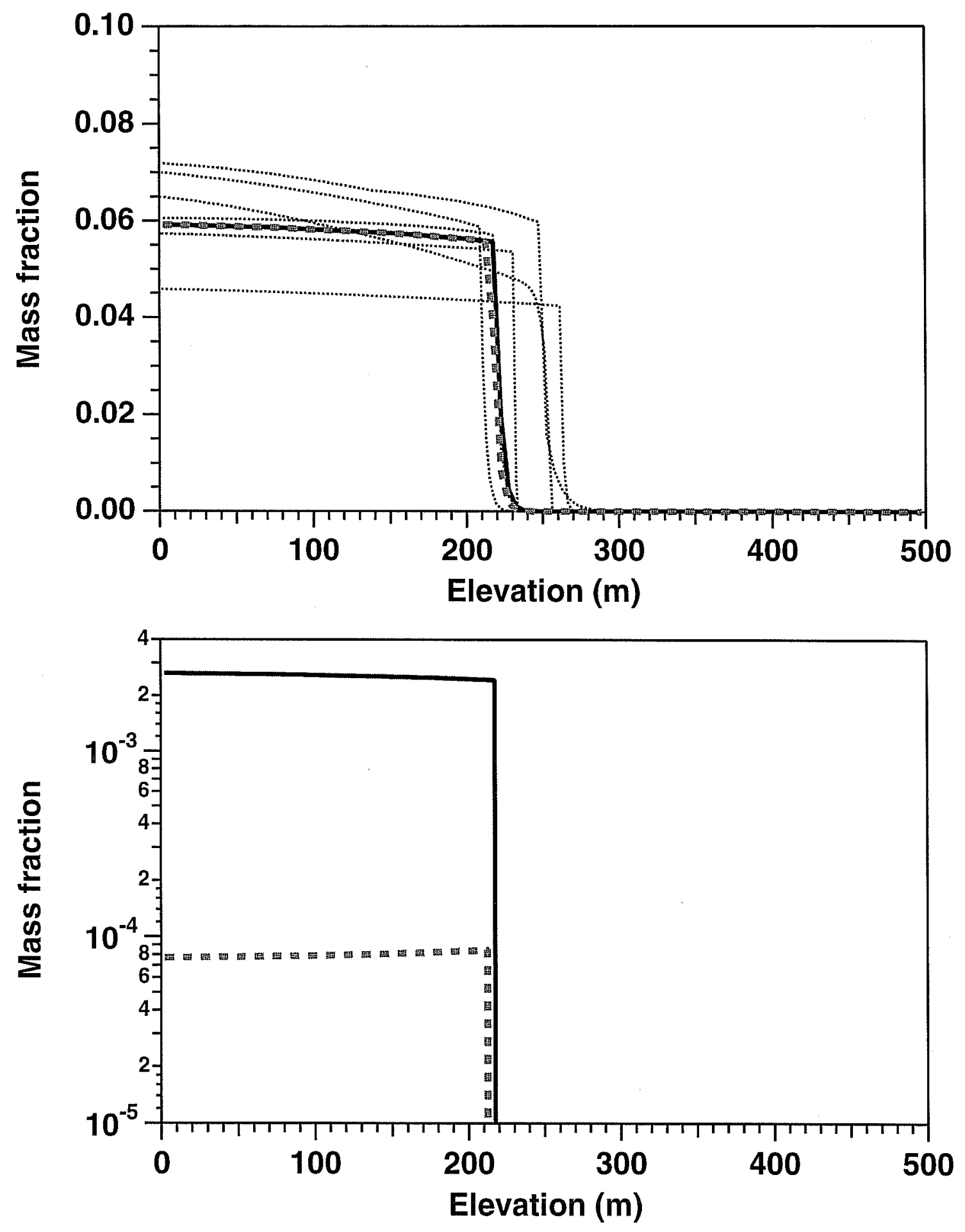

Figure 30. Dissolved $\mathrm{CO}_{2}$ mass fraction in aqueous phase (top) and dissolved water mass fraction in gas (bottom) after $10^{7} \mathrm{~s}$. Thick lines are for variation (1), dashed lines for variation (2), and thin lines represent results submitted in the code intercomparison project. 


\subsection{Problem No. 4 (*rtp7*) - $\mathrm{CO}_{2}$ Injection into a 2-D Layered Brine Formation}

The first industrial-scale $\mathrm{CO}_{2}$ disposal project to become operational is at the Sleipner Vest field in the Norwegian sector of the North Sea, where approximately $10^{6}$ tonnes of $\mathrm{CO}_{2}$ per year have been injected since 1996 through a horizontal well into sands of the Utsira formation. Timelapse seismic surveys have shown that $\mathrm{CO}_{2}$ migration at Sleipner is dominated by buoyancy effects and is strongly affected by shale interbeds of low permeability (Lindeberg et al., 2002). The present test problem was patterned after conditions at Sleipner and was designed to investigate $\mathrm{CO}_{2}$ migration in a heterogeneous sand-shale sequence. It had been included as \#7 in the code intercomparison project (Pruess et al., 2002, 2004). A 2-D vertical section was modeled (Fig. C.1, Appendix C), with problem specifications given in Appendix C. The problem was run in several segments to first obtain the initial and boundary conditions, and then inject $\mathrm{CO}_{2}$ according to specifications. All runs were performed in isothermal mode at a temperature of $37^{\circ} \mathrm{C}$ and a salinity of 3.2 wt. $\%$ NaCl.

The grid should be designed in such a way as to obtain "adequate" spatial resolution in regions where significant gradients occur, i.e., near the injection well, and near the shale layers (Fig. C.1). The grid is generated with the MESHMAKER facility of TOUGH2 as a horizontal ( $x-y)$ grid and is then rotated by 90 degrees around the $x$-axis to obtain a vertical section. Subroutine GXYZ was modified to automatically assign "sand" and "shale" domain identifiers to grid blocks at the appropriate elevations (Fig. 31). Gridding in the x-direction starts with $1 \mathrm{~m}$ increments at the well, and becomes coarser at increasing distance (Table 6). 28 grid blocks are used to get out to a distance of $6,000 \mathrm{~m}$, followed by a small grid increment of $10^{-3} \mathrm{~m}$ to serve as boundary blocks to maintain a hydrostatic pressure profile. Gridding in the y-direction also uses a $1 \mathrm{~m}$ increment at the well, with coarser gridding below and above. The shale layers are represented as single grid layers of $3 \mathrm{~m}$ height, with $3 \mathrm{~m}$ gridding also in the sands above and below. The thickness of the grid is 1 $\mathrm{m}$. Overall the gridding is considered rather coarse, meeting minimum requirements for spatial resolution at the well and at the shale layers.

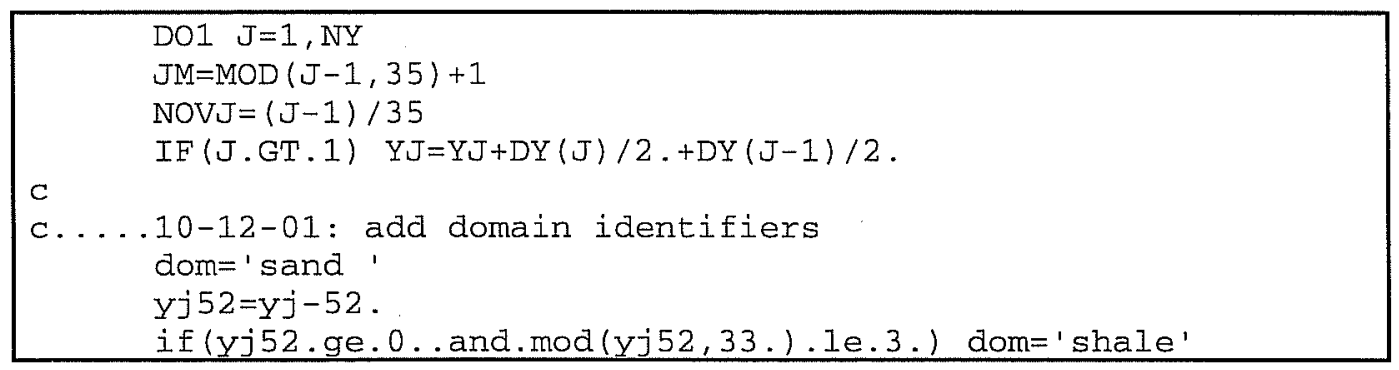

Figure 31. Code fragment of subroutine GXYZ (module meshm.f), showing modifications for assigning domain identifiers to the heterogeneous sand-shale medium. 
Table 6. MESHMAKER input data for grid generation.

\begin{tabular}{|c|c|c|c|c|c|c|c|c|}
\hline & 90. & & & & & & & \\
\hline \multirow[t]{5}{*}{$N X$} & 29 & & & & & & & \\
\hline & 1. & 1. & 2 . & 4. & 4. & 8. & 15. & 20. \\
\hline & 30. & 40. & 50. & 50. & 100. & 150. & 50. & 150. \\
\hline & 300. & 50. & 475 . & 500 & 500. & 500 & 500. & 500. \\
\hline & 500. & 500. & 500. & 500 & $1 . e-3$ & & & \\
\hline \multirow[t]{6}{*}{ NY } & 34 & & & & & & & \\
\hline & 7. & 6. & 6. & 2.5 & 1. & 2.5 & 6. & 12. \\
\hline & 6. & 3. & 3. & 3. & 6. & 12. & 6. & 3. \\
\hline & 3. & 3. & 6. & 12. & 6. & 3. & 3. & 3. \\
\hline & 6. & 12. & 6. & 3. & 3. & 3. & 6. & 12. \\
\hline & 6. & 3. & & & & & & \\
\hline NZ & 1 & 1.0 & & & & & & \\
\hline
\end{tabular}

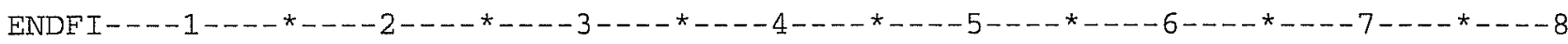

\subsubsection{Gravity Equilibration}

Initial conditions are generated in stages. A first simulation run uses a slightly modified version of the input file shown in Fig. 32 and involves just the column of boundary grid blocks beyond $x=6,000 \mathrm{~m}$. Thermodynamic properties are specified as $\mathrm{P}=110$ bars, $\mathrm{T}=37^{\circ} \mathrm{C}$, salinity $X_{\mathrm{S}}=0.032, \mathrm{CO}_{2}$ mass fraction $\mathrm{X}_{\mathrm{CO} 2}=4.54104 \times 10^{-4}$. The latter value was obtained by trial and error, executing a few single-grid block initializations to obtain the desired $\mathrm{P}_{\mathrm{CO} 2}=0.5$ bar. Pressure is held constant at $\mathrm{P}=110$ bar at the elevation of the injection node $(22 \mathrm{~m})$ and the system is run to gravity equilibrium. To facilitate reaching an accurate equilibrium state, the shale layers are given the same absolute permeability as the sand layers for this simulation. Gravity equilibrium using a tight convergence tolerance of $10^{-8}$ is attained in seven time steps, corresponding to a simulation time of $3.25 \times 10^{9} \mathrm{~s}$. Maximum pore velocities in the equilibrium state are below $10^{-17}$ $\mathrm{m} / \mathrm{s}$. A second run with the full two-dimensional grid is then performed, using the same initialization as for the 1-D gravity equilibration just described, and maintaining the 1-D gravity equilibrium as boundary conditions at the right hand side. For this calculation we again specify the same absolute permeability for shale as for sand. Gravity equilibration in the 2-D grid takes 12 time steps and a simulation time of $2.93 \times 10^{9} \mathrm{~s}$.

\subsubsection{Response to $\mathrm{CO}_{2}$ Injection}

$\mathrm{CO}_{2}$ injection at a constant prescribed rate of $0.1585 \mathrm{~kg} / \mathrm{s}$ is simulated with the input file as shown in Fig. 32. This input file specifies a total simulation time of $63.1152 \times 10^{6} \mathrm{~s}$ ( 2 years), with additional printout generated at times of 30 days $\left(2.592 \times 10^{6} \mathrm{~s}\right)$ and one year $\left(31.5576 \times 10^{6} \mathrm{~s}\right)$. A portion of the printed output is shown in Fig. 33, and results are given in Figs. 34-42. 
*rtp7* ... test problem \# 7: $\mathrm{CO} 2$ in layered formation

\begin{tabular}{|c|c|c|c|c|c|c|c|c|}
\hline sand & 2 & $2600 . e 00$ & .35 & $3 \cdot e-12$ & $3 \cdot e-12$ & $3 \cdot e-12$ & 2.51 & 920. \\
\hline \multicolumn{9}{|c|}{$0.0 e-10$} \\
\hline 7 & & 0.40 & 0.20 & 1. & 0.05 & & & \\
\hline 7 & & 0.40 & 0.20 & $2.79 e-4$ & 1.e7 & .999 & & \\
\hline shale & 2 & 2600.000 & .1025 & $10 \cdot e-15$ & $10 \cdot e-15$ & $10 \cdot e-15$ & 2.51 & 920. \\
\hline \multicolumn{8}{|c|}{$0.0 e-10$} & \\
\hline 7 & & 0.40 & 0.20 & 1. & 0.05 & & & \\
\hline 7 & & 0.40 & 0.20 & $1.61 e-5$ & $1 . e 7$ & .999 & & \\
\hline
\end{tabular}

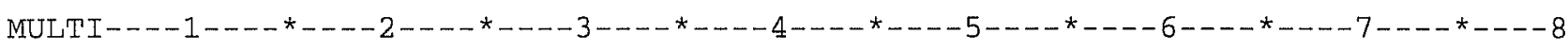
$\begin{array}{llll}3 & 3 & 3 & 6\end{array}$

SELEC $\ldots 2 \ldots 3 \ldots 4 \ldots 5 \ldots 6 \ldots 7 \ldots 8 \ldots 9 \ldots 10 \ldots 11 \ldots 12 \ldots 13 \ldots 14 \ldots 15 \ldots 16$

1

$.8 \quad .8$

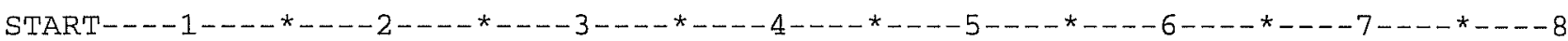

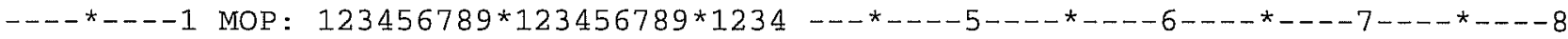

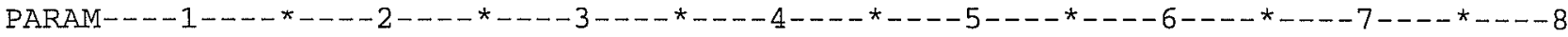

$1600 \quad 9999100000000000 \quad 4 \quad 3$

$1 . e 2$

$63.1152 e 6 \quad-1$.

1.E-5 1.E00

$110 . e 5 \quad 3.2 e-2 \quad .454104 e-03 \quad 37$.

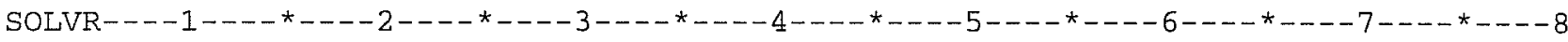

$5 \mathrm{Z} 100 \quad 8.0 \mathrm{e}-1 \quad 1.0 \mathrm{e}-7$

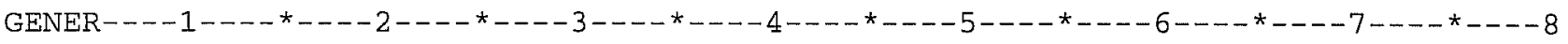

A15 linj $1 \quad 1 \quad \operatorname{COM} 3 \quad .1585$

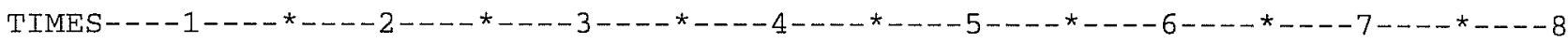

3

$2.592 e 6 \quad 31.5576 e 6 \quad 63.1152 e 6$

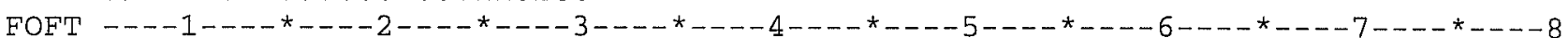

A14 1 sand .2500E+01 .5000E+01 .5000E+00 .2025E+02-.5000E+00

A15 1 sand .1000E+01 $.2000 \mathrm{E}+01 \quad .5000 \mathrm{E}+00.2200 \mathrm{E}+02-.5000 \mathrm{E}+00$

A16 1 sand .2500E+01 $.5000 \mathrm{E}+01 \quad .5000 \mathrm{E}+00 \quad .2375 \mathrm{E}+02-.5000 \mathrm{E}+00$

A1G 1 sand .3000E+01 .6000E+01 .5000E+00 $.8350 \mathrm{E}+02-.5000 \mathrm{E}+00$

A15 2 sand .1000E+01 .2000E+01 .1500E+01 .2200E+02-.5000E+00

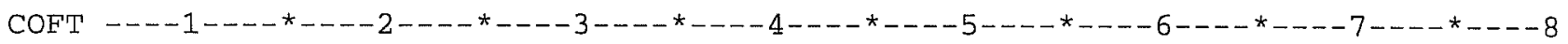

A14 1A15 1 $2.1250 \mathrm{E}+01 \quad .5000 \mathrm{E}+00 \quad .1000 \mathrm{E}+01 \quad .1000 \mathrm{E}+01$

$\begin{array}{llllllll}\text { A15 } 1 \mathrm{~A} 15 & 2 & 1 & .5000 \mathrm{E}+00 & .5000 \mathrm{E}+00 & .1000 \mathrm{E}+01\end{array}$

$\begin{array}{llllllllll}\mathrm{A} 15 & 1 \mathrm{~A} 161 & 2 & .5000 \mathrm{E}+00 & .1250 \mathrm{E}+01 & .1000 \mathrm{E}+01 & .1000 \mathrm{E}+01\end{array}$

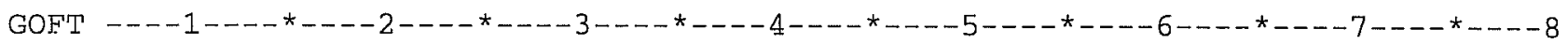

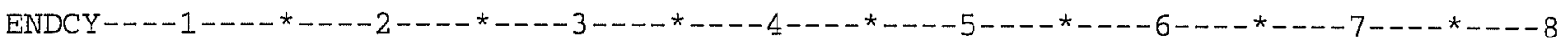

Figure 32. TOUGH2 input file for $\mathrm{CO}_{2}$ injection into a 2-D layered brine formation. 
...ITERATING... AT $[1,1]-1$, DELTEX $=.100000 \mathrm{E}+03$ ...ITERATING. . . AT $[1,2]-1$, DELTEX $=.100000 \mathrm{E}+03$ … ITERATING A AT [ 1. 3] - DELTEX $=100000 \mathrm{E}+03$ A15 111,4$) \mathrm{ST}=.100000 \mathrm{E}+03 \mathrm{DT}=.100000 \mathrm{E}+03 \mathrm{DX} 1=$ ...ITERATING... AT $[2,1] \ldots$ DELTEX $=.200000 \mathrm{E}+03$ ...ITERATTNG... AT $[2,2]-$. DELTEX $=.200000 \mathrm{E}+03$ ..ITERATING... AT $[2,3]-2$ DELTEX $=.200000 E+03$ . ITERATING... AT [ 2 A 4] $\ldots$ DELTEX $=.200000 E+03$ ..ITERATING... AT $[2,5] \ldots$ ATETEX $=.20000 \mathrm{E}+03$

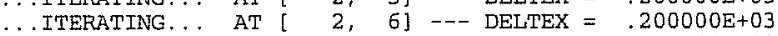
$\ldots$...TERATING. . . AT $[2,7]--$ DELTEX $=.200000 \mathrm{E}+03$ $\mathrm{A} 15212$ 2, 8) $\mathrm{ST}=.300000 \mathrm{E}+03 \mathrm{DT}=.200000 \mathrm{E}+03 \mathrm{DX}=$ ...ITERATING. . A AT [ 3,1$] \ldots$ DELTEX $=.200000 \mathrm{E}+03$ .. ITERATING. . . AT [ 3,2$]-2$ DELTEX $=.200000 \mathrm{E}+03$ ... ITERATING... AT [ 3, 3] $\ldots$ AELTEX $=.200000 \mathrm{D}+03$ $\ldots$...ITERATING... $\ldots$ ITERATING. .. AT [ AT 3,5$]-2$ DELTEX $=.200000 E+03$ Ais $2(3,6)$ ST $=.500000 \mathrm{E}+03 \mathrm{DT}=.200000 \mathrm{E}+03 \mathrm{DX}=$

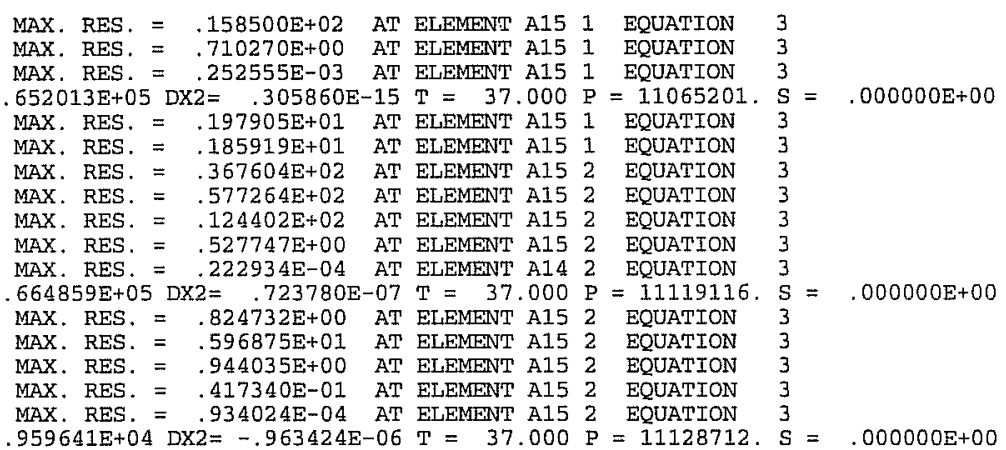
EQTION $652013 \mathrm{E}+05 \mathrm{DX} 2=305860 \mathrm{E}-15 \mathrm{~T}=37.000 \mathrm{P}=11065201$. MAX. RES. $=.197905 \mathrm{E}+01$ AT ELEMENT A15 1 EQUATION MAX. RES. $=.185919 E+01$ AT ELEMENT AI5 1 EQUATION $577264 \mathrm{E}+02$ AT ELEMENT A15 2 MAX RES $=124402 \mathrm{E}+02$ AT TIEMENT A15 2 EOUATTON MAX. RES. $=.527747 \mathrm{E}+00$ AT ELEMENT A15 2 EQUATION MAX. RES $=.824732 \mathrm{E}+00$ AT ELEMENT A15 2 EOUATION .596875 E +01 AT ELEMENT A15 2 EQUATION MAX RES $=417340$ E-01 AT ELTMETT A15 2 EOUATION MAX. RES. $=.934024 \mathrm{E}-04$ AT ELEMENT A15 2 EQUATION

${ }^{\star} \operatorname{rtp} 7 * \ldots$ test problem \# 7: $\mathrm{CO} 2$ in layered formation

OUTPUT DATA AFTER ( 110,4$)$-2-TIME STEPS

THE TIME IS .300000E+02 DAYS

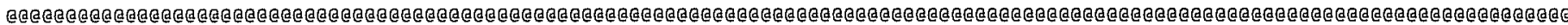

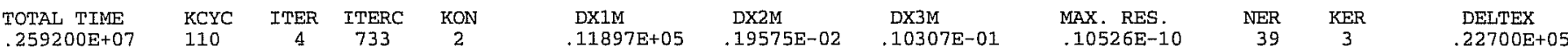

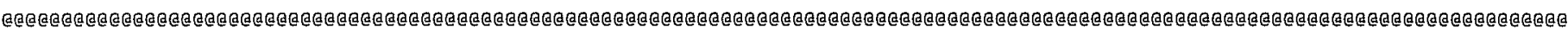

\begin{tabular}{|c|c|c|c|c|c|c|c|c|c|c|c|c|}
\hline ELEM. & INDEX & $\stackrel{P}{(P a)}$ & $(\mathrm{deg}-\mathrm{C})$ & SG & SS & XINACL & YH2OG & $\mathrm{xco} 2 \mathrm{aq}$ & $\begin{array}{l}\text { PCAP } \\
(\mathrm{Pa})\end{array}$ & k-red. & $\begin{array}{c}D G \\
\mathrm{~kg} / \mathrm{m} 3)\end{array}$ & $\begin{array}{l}\mathrm{DL} \\
(\mathrm{kg} / \mathrm{m} 3)\end{array}$ \\
\hline 11 & 1 & $9 \mathrm{E}+\mathrm{U} 0$ & & FETU & . & 20 & & & NDT & & & \\
\hline 12 & 2 & $1 E+08$ & $7=0$ & & $.00000 \mathrm{E}+00$ & & & & & & & \\
\hline$A 13$ & 3 & $9 E+08$ & 37.00 & $1 E+00$ & $.00000 \mathrm{E}+00$ & $.30427 E-01$ & $751 E-02$ & $.49246 \mathrm{E}-01$ & $.95948 \mathrm{E}+$ & $10000 E+01$ & 76 & 8.70 \\
\hline A14 & 4 & $12 \mathrm{E}+08$ & 37.00 & $E+00$ & $E+00$ & .3 & $=-0$ & E-01 & -.21 & $0 E+01$ & & 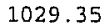 \\
\hline A15 & 5 & $.12931 E+08$ & 37. & $E+00$ & $8+00$ & +00 & -02 & $E-01$ & -.1 & $E+01$ & & $\begin{array}{c}0.2 \\
.\end{array}$ \\
\hline 16 & 6 & $.12915 \mathrm{E}+08$ & 37.00 & +00 & +00 & -01 & -02 & -01 & -.1 & $2+01$ & & 30 \\
\hline A.17 & 7 & $.12875 \mathrm{E}+08$ & 37.00 & +00 & .00 & .3 & $E-02$ & $3 E-01$ & -.8 & $\mathrm{E}+01$ & & 10 \\
\hline$A 18$ & 8 & $.12791 \mathrm{E}+08$ & 37.00 & $E+00$ & $\mathrm{E}+00$ & $E-01$ & $E-02$ & $E-01$ & $87 \mathrm{E}+04$ & $\mathrm{E}+01$ & & 1028.62 \\
\hline A19 & 0 & $.12710 \mathrm{E}+08$ & 37.00 & +00 & $E+00$ & $\Xi-01$ & $E-02$ & $E-01$ & $03 E+04$ & $E+01$ & & 1028.58 \\
\hline & 10 & .12 & & & & & & & -.1 & & & \\
\hline & 11 & $.12651 \mathrm{E}+08$ & 37.00 & .00 & 00 & .3 & -02 & 1 & -.5 & 01 & & \\
\hline & 12 & $.12238 E+08$ & 37.00 & $24 \mathrm{E}-01$ & $.00000 E+00$ & $.30437 \mathrm{E}-01$ & $431 E-02$ & $40 \mathrm{E}-01$ & $12 \mathrm{E}+04$ & $\Xi+01$ & 754.75 & \\
\hline A1 & 13 & $190 \mathrm{E}+08$ & 37.00 & $00 \mathrm{E}+00$ & $.00000 \mathrm{E}+00$ & $6 \mathrm{E}-01$ & $20 E+01$ & $73 E-02$ & $100 \mathrm{E}+00$ & $E+01$ & .00 & .08 \\
\hline & 14 & $.12099 \mathrm{E}+08$ & & $00 E+00$ & $0 O E+00$ & $80 E-01$ & $00 \mathrm{E}+01$ & $78 \mathrm{E}-03$ & $00 \mathrm{E}+00$ & $.10000 \mathrm{E}+01$ & .00 & 1019.08 \\
\hline & 15 & $.12009 \mathrm{E}+08$ & 37.00 & $.00000 \mathrm{E}+00$ & $.00000 E+00$ & $.31985 \mathrm{E}-01$ & $.10000 \mathrm{E} \div 01$ & $.46419 E-03$ & $.00000 \mathrm{E}+00$ & $10000 \mathrm{E}+01$ & .00 & 1019.01 \\
\hline
\end{tabular}

Figure 33. Part of printed output for problem of $\mathrm{CO}_{2}$ injection into a layered brine formation.

Startup of $\mathrm{CO}_{2}$ injection causes pressures to rise initially, most strongly and rapidly in the well block, and less strongly and with some time delay at more distant locations (Fig. 34). The system quickly establishes quasi-steady flow conditions at the well block (Fig. 35), and the sum of the absolute values of the flow rates quickly approaches the total injection rate of $0.1585 \mathrm{~kg} / \mathrm{s}$. As gas saturations increase near the injection point, injection pressures actually decline slowly. The plot of time steps vs. time shows decreasing slope over time (Fig. 34), reflecting an overall trend towards increasing time step sizes as the simulation progresses.

Gas saturations at and near the well block (A15 1) show interesting non-monotonic behavior (Fig. 36), due to an interplay of gas-liquid counterflow, relative permeability effects and precipitation of solid salt. After approximately $4.5 \times 10^{6} \mathrm{~s}$, gas saturation at the well block reaches a maximum value of $75.1 \%$ and then declines slowly. This decline is caused by increasing salt precipitation (Fig. 37). Liquid saturation declines rapidly initially, but later almost stabilizes near 20 $\%$ (note the logarithmic time scale on Fig. 37), due to capillary-driven inflow of liquid from 
neighboring grid blocks. At early time liquid flow is away from the well block, but at approximately $5 \times 10^{5} \mathrm{~s}$ liquid flow reverses and subsequently is towards the well block, as capillary pressures there become stronger due to increasing gas saturation (Fig. 38). As time goes on, gas saturations in the blocks adjacent to the well block continue a slow increase (Fig. 36). This reduces relative permeability to liquid, but liquid flow rates into the well block remain essentially constant for a while, because increasing strength of capillary pressure in the well block compensates for the reduction in relative permeability. After approximately $10^{7} \mathrm{~s}$, capillary pressure in the well block reaches the cutoff value of $10^{7} \mathrm{~Pa}$ specified in the input file (Fig. 32). Subsequently the flow of aqueous phase towards the well block brings in less water than is carried out by the gas phase, leading to accelerated precipitation and rapid dry-out. This explains the very rapid increase in gas saturation in the well block at approximately $1.1 \times 10^{7} \mathrm{~s}$. Fig. 36 shows similar patterns of gas saturation behavior in grid blocks neighboring the well block that dry out at later times. The evolution of solid saturations in selected blocks is shown in Fig. 39.

The simulation of this problem previously submitted by LBNL for the code intercomparison project did not generate any solid precipitate (Pruess et al., 2002, 2004). The different behavior seen in the present simulation is due to the much more vigorous removal of water into the flowing gas stream, as compared to the evaporation model for water partitioning into the gas phase that had been used in the earlier calculation. The mechanisms contributing to solid precipitation and formation dry-out near the injection well are believed to be represented realistically in the present simulation, but the space discretization near the injection well is rather coarse, and considerably finer gridding would be needed to achieve accurate results.

Figs. 40-42 show contour maps of pressure, gas saturation, and dissolved $\mathrm{CO}_{2}$ mass fraction after two years of simulation time. These results are all very similar to our earlier calculations using an evaporation model for water in the $\mathrm{CO}_{2}$ rich phase. Highest gas saturations of approximately $60 \%$ occur beneath the shale layers at elevations of 52,85 , and $118 \mathrm{~m}$. Gas is just beginning to reach the top shale layer at an elevation of $151 \mathrm{~m} . \mathrm{CO}_{2}$ mass fraction dissolved in the aqueous phase after two years is in the range of $4.5-4.85 \%$ throughout most of the two-phase zone, with smaller but significant $\mathrm{CO}_{2}$ concentrations occurring beyond the two-phase region. 


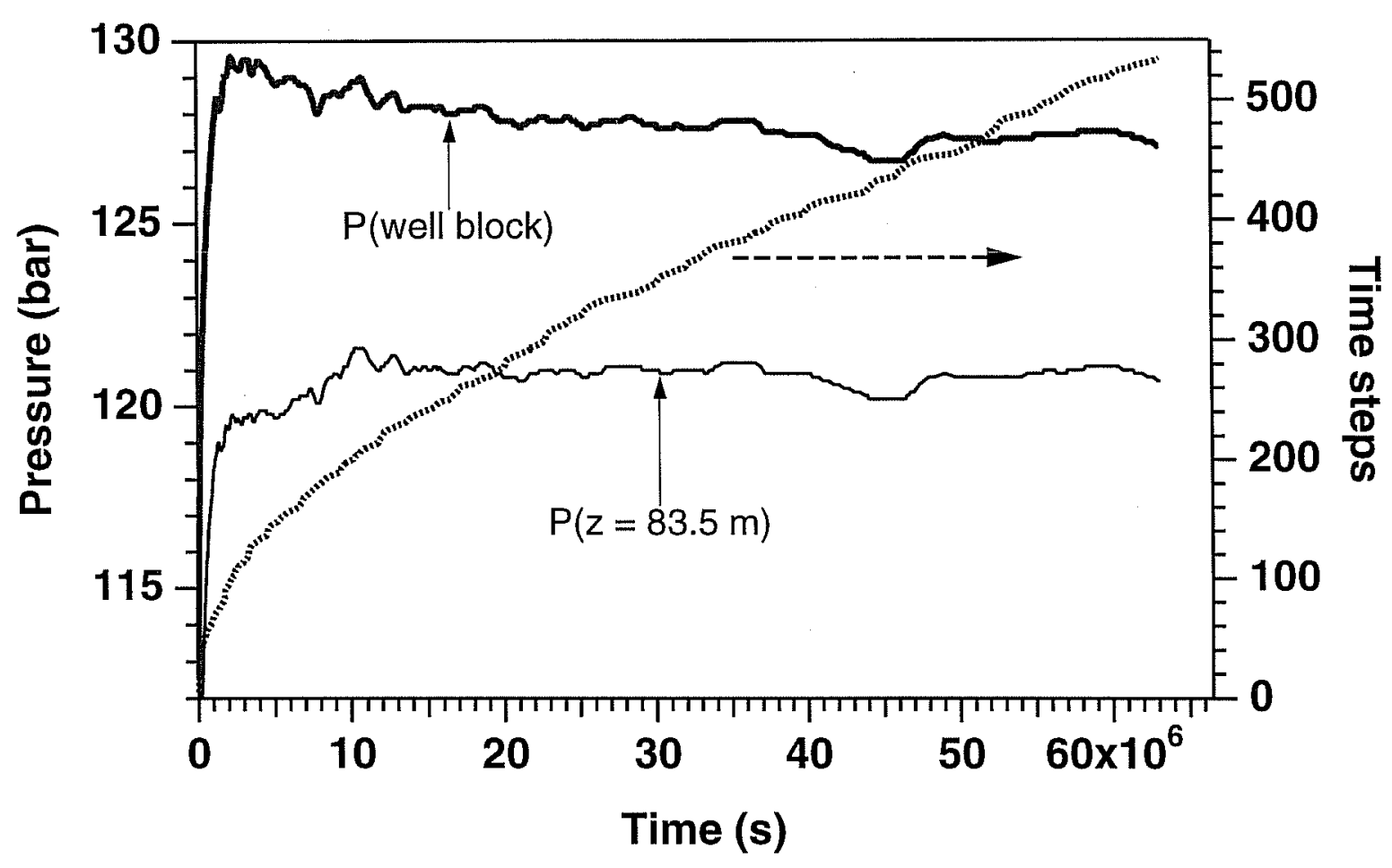

Figure 34. Time evolution of pressures in two grid blocks (A15 1 and A1G 1) and time stepping for $\mathrm{CO}_{2}$ injection into a layered brine formation.

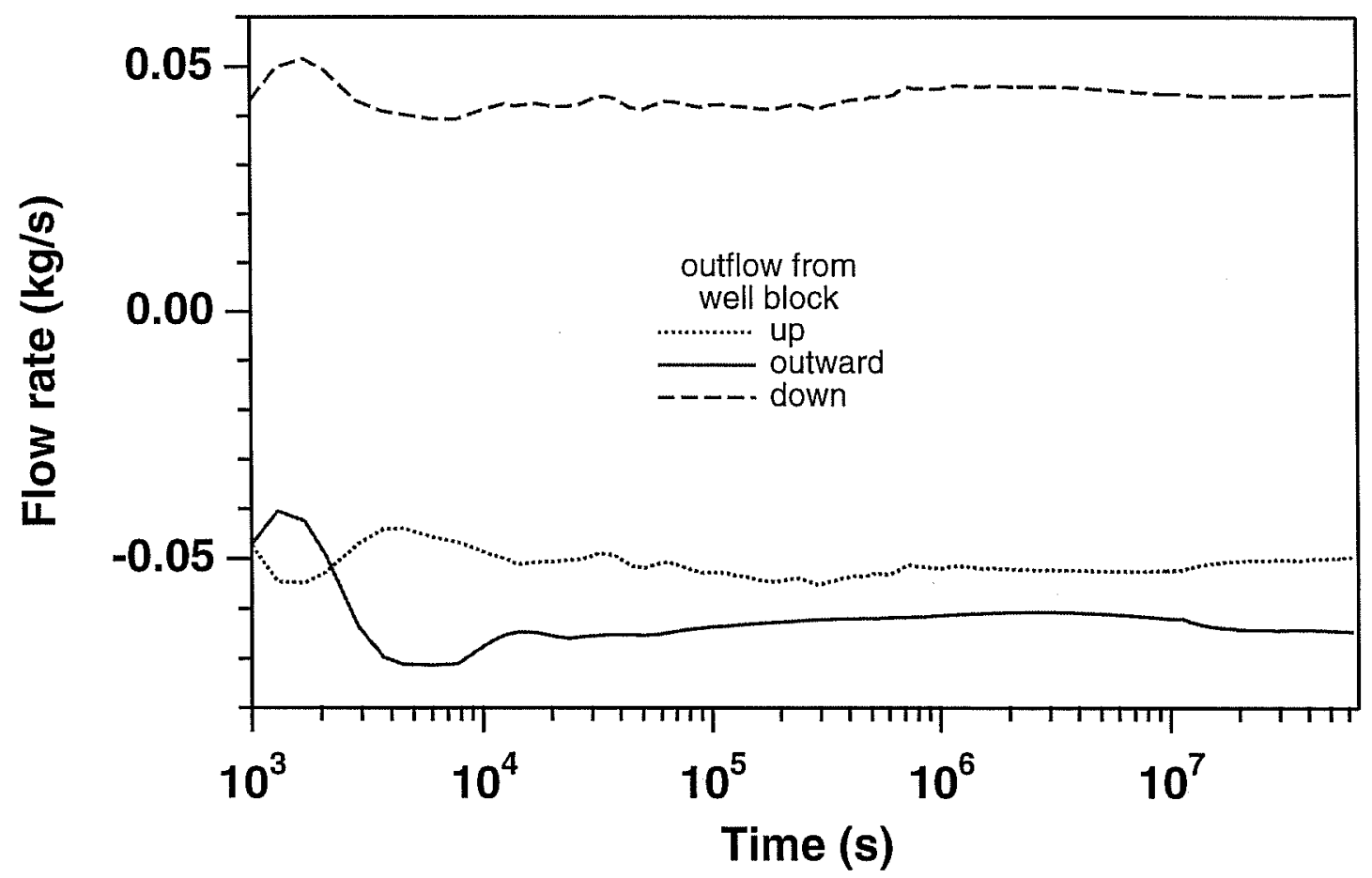

Figure 35. Gas flow rates at the well block. Gas flow is away from the well block, and is plotted as a positive or negative, depending upon whether the well block is the first or second element in a flow connection. 


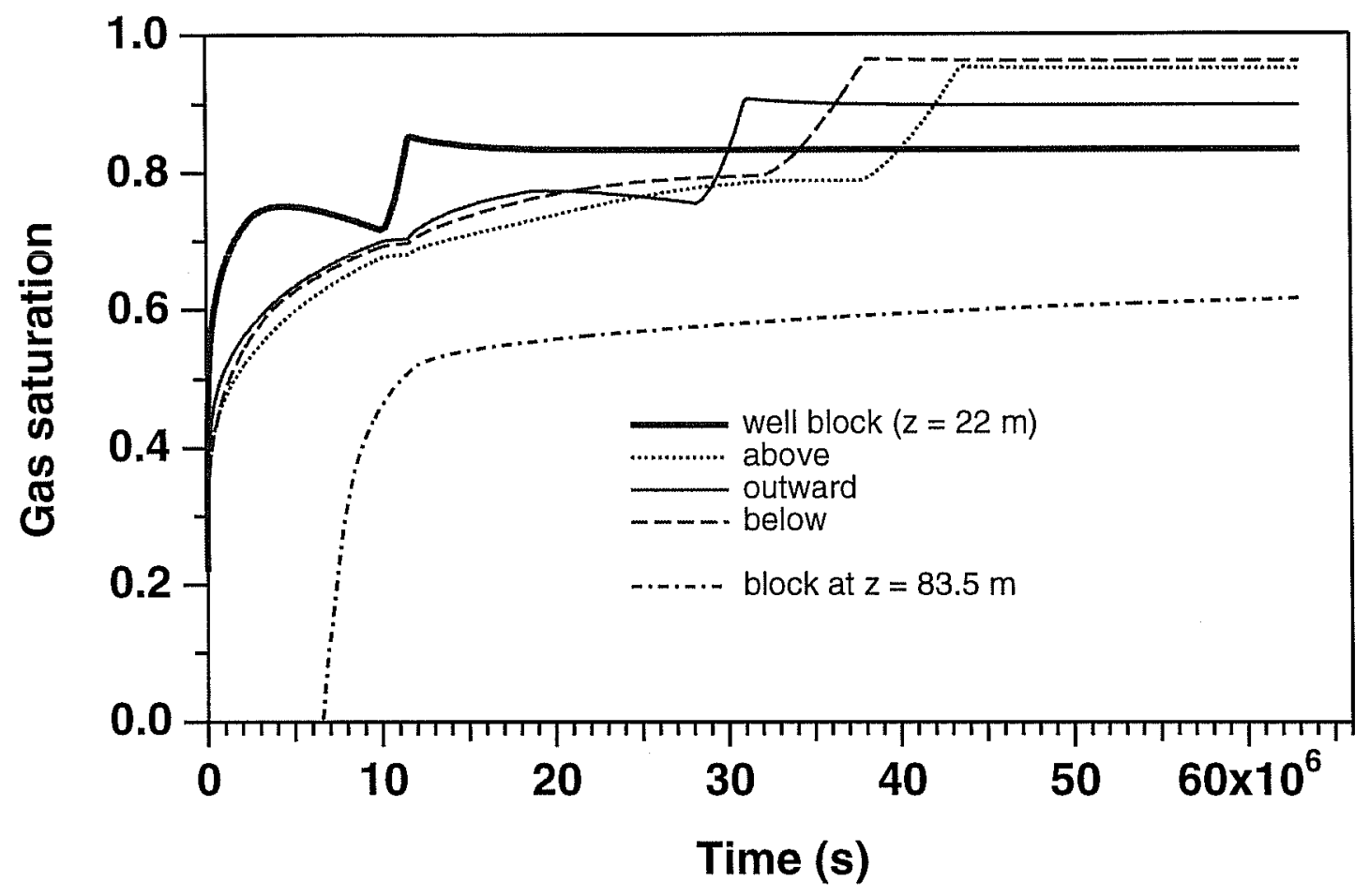

Figure 36. Gas saturations at the well block and its neighbors (above - A16 1; outward - A15 2; below - A14 1). Gas saturations at block A1G 1 at an elevation of $83.5 \mathrm{~m}$ ( $61.5 \mathrm{~m}$ above well block) are also shown.

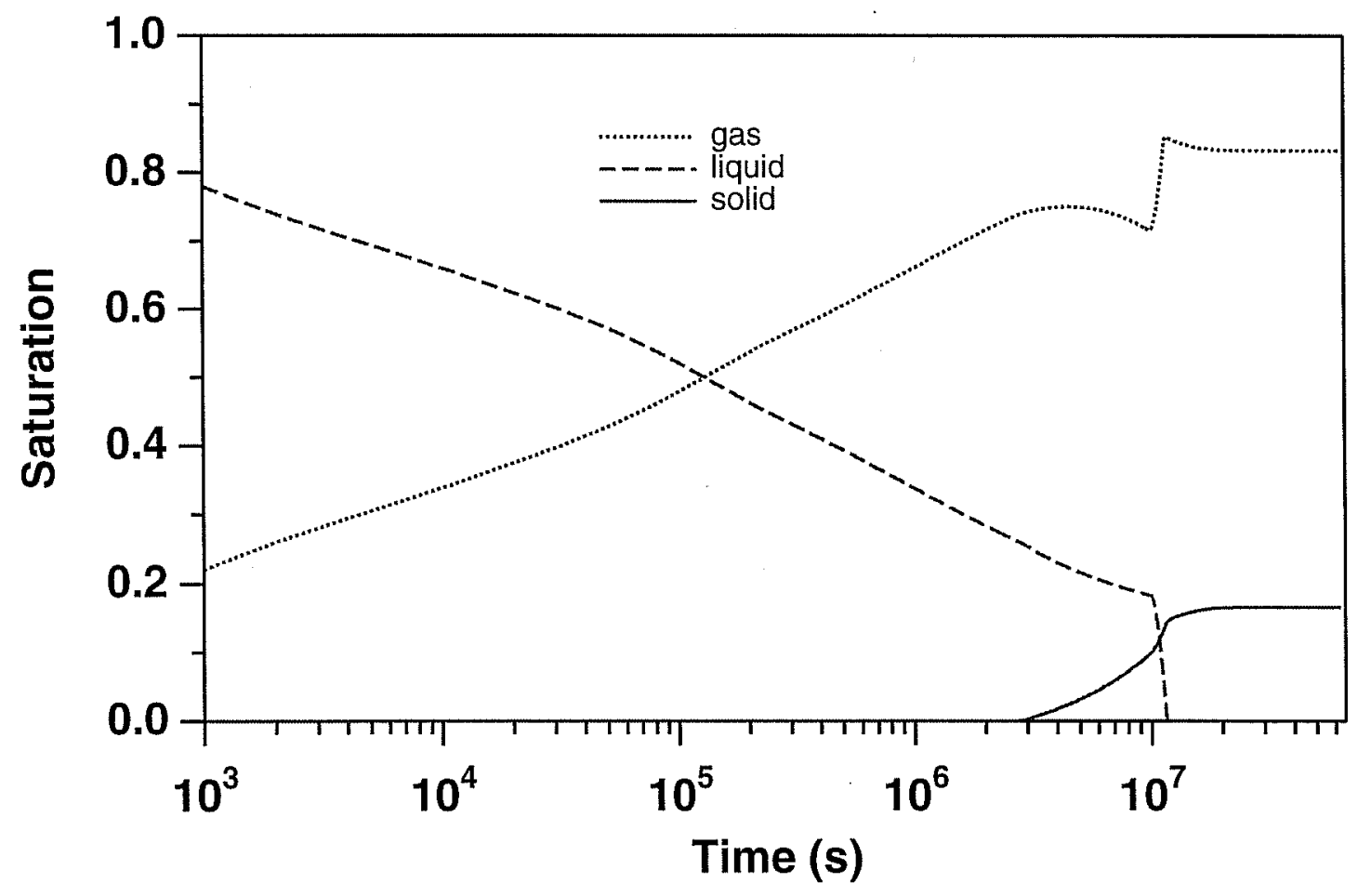

Figure 37. Phase saturations at the well block (A15 1). 


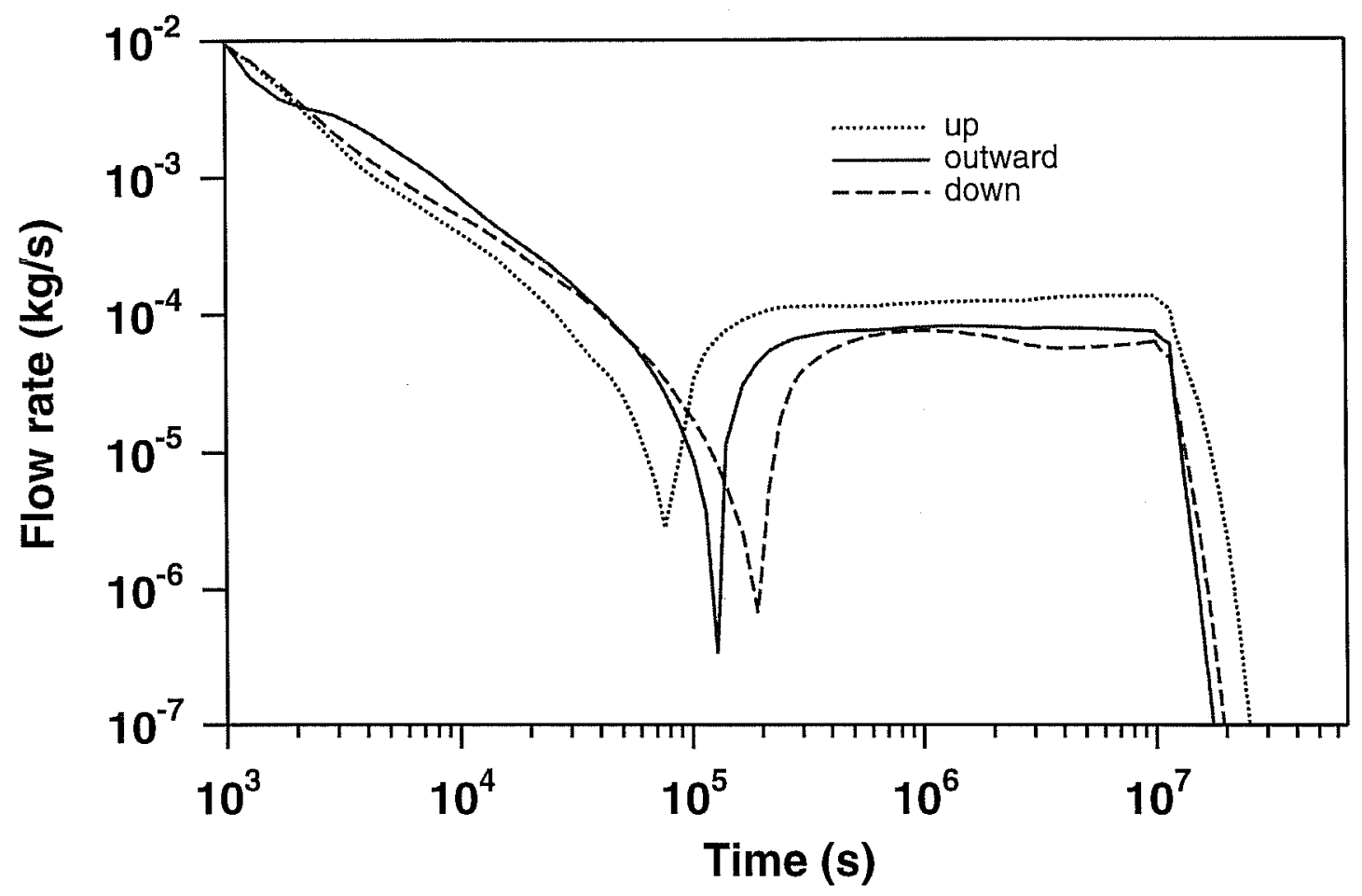

Figure 38. Absolute values of aqueous phase flow rates between the well block and neighboring grid blocks. Up to approximately $10^{5} \mathrm{~s}$ flow is away from the well block, then reverses.



Figure 39. Solid saturations (fraction of void space taken up by solid precipitate) in the well block and its neighbors. 


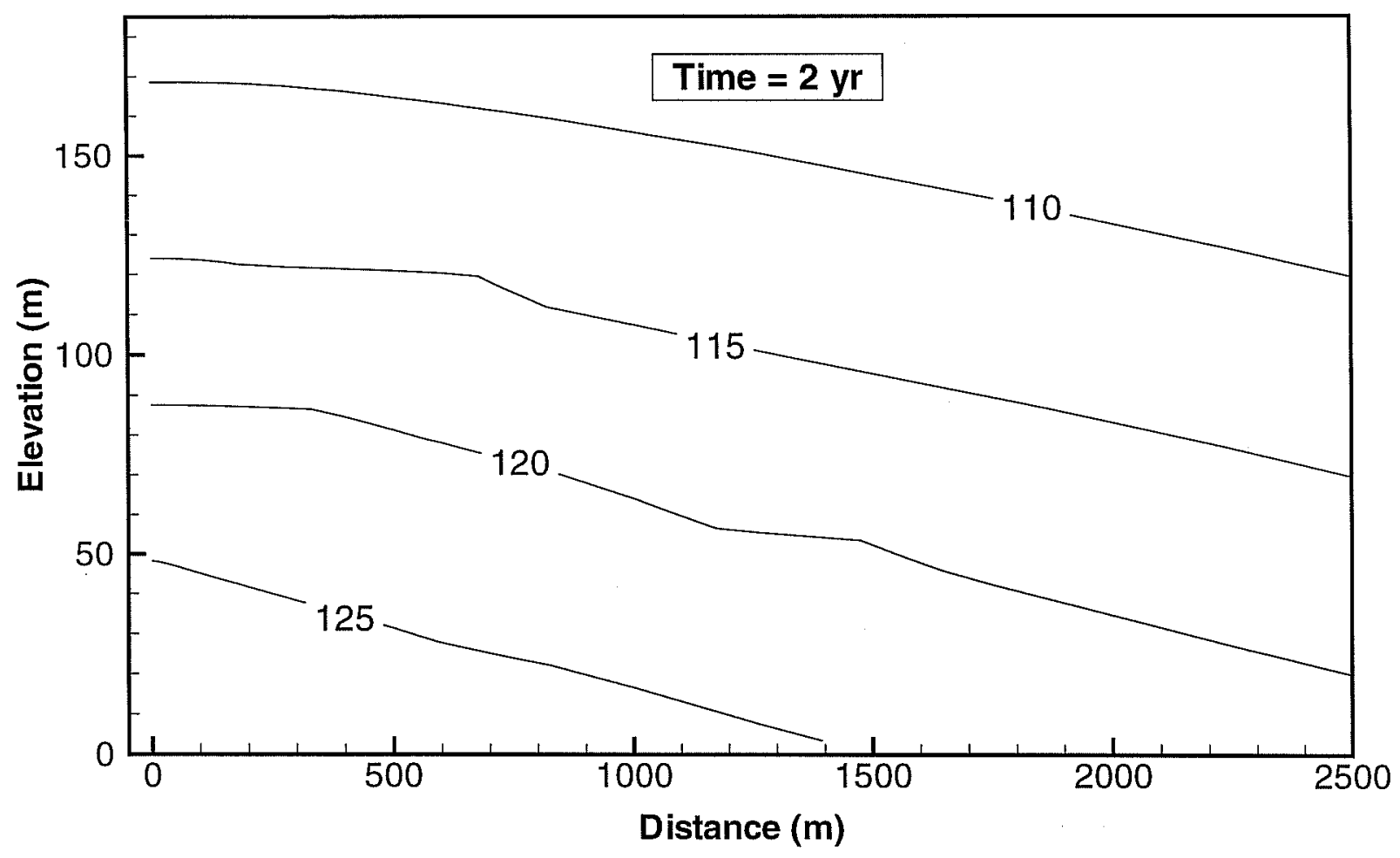

Figure 40. Contour map of fluid pressures after 2 years of $\mathrm{CO}_{2}$ injection.

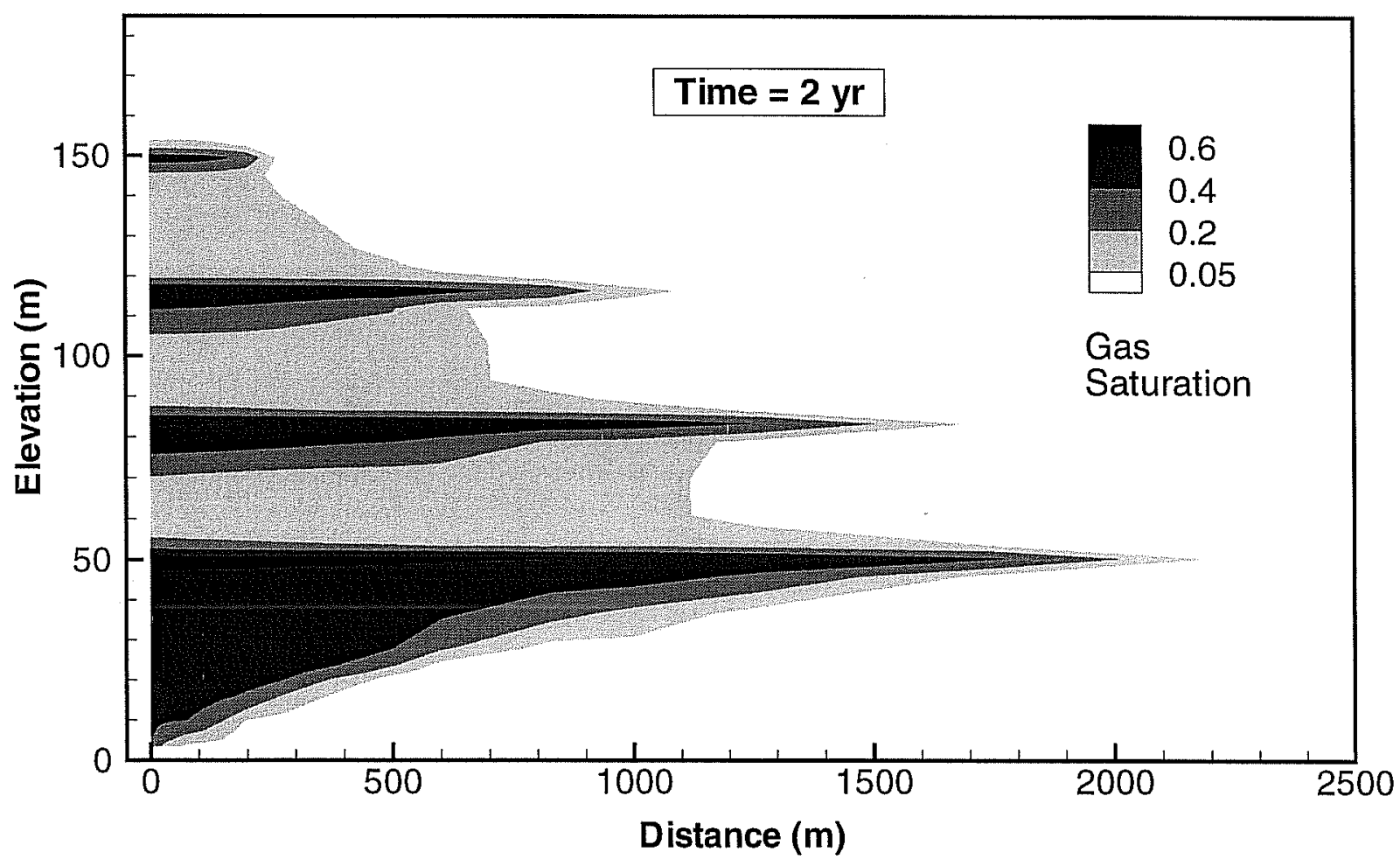

Figure 41. Contour map of gas saturations after 2 years of $\mathrm{CO}_{2}$ injection. 


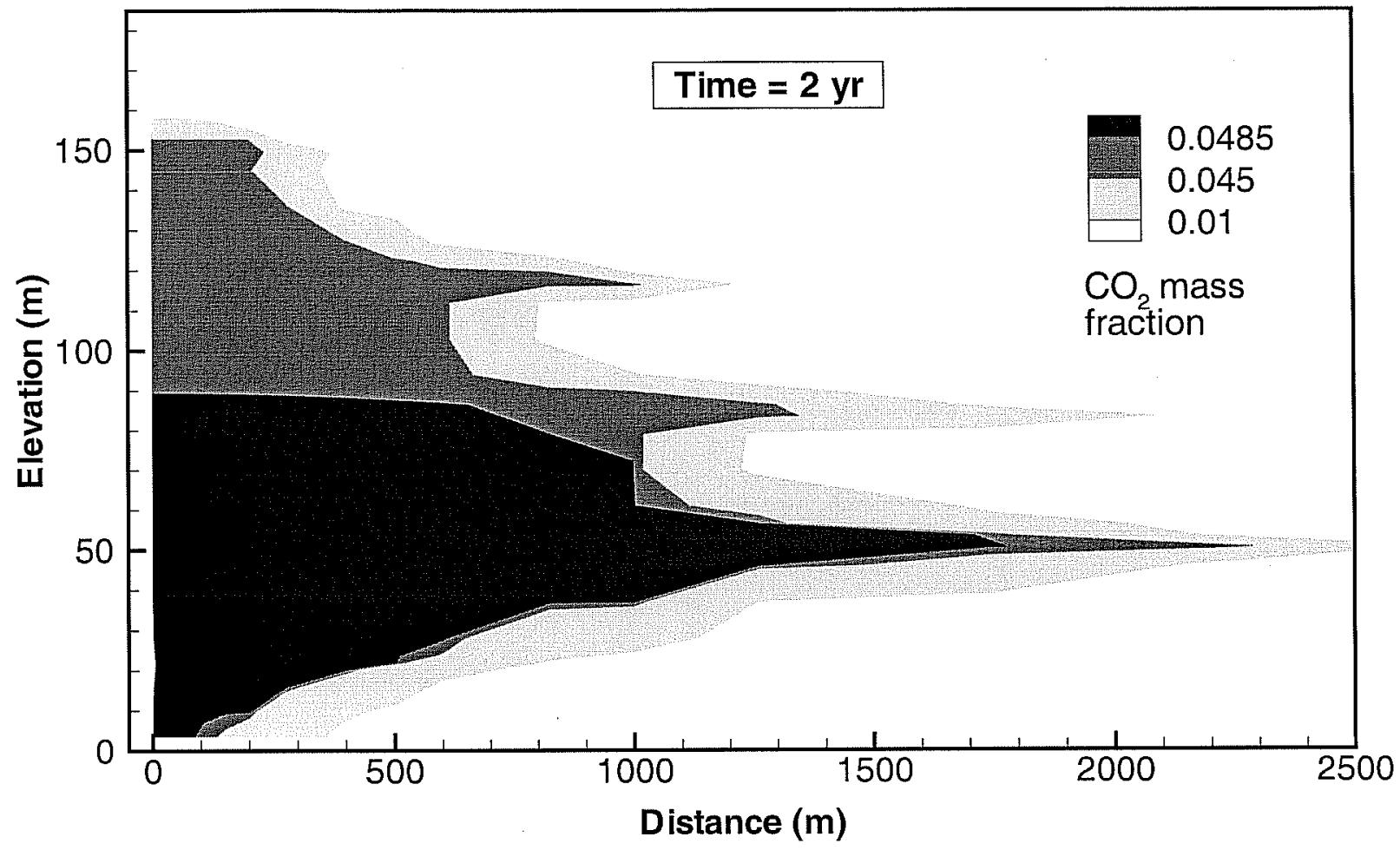

Figure 42. Contour map of dissolved $\mathrm{CO}_{2}$ mass fractions after 2 years of $\mathrm{CO}_{2}$ injection.

Table 7. $\mathrm{CO}_{2}$ inventory (in units of $10^{6} \mathrm{~kg}$ ) for injection into a saline 2-D layered system.

\begin{tabular}{|l|c|c|c|c|}
\hline & $\mathrm{t}=0$ & 30 days & 1 year & 2 years \\
\hline \hline total CO2 & 0.1787 & 0.5893 & 5.178 & 10.18 \\
\hline $\mathrm{CO} 2$ injected & 0.0000 & 0.4108 & 5.002 & 10.00 \\
\hline $\mathrm{CO} 2$ (aq.) & 0.1787 & 0.2708 & 1.120 & 2.037 \\
\hline $\mathrm{CO} 2$ (gas) & 0.0000 & 0.3185 & 4.058 & 8.140 \\
\hline $\begin{array}{l}\text { fraction of CO2 } \\
\text { in aq. phase }\end{array}$ & 1.000 & 0.4596 & 0.2163 & 0.2002 \\
\hline
\end{tabular}




\section{Concluding Remarks}

$\mathrm{ECO} 2 \mathrm{~N}$ is a new fluid property module for the multiphase, multicomponent simulator TOUGH2, Version 2.0. It provides capabilities for modeling advective and diffusive flow and transport in multidimensional heterogeneous systems containing $\mathrm{H}_{2} \mathrm{O}-\mathrm{NaCl}-\mathrm{CO}_{2}$ mixtures. Process capabilities include coupling between fluid and heat flow, partitioning of $\mathrm{H}_{2} \mathrm{O}$ and $\mathrm{CO}_{2}$ among different phases, and precipitation/dissolution of solid salt. The code represents thermophysical properties of brine- $\mathrm{CO}_{2}$ mixtures generally within experimental accuracy for the range of conditions of interest in geologic disposal of $\mathrm{CO}_{2}$. A fluid property table provided with ECO2N covers temperatures from ambient to $103{ }^{\circ} \mathrm{C}$ and pressures from ambient to 600 bar. Software to generate property tables is provided with ECO2N, making possible applications to a more extensive range of conditions. Super- as well as sub-critical conditions may be modeled, but the code currently has no provisions to treat separate liquid and gas $\mathrm{CO}_{2}$ phases, or transitions between them.

\section{Acknowledgement}

Thanks are due to Sally Benson and Jens Birkholzer for a careful review of the manuscript and the suggestion of improvements. This work was supported by the Director, Office of Science, Office of Basic Energy Sciences of the U.S. Department of Energy, and by the Zero Emission Research and Technology project (ZERT) under Contract No. DE-AC03-76SF00098. 


\section{References}

Altunin, V.V. Thermophysical Properties of Carbon Dioxide, Publishing House of Standards, 551 pp., Moscow, 1975 (in Russian).

Andersen, G., A. Probst, L. Murray and S. Butler. An Accurate PVT Model for Geothermal Fluids as Represented by $\mathrm{H}_{2} \mathrm{O}-\mathrm{NaCl}-\mathrm{CO}_{2}$ Mixtures, Proceedings 17th Workshop on Geothermal Reservoir Engineering, pp. 239 - 248, Stanford, CA, 1992.

Battistelli, A., C. Calore and K. Pruess. The Simulator TOUGH2/EWASG for Modeling Geothermal Reservoirs with Brines and Non-Condensible Gas, Geothermics, Vol. 26, No. 4, pp. 437 - 464, 1997.

Chou, I.M. Phase Relations in the System NaCl-KCl-- $\mathrm{H}_{2} \mathrm{O}$ : III: Solubilities of Halite in VaporSaturated Liquids Above $445^{\circ} \mathrm{C}$ and Redetermination of Phase Equilibrium Properties in the System NaCl- $\mathrm{H}_{2} \mathrm{O}$, Geochim. Cosmochim. Acta, Vol. 51, pp. 1965-1975, 1987.

Doughty, C. and K. Pruess. A Similarity Solution for Two-Phase Water, Air and Heat Flow Near a Linear Heat Source in a Porous Medium, J. of Geophys. Res., Vol. 97 (B2), pp. 1821 - 1838, 1992.

Evans, R.D. The Atomic Nucleus, Reprint Edition, Robert E. Krieger Publ. Co., Malabar, FL, 1982.

García, J.E. Density of Aqueous Solutions of CO2, Lawrence Berkeley National Laboratory Report LBNL-49023, Berkeley, CA, 2001.

García, J.E. Fluid Dynamics of Carbon Dioxide Disposal into Saline Aquifers, PhD Thesis, University of California at Berkeley, December 2003.

Haas, J.L. Jr. Physical Properties of the Coexisting Phases and Thermochemical Properties of the $\mathrm{H} 2 \mathrm{O}$ Component in Boiling $\mathrm{NaCl}$ solutions, USGS Bulletin 1421-A, Washington, DC, 73 pp., 1976.

Himmelblau, D.M. Partial Molal Heats and Entropies of Solution for Gases Dissolved in Water from the Freezing to the Near Critical Point, J. of Phys. Chem., Vol. 63, pp. 1803-1808, 1959.

Hitchon, B. (ed.). Aquifer Disposal of Carbon Dioxide, Geoscience Publishing, Ltd., Sherwood Park, Alberta, Canada, 1996.

International Formulation Committee. A Formulation of the Thermodynamic Properties of Ordinary Water Substance, IFC Secretariat, Düsseldorf, Germany, 1967.

Kongsjorden, H., O. Karstad and T.A. Torp. Saline Aquifer Storage of Carbon Dioxide in the Sleipner Project, Waste Management, Vol. 17, No. 5/6, pp. 303 - 308, 1997.

Lindeberg, E., P. Bergmo and A. Moen. The Long-Term Fate of CO2 Injected into an Aquifer, paper G1-4, presented at Sixth International Conference on Greenhouse Gas Technologies (GHGT-6), Kyoto, Japan, October 1-4, 2002.

Lorenz, S., D. Maric and C. Rirschl. Eine analytische Funktion zur Bestimmung der Enthalpie wässriger $\mathrm{NaCl}$ Lösungen, draft report, Institut für Sicherheitstechnologie, Köln, Germany, April 2000. 
Michaelides, E.E. Thermodynamic Properties of Geothermal Fluids, Geothermal Resources Council Transactions, Vol. 5, pp. $361-364,1981$.

Miller, A.B. A Brine-Steam Properties Computer Program for Geothermal Energy Calculations, Lawrence Livermore National Laboratory Report UCRL-52495, Livermore, CA, June 1978.

O'Sullivan, M.J. A Similarity Method for Geothermal Well Test Analysis, Water Resour. Res., Vol. 17, No. 2, pp. $390-398,1981$.

Phillips, S.L., A. Igbene, J.A. Fair, H. Ozbek and M. Tavana. A Technical Databook for Geothermal Energy Utilization, Lawrence Berkeley National Laboratory Report LBL-12810, Berkeley, CA, 46 pp., 1981.

Prausnitz, J. M., R. N. Lichtenthaler, and E. G. de Azevedo. Molecular Thermodynamics of FluidPhase Equilibria, Prentice-Hall Inc., Englewood Cliffs, N. J., 1986.

Pruess, K. The TOUGH Codes-A Family of Simulation Tools for Multiphase Flow and Transport Processes in Permeable Media, Vadose Zone J., Vol. 3, pp. 738 - 746, 2004.

Pruess, K., C. Oldenburg and G. Moridis. TOUGH2 User's Guide, Version 2.0, Lawrence Berkeley National Laboratory Report LBNL-43134, Berkeley, CA, November 1999.

Pruess, K. and J. García. Multiphase Flow Dynamics During CO2 Injection into Saline Aquifers, Environmental Geology, Vol. 42, pp. 282 - 295, 2002.

Pruess, K., J. García, T. Kovscek, C. Oldenburg, J. Rutqvist, C. Steefel and T. Xu. Intercomparison of Numerical Simulation Codes for Geologic Disposal of CO2, Lawrence Berkeley National Laboratory Report LBNL-51813, Berkeley, CA 94720, December 2002.

Pruess, K., J. García, T. Kovscek, C. Oldenburg, J. Rutqvist, C. Steefel and T. Xu. Code Intercomparison Builds Confidence in Numerical Simulation Models for Geologic Disposal of CO2, Energy, Vol. 29, Issues 9-10, pp. 1431-1444, doi:10.1016/j.energy.2004.03.077, July-August 2004.

Span, R. and W. Wagner. A New Equation of State for Carbon Dioxide Covering the Fluid Region from the Triple-Point Temperature to $1100 \mathrm{~K}$ at Pressures up to $800 \mathrm{MPa}$, J. Phys. Chem. Ref. Data, Vol. 25, No. 6, pp. 1509 - 1596, 1996.

Spycher, N., K. Pruess and J. Ennis-King. $\mathrm{CO}_{2}-\mathrm{H}_{2} \mathrm{O}$ Mixtures in the Geological Sequestration of $\mathrm{CO}_{2}$. I. Assessment and Calculation of Mutual Solubilities from 12 to $100{ }^{\circ} \mathrm{C}$ and up to 600 bar, Geochim. Cosmochim. Acta, Vol. 67, No. 16, pp. 3015 - 3031, doi:10.1016/S00167037(03)00273-4, 2003.

Spycher, N. and K. Pruess. $\mathrm{CO}_{2}-\mathrm{H}_{2} \mathrm{O}$ Mixtures in the Geological Sequestration of $\mathrm{CO}_{2}$. III. Partitioning in Chloride Brines at $12-100{ }^{\circ} \mathrm{C}$ and up to $600 \mathrm{bar}$, Geochim. Cosmochim. Acta, Vol. 69, No. 13, pp. 3309-3320, doi:10.1016/j.gca.2005.01.015, 2005.

Vargaftik, N.B. Tables on the Thermophysical Properties of Liquids and Gases, 2nd Ed., John Wiley \& Sons, New York, NY, 1975.

Verma, A. and K. Pruess. Thermohydrologic Conditions and Silica Redistribution Near HighLevel Nuclear Wastes Emplaced in Saturated Geological Formations, Journal of Geophysical Res., Vol. 93 (B2), pp. 1159-1173, 1988. 


\section{APPENDIX A}

\section{Code Intercomparison Problem 3: Radial Flow from a CO2 Injection Well\&}

\section{INTRODUCTION AND GENERAL DESCRIPTION}

This problem addresses two-phase flow of $\mathrm{CO} 2$ and water for simplified flow geometry and medium properties. The aquifer into which injection is made is assumed infinite-acting, homogenoeus, and isotropic. Gravity and inertial effects are neglected, injection is made at a constant mass rate, and flow is assumed 1-D radial (line source). Under the conditions stated the problem has a similarity solution where dependence on radial distance $\mathrm{R}$ and time t occurs only through the similarity variable $\xi=\mathrm{R}^{2} / \mathrm{t}$ (O'Sullivan 1981; Doughty and Pruess 1992).

\section{LIST OF PROCESSES BEING STUDIED}

Two-phase flow of $\mathrm{CO} 2$ and water subject to relative permeability and capillary effects.

Change of fluid density, viscosity, and $\mathrm{CO} 2$ solubility with pressure and salinity.

Formation dry-out with precipitation of salt.

\section{DEFINITION OF THE PROBLEM AND INPUT DATA}

Problem parameters are summarized in Tables A.1 and A.2.

\section{PROBLEM VARIATIONS}

Neglect salinity of the aqueous phase. Include non-isothermal effects. Include permeability changes due to precipitation. Inject gas that is $50 \% \mathrm{CO} 2,50 \% \mathrm{~N} 2$.

\section{DEFINITION OF RESULTS TO BE CALCULATED}

Data on $\mathrm{CO} 2$ and brine density and viscosity, and $\mathrm{CO} 2$ solubility, for the range of thermodynamic conditions encountered in the problem. Gas saturation, dissolved $\mathrm{CO} 2$ mass fraction, fraction of void space containing precipitated salt, and fluid pressure as functions of the similarity variable $\xi=$ $\mathrm{R}^{2} / \mathrm{t}$. (Use both profiles at constant time and time-series data at a specific location for plotting.)

\section{COMPARISON CRITERIA}

Results should match within $+/-5 \%$.

\section{REFERENCES}

Corey, A.T. The Interrelation Between Gas and Oil Relative Permeabilities, Producers Monthly, pp. 38 - 41, November 1954.

\& proposed by Karsten Pruess; e-mail: K_Pruess@lbl.gov 
Doughty, C. and K. Pruess. A Similarity Solution for Two-Phase Water, Air and Heat Flow Near a Linear Heat Source in a Porous Medium, J. of Geophys. Res., 97 (B2), 1821-1838, 1992.

O'Sullivan, M.J. A Similarity Method for Geothermal Well Test Analysis, Water Resour. Res., Vol. 17, No. 2, pp. 390-398, 1981.

van Genuchten, M.Th. A Closed-Form Equation for Predicting the Hydraulic Conductivity of Unsaturated Soils, Soil Sci. Soc. Am. J., Vol. 44, pp. 892 - 898, 1980.

Table A.1 Hydrogeologic parameters.

\begin{tabular}{|c|c|}
\hline $\begin{array}{l}\text { Permeability } \\
\text { Porosity } \\
\text { Pore compressibility } \\
\text { Aquifer thickness }\end{array}$ & $\begin{array}{l}\mathrm{k}=10^{-13} \mathrm{~m}^{2} \\
\phi=0.12 \\
\mathrm{c}=4.5 \times 10^{-10} \mathrm{~Pa}^{-1} \\
100 \mathrm{~m}\end{array}$ \\
\hline Relative permeability & \\
\hline $\begin{array}{l}\text { liquid: van Genuchten function (1980) } \\
\mathrm{k}_{\mathrm{rl}}=\sqrt{\mathrm{s}^{*}}\left\{1-\left(1-\left[\mathrm{s}^{*}\right]^{1 / \lambda}\right)^{\lambda}\right\}^{2} \\
\text { irreducible water saturation } \\
\text { exponent }\end{array}$ & $\begin{array}{l}s^{*}=\left(S_{1}-S_{1 r}\right) /\left(1-S_{1 r}\right) \\
S_{1 \mathrm{r}}=0.30 \\
\lambda=0.457\end{array}$ \\
\hline $\begin{array}{l}\text { gas: Corey curve (1954) } \\
\qquad \mathrm{k}_{\mathrm{rg}}=(1-\hat{\mathrm{S}})^{2}\left(1-\hat{\mathrm{S}}^{2}\right) \\
\text { irreducible gas saturation }\end{array}$ & $\begin{array}{l}\hat{S}=\frac{\left(S_{1}-S_{\mathrm{lr}}\right)}{\left(1-S_{\mathrm{lr}}-S_{\mathrm{gr}}\right)} \\
S_{\mathrm{gr}_{\mathrm{r}}}=0.05\end{array}$ \\
\hline Capillary pressure & \\
\hline $\begin{array}{l}\text { van Genuchten function (1980) } \\
\qquad \mathrm{P}_{\text {cap }}=-\mathrm{P}_{0}\left(\left[\mathrm{~S}^{*}\right]^{-1 / \lambda}-1\right) 1-\lambda \\
\text { irreducible water saturation } \\
\text { exponent } \\
\text { strength coefficient }\end{array}$ & $\begin{array}{l}\mathrm{S}^{*}=\left(\mathrm{S}_{\mathrm{l}}-\mathrm{S}_{\mathrm{lr}}\right) /\left(1-\mathrm{S}_{\mathrm{lr}}\right) \\
\mathrm{S}_{\mathrm{lr}}=0.0 \\
\lambda=0.457 \\
\mathrm{P}_{0}=19.61 \mathrm{kPa}\end{array}$ \\
\hline
\end{tabular}

Table A.2 Initial conditions and injection specifications

\begin{tabular}{|l|l|}
\hline Pressure & $120 \mathrm{bar}$ \\
\hline Temperature & $45^{\circ} \mathrm{C}$ \\
\hline Salinity & $15 \mathrm{wt} .-\% \mathrm{NaCl}$ \\
\hline $\mathrm{CO} 2$ injection rate & $100 \mathrm{~kg} / \mathrm{s}$ \\
\hline
\end{tabular}




\section{APPENDIX B}

\section{Code Intercomparison Problem 4: CO2 Discharge Along a Fault Zone*}

\section{INTRODUCTION AND GENERAL DESCRIPTION}

This problem explores $\mathrm{CO} 2$ loss from storage through a leaky fault, using a highly simplified 1-D linear flow geometry. It is envisioned that an aquifer into which $\mathrm{CO} 2$ disposal is made is intersected by a vertical fault, which establishes a connection through an otherwise impermeable caprock to another aquifer $500 \mathrm{~m}$ above the storage aquifer (Fig. B.1a). This situation is idealized by assuming 1-D flow geometry and constant pressure boundary conditions as shown in Fig. B.1b (Pruess and García, 2000).

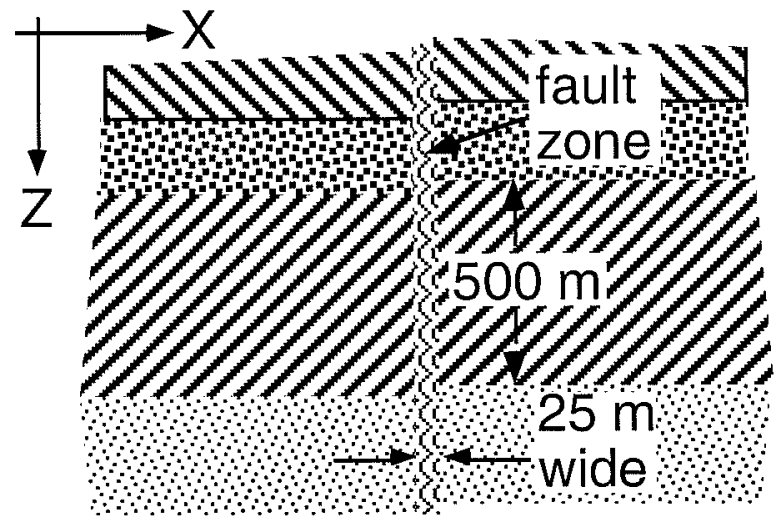

(a)

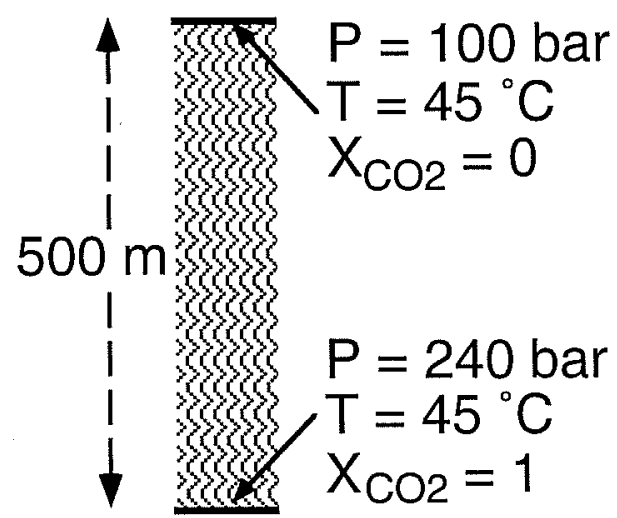

(b)

Figure B.1 Schematic of the fault zone model (a) and applied boundary conditions (b).

\section{LIST OF PROCESSES BEING STUDIED}

Immiscible displacement of water by $\mathrm{CO} 2$ subject to pressure, gravity, and capillary pressure effects.

Change of fluid density, viscosity, and $\mathrm{CO} 2$ solubility with pressure.

Formation dry-out.

\section{DEFINITION OF THE PROBLEM AND INPUT DATA}

Hydrogeologic parameters are identical to those of problem 3 (Table A.1), except that porosity is increased to $35 \%$. The fault zone is assumed to be $25 \mathrm{~m}$ wide and $500 \mathrm{~m}$ tall, with boundary conditions as given in Fig. B.1b. The reservoir fluid is assumed to be pure water (no salinity). Initial conditions are pressures in hydrostatic equilibrium relative to $\mathrm{P}=100$ bar at the top; temperature is held constant at $\mathrm{T}=45^{\circ} \mathrm{C}$ throughout.

\footnotetext{
* proposed by Karsten Pruess; e-mail: K_Pruess@lbl.gov
} 


\section{PROBLEM VARIATIONS}

Include salinity of the aqueous phase and permeability changes due to precipitation. Include nonisothermal effects. Assume gas composition is $50 \% \mathrm{CO} 2,50 \% \mathrm{~N} 2$.

\section{DEFINITION OF RESULTS TO BE CALCULATED}

Data on $\mathrm{CO} 2$ and water density and viscosity, and $\mathrm{CO} 2$ solubility, for the range of thermodynamic conditions encountered in the problem. Vertical profiles of gas saturation, fluid pressure, and dissolved $\mathrm{CO} 2$ mass fraction at different times. $\mathrm{CO} 2$ inventory in gas and liquid phases after $10^{7}$ seconds. Mass flow rates of $\mathrm{CO} 2$ at the bottom and of water at the top vs. time (normalized for a 1 $m$ thick section).

\section{COMPARISON CRITERIA}

Results should match to with $+/-5 \%$.

\section{REFERENCES}

Pruess, K. and J. García. Multiphase Flow Dynamics During CO2 Injection into Saline Aquifers, Environmental Geology, Vol. 42, pp. 282 - 295, 2002. 


\section{A PPENDIX C}

\section{Code Intercomparison Problem 7: $\mathrm{CO}_{2}$ Injection into a 2-D Layered Brine Formation"}

\section{INTRODUCTION AND GENERAL DESCRIPTION}

This test problem is patterned after the $\mathrm{CO}_{2}$ injection project at the Sleipner Vest field in the Norwegian sector of the North Sea, and is intended to investigate the dominant physical processes associated with the injection of supercritical $\mathrm{CO}_{2}$ into a layered medium. Significant simplifications have been made, the most important of which is the assumption of isothermal conditions $\left(37^{\circ} \mathrm{C}\right.$, the ambient temperature of the formation). $\mathrm{CO}_{2}$ injection rates $(1,000,000$ tonnes per year), system geometry, and system permeabilities correspond approximately to those at Sleipner, although no attempt was made to represent details of the permeability structure within the host formation. Injection of the supercritical $\mathrm{CO}_{2}$, which is less dense than the saline formation waters into which it is injected, causes it to rise through the formation. Its rate of ascent, however, is limited by the presence of four relatively low permeability shales. The top and bottom of the formation is assumed to be impermeable. The only reactive chemistry considered in this problem is the dissolution of $\mathrm{CO}_{2}$ in the aqueous phase.

\section{LIST OF PROCESSES BEING STUDIED}

a) Gravity-driven advection in response to strong vertical and lateral density gradients induced by the injection of $\mathrm{CO}_{2}$ into saline formation water.

b) Density, viscosity, and solubility formulations of water and $\mathrm{CO}_{2}$ as a function of pressure and temperature ( $\mathrm{P}$ and $\mathrm{T})$.

\section{DEFINITION OF THE PROBLEM AND INPUT DATA System Geometry:}

The system is idealized as a two dimensional symmetric domain perpendicular to the horizontal injection well which has a screen length of 100 meters (Figure C.1). A one meter thick section perpendicular to the horizontal well is considered. The thickness of the formation at the injection site is 184 meters. The injection point is 940 meters below the sea floor, while the ocean depth at the site is 80 meters. The formation is assumed to consist of four lower permeability shale units 3 meters thick which are distributed within the high permeability sand. Each shale unit is separated by 30 meters. The well is 30 meters below the lowest shale unit, while the bottom of the aquifer is another 22 meters below the well.

\footnotetext{
\# proposed by Carl Steefel; e-mail: CISteefel@lbl.gov
} 


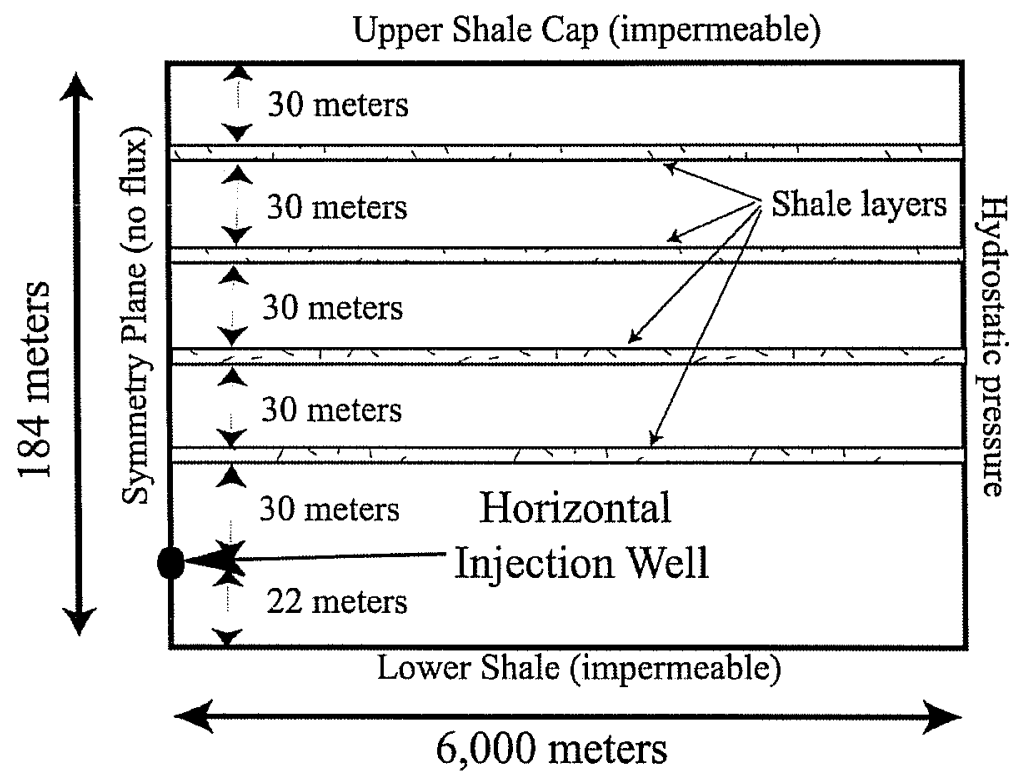

Figure C.1 Schematic representation of geometry for $\mathrm{CO} 2$ injection in Utsira Formation.

\section{Boundary conditions:}

No heat or mass flux is allowed across any of the boundaries except the vertical boundary 6,000 meters from the injection well. This boundary is fixed at hydrostatic pressure, thus allowing flow into and out of the domain so as to avoid overpressuring the formation. The 6,000 meter boundary is chosen, however, to be far enough from the injection well that the $\mathrm{CO}_{2}$ does not reach this boundary after 2 years of injection.

Initial conditions (Table C.1):

a) $\mathrm{T}=37^{\circ} \mathrm{C}$ (isothermal throughout)

b) $\mathrm{P}=$ hydrostatic (approximately 110 bars at injection point, approximately 90 bars at top of formation).

c) $\mathrm{CO}_{2}$ in the aqueous phase in equilibrium with a $\mathrm{P}_{\mathrm{CO} 2}$ of 0.5 bars, a typical value for sedimentary formation waters at the temperature we are considering.

Table C.1 Initial conditions and injection specifications

\begin{tabular}{|l|l|}
\hline Pressure at well & $110 \mathrm{bar}$ \\
\hline Temperature & $37^{\circ} \mathrm{C}$ \\
\hline Salinity & $3.2 \mathrm{wt} .-\% \mathrm{NaCl}$ \\
\hline $\mathrm{CO} 2$ injection rate & $0.1585 \mathrm{~kg} / \mathrm{s}$ in half space \\
\hline
\end{tabular}


Injection specifications (Table C.1):

a) Temperature $=37^{\circ} \mathrm{C}$

b) Injection rate: $31.7 \mathrm{~kg} / \mathrm{s}$ over entire screen length (100 meters), corresponding to $0.317 \mathrm{~kg} / \mathrm{s}$ for the 1 meter thick section considered. Because of symmetry, injection rate in half space is therefore $0.1585 \mathrm{~kg} / \mathrm{s}$.

c) Height of well cell: 1 meter.

d) Injection time scale: 2 years

Input data (Table C.2):

a) Capillary pressure and liquid relative permeability described with van Genuchten (1980) functions; gas relative permeability after Corey (1954). Porosity is $35 \%$ for sands, $10.25 \%$ for shales.

b) Fully saturated permeability ( $\mathrm{k}=3 \times 10^{-12} \mathrm{~m}^{2}$ in sand layers, $10^{-14} \mathrm{~m}^{2}$ in shales)

c) Density, viscosity, and solubility in water of $\mathrm{CO}_{2}$ as functions of $\mathrm{P}$ and $\mathrm{T}$ (Span and Wagner, 1996).

d) Vapor-liquid equilibrium properties of water.

\section{PROBLEM VARIATIONS}

Include non-isothermal effects by making the $\mathrm{CO}_{2}$ injection temperature equal to $65^{\circ} \mathrm{C}$.

\section{RESULTS TO BE CALCULATED}

Liquid and gas saturations as a function of space and time. $\mathrm{CO}_{2}$ concentration in the aqueous phase as a function of space. Gas and liquid fluxes.

\section{COMPARISON CRITERIA}

Results should match within $+/-5 \%$.

\section{IMPORTANT NOTICE}

A first version of this test problem had specified that gas relative permeability was to be calculated from a van Genuchten function. In a workshop held in October 2001 in Berkeley, participants in the code intercomparison project agreed to change this specification to using a Corey (1954) curve instead, with parameters as given in Table C.2. In two subsequently issued laboratory reports with results of the code intercomparison project (Pruess and García, 2002; Pruess et al., 2002), the original van Genuchten specifications were inadvertently retained, even though all simulations had used the altered (Corey, 1954) specifications. 
Table C.2 Hydrogeologic parameters

\begin{tabular}{|c|c|}
\hline $\begin{array}{l}\text { Permeability } \\
\text { Porosity } \\
\text { Aquifer thickness }\end{array}$ & $\begin{array}{l}\text { Sands: } 3 \times 10^{-12} \mathrm{~m}^{2} \text {; Shales: } 10^{-14} \mathrm{~m}^{2} \\
\text { Sands: } \phi=0.35 \text {; Shales: } \phi=0.1025 \\
184 \mathrm{~m}\end{array}$ \\
\hline Relative permeability & \\
\hline $\begin{array}{l}\text { liquid: van Genuchten function (1980) } \\
k_{r l}=\sqrt{S^{*}}\left\{1-\left(1-\left[s^{*}\right]^{1 / \lambda}\right)^{\lambda}\right\}^{2} \\
\text { irreducible water saturation } \\
\text { exponent }\end{array}$ & $\begin{array}{l}S^{*}=\left(S_{l}-S_{l r}\right) /\left(1-S_{l r}\right) \\
S_{\mathrm{lr}}=0.20 \\
\lambda=0.400\end{array}$ \\
\hline $\begin{array}{l}\text { gas: Corey (1954) } \\
\mathrm{k}_{\mathrm{rg}}=(1-\hat{\mathrm{S}})^{2}\left(1-\hat{\mathrm{S}}^{2}\right) \\
\text { irreducible water saturation } \\
\text { irreducible gas saturation }\end{array}$ & $\begin{array}{l}\hat{S}=\left(S_{1}-S_{\mathrm{lr}}\right) /\left(1-S_{\mathrm{lr}}-S_{\mathrm{gr}}\right) \\
S_{\mathrm{lr}}=0.20 \\
S_{\mathrm{gr}}=0.05\end{array}$ \\
\hline Capillary pressure & \\
\hline $\begin{array}{l}\text { van Genuchten function }(1980) \\
P_{\text {cap }}=-P_{0}\left(\left[S^{*}\right]^{-1 / \lambda}-1\right)^{1-\lambda} \\
\text { irreducible water saturation } \\
\text { exponent } \\
\text { strength coefficient }\end{array}$ & $\begin{array}{l}S^{*}=\left(S_{l}-S_{l r}\right) /\left(1-S_{l r}\right) \\
S_{l r}=0.20 \\
\lambda=0.400 \\
\text { Sand: } P_{0}=3.58 \mathrm{kPa} ; \text { Shale: } \mathrm{P}_{0}=62.0 \mathrm{kPa}\end{array}$ \\
\hline
\end{tabular}

\section{REFERENCES}

Corey, A.T. The Interrelation Between Gas and Oil Relative Permeabilities, Producers Monthly, 38-41, November 1954.

Pruess, K. and J. García. Solutions of Test Problems for Disposal of CO2 in Saline Aquifers, Lawrence Berkeley National Laboratory Report LBNL-51812, December 2002.

Pruess, K., J. García, T. Kovscek, C. Oldenburg, J. Rutqvist, C. Steefel and T. Xu. Intercomparison of Numerical Simulation Codes for Geologic Disposal of CO2, Lawrence Berkeley National Laboratory Report LBNL-51813, Berkeley, CA 94720, December 2002.

van Genuchten, M.Th. A Closed-Form Equation for Predicting the Hydraulic Conductivity of Unsaturated Soils, Soil Sci. Soc. Am. J., Vol. 44, pp. 892 - 898, 1980.

Span, R. and W. Wagner. A New Equation of State for Carbon Dioxide Covering the Fluid Region from the Triple-Point Temperature to $100 \mathrm{~K}$ at Pressures up to $800 \mathrm{MPa}, J$. Phys. Chem. Ref. Data, Vol. 25, No. 6, pp. 1509 - 1596, 1996. 